\title{
SINGLET-OXYGEN OXIDATION OF THIOSALTS
}

by

\author{
Sana Sultan Siddiqi, B.Sc. (Hon)
}

\begin{abstract}
A thesis submitted to the Faculty of Graduate Studies and Research in partial fulfilment of the requirements for the degree of Master of Science
\end{abstract}

Department of Chemistry

Carleton University

Ottawa, Ontario

September 18, 2008 


$\begin{array}{ll}\begin{array}{l}\text { Library and } \\ \text { Archives Canada }\end{array} & \begin{array}{l}\text { Bibliothèque et } \\ \text { Archives Canada }\end{array} \\ \begin{array}{l}\text { Published Heritage } \\ \text { Branch }\end{array} & \begin{array}{l}\text { Direction du } \\ \text { Patrimoine de l'édition }\end{array} \\ \begin{array}{l}\text { 395 Wellington Street } \\ \text { Ottawa ON K1A 0N4 } \\ \text { Canada }\end{array} & \begin{array}{l}\text { 395, rue Wellington } \\ \text { Ottawa ON K1A 0N4 } \\ \text { Canada }\end{array}\end{array}$

Your file Votre référence ISBN: 978-0-494-44139-8

Ourfile Notre référence

ISBN: 978-0-494-44139-8

NOTICE:

The author has granted a nonexclusive license allowing Library and Archives Canada to reproduce, publish, archive, preserve, conserve, communicate to the public by telecommunication or on the Internet, loan, distribute and sell theses worldwide, for commercial or noncommercial purposes, in microform, paper, electronic and/or any other formats.

The author retains copyright ownership and moral rights in this thesis. Neither the thesis nor substantial extracts from it may be printed or otherwise reproduced without the author's permission.
AVIS:

L'auteur a accordé une licence non exclusive permettant à la Bibliothèque et Archives Canada de reproduire, publier, archiver, sauvegarder, conserver, transmettre au public par télécommunication ou par l'Internet, prêter, distribuer et vendre des thèses partout dans le monde, à des fins commerciales ou autres, sur support microforme, papier, électronique et/ou autres formats.

L'auteur conserve la propriété du droit d'auteur et des droits moraux qui protège cette thèse. $\mathrm{Ni}$ la thèse ni des extraits substantiels de celle-ci ne doivent être imprimés ou autrement reproduits sans son autorisation.
In compliance with the Canadian Privacy Act some supporting forms may have been removed from this thesis.

While these forms may be included in the document page count, their removal does not represent any loss of content from the thesis.
Conformément à la loi canadienne sur la protection de la vie privée, quelques formulaires secondaires ont été enlevés de cette thèse.

Bien que ces formulaires aient inclus dans la pagination, il n'y aura aucun contenu manquant.

\section{Canada}




\section{ABSTRACT}

The milling of sulfide ores forms thiosalts that are dissolved in effluent which is stored in holding ponds. The natural oxidation of these thiosalts generates significant acid concentrations that elicit toxic effects in aquatic life. The purpose of this research is to address the potential adverse effects of thiosalts in the mining effluents by singlet oxygen oxidation of thiosalts (SOOT). In the current research Zinc 2,3,9,10,16,17(hexacarboxylate)-23,24-(dicarboximide) phthalocyanine sodium salt was synthesized, purified and characterized using electronic absorption spectroscopy and elemental analysis and used as the photosensitizer in the SOOT experiment. The monomer/dimer equilibrium of the photosensitizer in aqueous solution was investigated under various $\mathrm{pH}$ conditions and in the presence of surfactants. Cationic surfactants were found to be effective in promoting monomer formation in slightly acidic solutions at approximately the critical micelle concentration of surfactants. The quantum yield of singlet oxygen production in $\mathrm{pH} 11$ solution remained approximately the same in the presence and absence of DTAB with $Q_{s}=0.47$ and 0.50 , respectively. This suggested that the primary function of the surfactant in the SOOT process was to protect the photosensitizer from oxidation by hydrogen peroxide anion and not to prevent dimerization. SOOT experiments were carried out in the presence of DTAB at $\mathrm{pH} 11$ to compare the photoactivity of the $\mathrm{ZnPc}(\mathrm{COONa})_{4}$ with the photosensitizer, the yield of sulfate at the end of 8 hours was determined to be $33 \%$ and $67 \%$ respectively. Therefore, it is evident that the photosensitizer is more efficient in converting thiosalts to sulfates at lower temperature when compared to $\mathrm{ZnPc}(\mathrm{COONa})_{4}$. 


\section{ACKNOWLEDGEMENTS}

It is a pleasure to acknowledge my gratitude to my research supervisor, Dr. Robert J. Crutchley. His dedication, guidance and knowledge made the work an extremely valuable learning experience.

I would like to thank Dr. Tito Scaiano and Michel Grenier from the University of Ottawa for their technical assistance required for running the experiments used to determine the quantum yields of singlet oxygen.

I would like to thank my parents, Commodore (Retired) Taimoor Sultan and Nasrin Temur for their strong support and encouragement in getting me this far. I would like to thank Yasir Sultan for all his help and guidance throughout my research project. I would like to thank my husband, Wahid Siddiqi who stood beside me and encouraged me constantly. Finally, I would also like to express my appreciation to Maliha Mohammed, Isa Mohammed, Hana Mohammed, Sameer Sultan, Maham Sultan, Zehra Sultan, Rashid Siddiqi, Anjum Siddiqi, Taranum Siddiqi, Fuwad Siddiqi and Ziad Siddiqi for their continued support. 
This work is dedicated to my beloved grandmother, Razia Zia, for giving me the courage and drive to complete my research 


\section{TABLE OF CONTENTS}

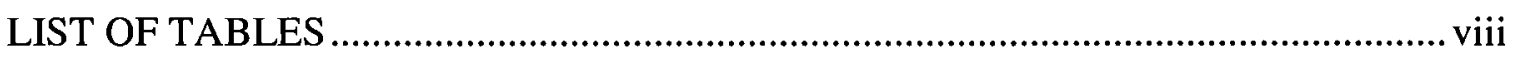

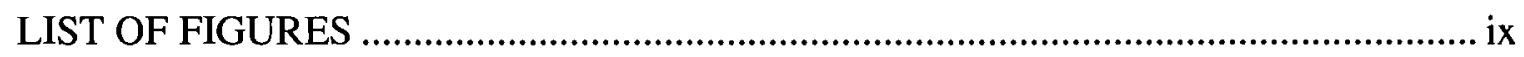

LIST OF REACTION SCHEMES ….................................................................

LIST OF REACTION SCHEMES ..................................................................... xii

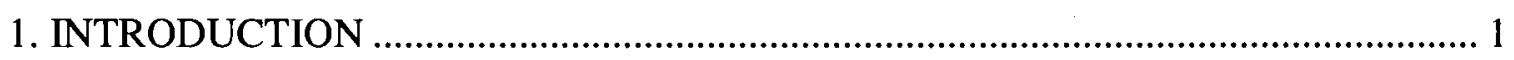

1.1 Singlet Oxygen Oxidation of Thiosalts (SOOT) Process .............................. 1

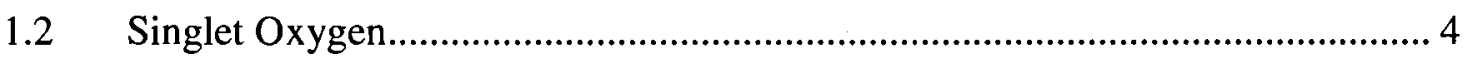

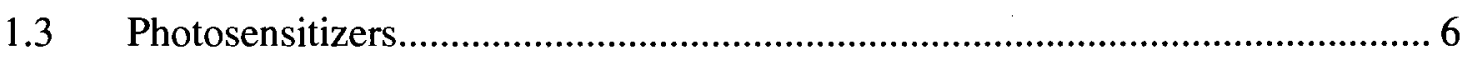

1.3.1 Energy Transfer Mechanisms ......................................................... 8

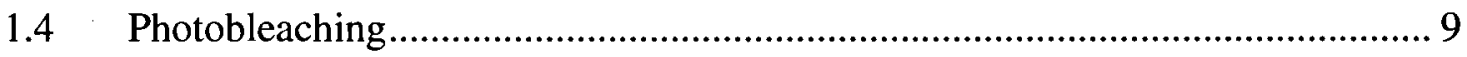

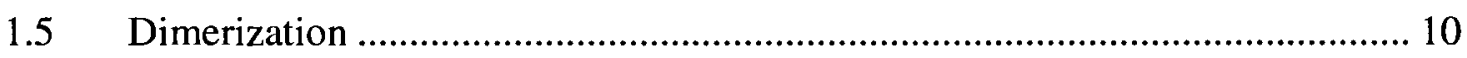

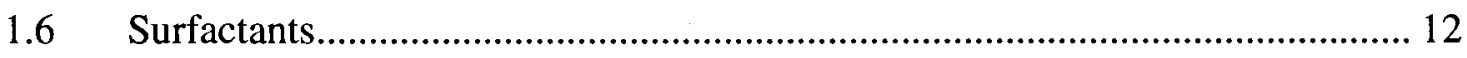

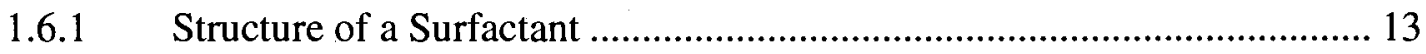

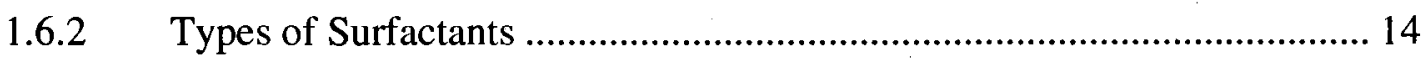

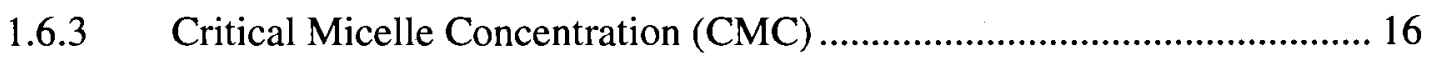

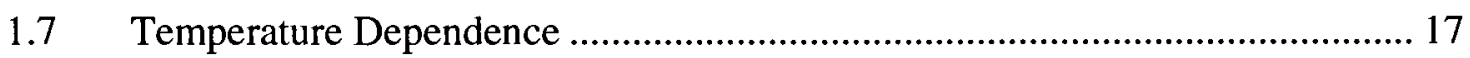

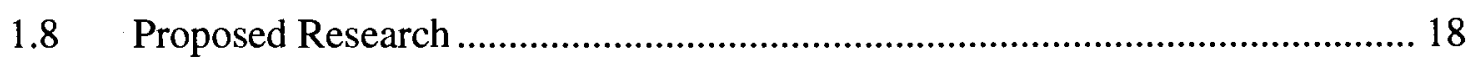

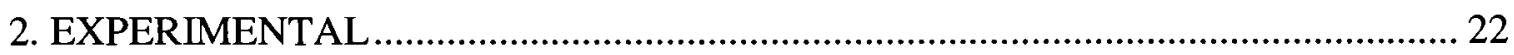

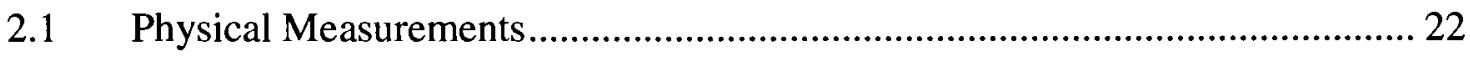

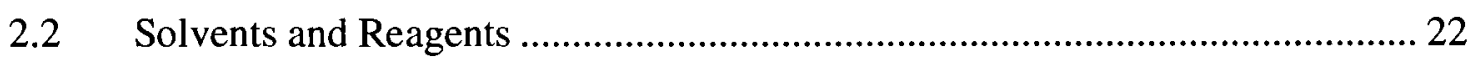

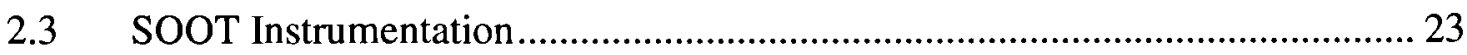


2.4 Test Solutions for the SOOT Experiment

2.4.1 Sample Calculation for the Percentage Conversion of Thiosulfate to Sulfate in the SOOT Experiment Carried Out in the Presence of DTAB at $22^{\circ} \mathrm{C} \ldots .26$

2.5 Singlet Oxygen Quantum Yield Determination........................................... 27

2.6 Test Solutions for Determining the Quantum Yield of Singlet Oxygen........... 28

2.6.1 Determining the Quantum Yield in the Absence of Surfactant ................ 28

2.6.2 Determining the Quantum Yield in the Presence of Surfactant............... 28

2.7 Attempted Synthesis of the Photosensitizer............................................. 28

2.7.1 V. Iliev and A. Mihaylova's Protocol ............................................ 29

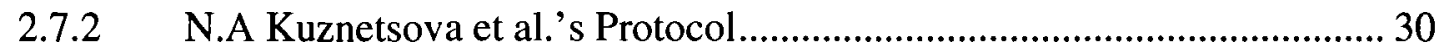

2.7.3 Soxhlet Extraction Purification .............................................................. 31

2.7.4 Flash Chromatography Purification ................................................... 31

2.7.5 Modifications to Kuznetsova et al.'s Protocol ...................................... 32

2.8 Synthesis of Zinc 2,3,9,10,16,17-(Hexacarboxylate)-23,24-(Dicarboximide)

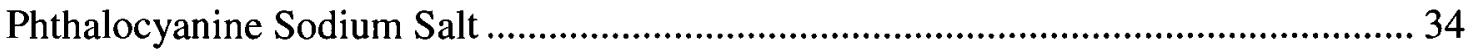

3. SYNTHESIS AND PROPERTIES OF THE PHOTOSENSITIZER ......................... 38

3.1 Synthesis of the Photosensitizer, Zinc 2,3,9,10,16,17-(hexacarboxylate)-23,24-

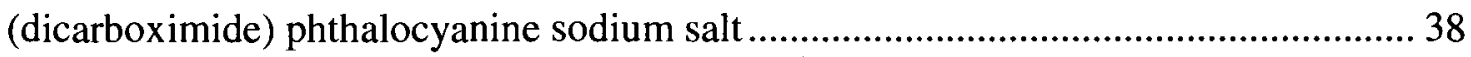

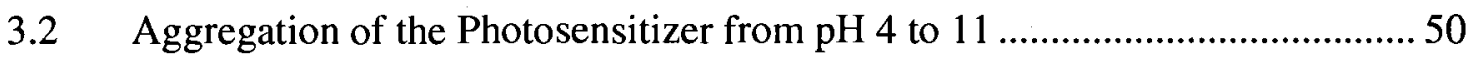

3.3 Influence of Concentration on the Monomer-Dimer Equilibrium at $\mathrm{pH} 11 \ldots . .52$

3.4 The Equilibrium Studies and Surfactants .................................................. 54

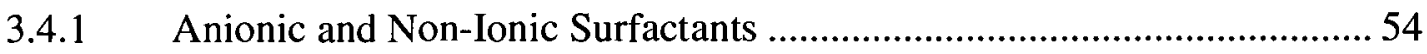

3.4.2 Monomer-Dimer Equilibrium and Cationic Surfactants.......................... 54 
3.4.3 Protonation-Deprotonation Equilibrium Studies ...................................... 60

3.5 pH Dependence on the Singlet Oxygen Quantum Yield ...................................61

3.5.1 Calculation of the Quantum Yield of Singlet Oxygen Formation $\left(\mathrm{Q}_{s}\right)$.... 67 4. SINGLET OXYGEN OXIDATION OF THIOSALTS (SOOT)................................... 69

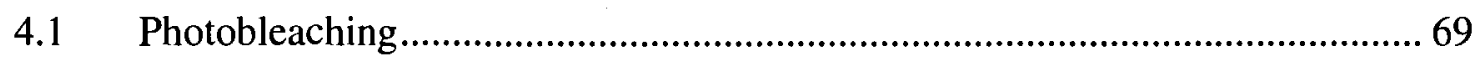

4.1.1 Photobleaching in the Absence of Surfactant ........................................... 69

4.1.2 Effect of $\mathrm{pH}$ on the Photobleaching of the Photosensitizer ........................ 71

4.1.3 Effect of Anionic, Non-Ionic and Amphoteric Surfactants on the

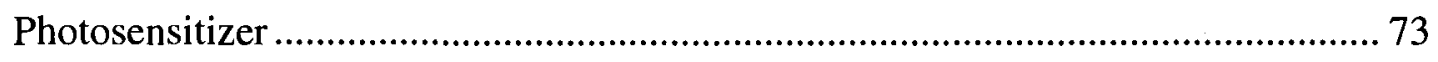

4.1.4 Comparison of Cationic Surfactants $\mathrm{CTAB}$ to $\mathrm{Bu}_{4} \mathrm{NBr}(\mathrm{TBAB})$............. 74

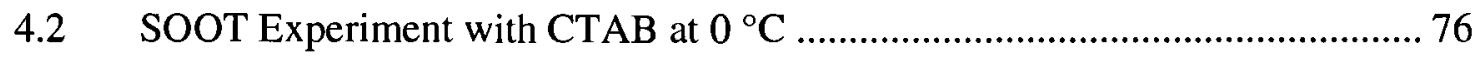

4.3 SOOT Experiment Evaluated in the Presence of DTAB ………………........ 79

4.4 Comparison of the Photosensitizer to the Tetracarboxylate $\mathrm{ZnPc}$ in the presence

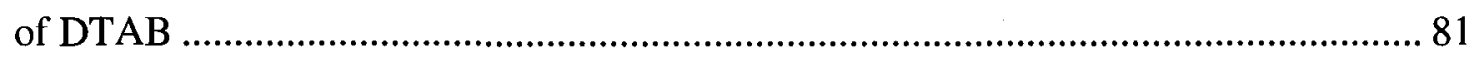

4.5 SOOT Experiment Evaluated in the Presence of DTAC …………………..... 81

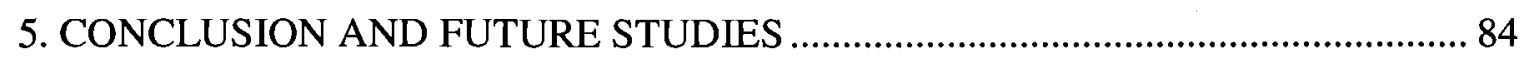

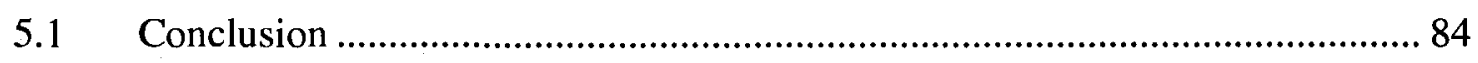

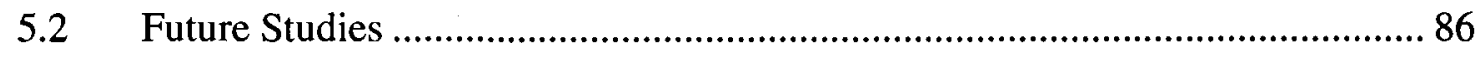

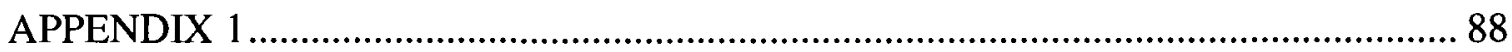

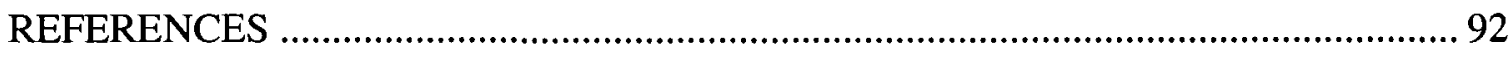




\section{LIST OF TABLES}

Table 1: Illustration of the Weight in Grams of Barium Sulfate in the SOOT Experiment Carried Out for 8 hours in the Presence of DTAB........................................................ 26

Table 2: Comparison of the Calculated and Found Elemental Analysis $(\mathrm{C}, \mathrm{H}$ and $\mathrm{N})$ for Kuznetsova's $\mathrm{ZnPc}(\mathrm{COONa})_{8}$ Product $\left[\mathrm{Zn}\left(\mathrm{C}_{40} \mathrm{H}_{8} \mathrm{~N}_{8} \mathrm{O}_{16} \mathrm{Na}_{8}\right), \mathrm{FW}=1105.84 \mathrm{~g} / \mathrm{mol}\right] \ldots . . .34$

Table 3: Calculated and Found Elemental Analysis (C, $\mathrm{H}$ and $\mathrm{N}$ ) for Zinc 2,3,9,10,16,17(Hexacarboxylate)-23,24-(Dicarboximide) Phthalocyanine. $\left[\mathrm{Zn}\left(\mathrm{C}_{40} \mathrm{H}_{15} \mathrm{~N}_{9} \mathrm{O}_{14}\right) \cdot 8 \mathrm{H}_{2} \mathrm{O}\right.$, $\mathrm{FW}=1055.11 \mathrm{~g} / \mathrm{mol}]$

Table 4: Comparison of the Carbon: Nitrogen $(\mathrm{C} / \mathrm{N})$ Ratios for the Synthesized Compound (A), (see Section 2.7.5) with the Calculated C/N Ratios of Phthalocyanine Polymers (B).

Table 5: IR Data for Zinc Tetraimide Phthalocyanine Using $\mathrm{KBr}$ Pellets at Room Temperature (see Appendix I), 44

Table 6: Calculated Values of the Quantum Yield of Singlet Oxygen for the Photosensitizer in Different pH Solutions in the Absence of Surfactant. 67

Table 7: Calculated Values of the Quantum Yield of Singlet Oxygen for the Photosensitizer in Different pH Solutions in the Presence of Surfactant. 68

Table 8: Comparison of the Percentage Conversion of Thiosulfate to Sulfate (Gravimetric Analysis of Barium Sulfate) for the SOOT Experiment Carried Out at $0{ }^{\circ} \mathrm{C}$ and $22{ }^{\circ} \mathrm{C}$ in the Presence of CTAB and $\mathrm{Bu}_{4} \mathrm{NBr}$. 78

Table 9: Illustration of the Percentage Conversion of Thiosulfate to Sulfate in the SOOT Experiment Carried Out in the Presence of Different Concentrations of DTAB. 79 


\section{LIST OF FIGURES}

Figure 1: Primitive representations of molecular oxygen lowest singlet and triplet states. [33]

Figure 2: A simplified Jablonski diagram for the photosensitizer.

Figure 3: From ref 12, the visible absorption spectrum of solutions of (a) $\mathrm{H}_{2} \mathrm{Pc}$ and (b) $\mathrm{CuPc}$ in chloroform as the solvent.

Figure 4: Electronic absorption spectrum of $\mathrm{ZnPc}(\mathrm{COONa})_{4}$ in the presence of $\mathrm{Bu}_{4} \mathrm{NBr}$ (b), and the $\mathrm{ZnPc}(\mathrm{COONa})_{4}$ aggregate (a), both in aqueous solution, $\mathrm{pH} 10$ borax buffer.

Figure 5: Schematic illustration of a surfactant molecule. 14

Figure 6: Demonstration of charges on different types of surfactants.

Figure 7: Illustration of a spherical micelle in A) non-aqueous solvent, B) aqueous solvent, C) aqueous solution containing a negatively charged complex and cationic surfactant molecules.

Figure 8: Temperature dependent SOOT experiment using $\mathrm{ZnPc}(\mathrm{COONa})_{4}$ as a photosensitizer. Conditions: $\mathrm{S}_{2} \mathrm{O}_{3}{ }^{2-} 1000 \mathrm{ppm}, \mathrm{ZnPc}(\mathrm{COONa})_{4} 5.7 \mu \mathrm{M}, \mathrm{Bu}_{4} \mathrm{NBr} 0.12 \mathrm{M}$, $\mathrm{pH}=10.0$ borax buffer, irradiation intensity $120 \mathrm{klux}$.

Figure 9: Structure of different surfactants, used to evaluate the SOOT process............ 20

Figure 10: Experimental setup to carry out the SOOT process. ...................................... 24

Figure 11: The experimental setup at University of Ottawa, for singlet oxygen quantum yield and lifetime measurements. Band width: $\pm 20 \mathrm{MHz}$, time: $25 \mu \mathrm{s}$, wavelength: 650 $\mathrm{nm}$, phosphorescence of singlet oxygen: $1270 \mathrm{~nm}$. 27

Figure 12: UV-vis spectrum of the photosensitizer in water. 49

Figure 13: UV-vis spectra showing the behavior of the photosensitizer at room temperature in a $\mathrm{pH}$ 4-11 water-alkaline medium.

Figure 14: Spectra showing the behavior of the photosensitizer in DMF at room temperature using different concentrations of $\mathrm{N}$-butylamine (BA) in $50 \mathrm{~mL}$ total volume of solution. 
Figure 15: A: Band profiles with respect to the various concentrations of the photosensitizer in a $\mathrm{pH} 11$ water-alkaline solution using different cells in aqueous solution at room temperature. B: Band profile with respect to the lowest concentration $\left(10^{-7}\right)$ of the photosensitizer in a $\mathrm{pH} 11$ medium. C: Plot of the logarithm of absorbance measured at $696 \mathrm{~nm}$ versus the logarithm of the photosensitizer concentration. A Cell with a $5 \mathrm{~cm}$ path length was used for $10^{-6}$ and $10^{-7} \mathrm{M}$ solutions. Cells with $0.2 \mathrm{~cm}$ and $\mathrm{l}$ $\mathrm{cm}$ path lengths were used for $10^{-4}$ and $10^{-5} \mathrm{M}$ solutions respectively. The absorbance was normalized relative to that of the $1 \mathrm{~cm}$ cell by dividing the measured absorbance by the path length of the cell used in the measurement. ..................................................53 Figure 16: Spectra showing the effect of different concentrations of CTAB on the photosensitizer at $\mathrm{pH} 4$ 55

Figure 17: Spectra showing the behavior of photosensitizer in a $\mathrm{pH} 4$ medium at room temperature using different concentrations of DTAB demonstration the monomer-dimer equilibrium. 56

Figure 18: Spectra showing the behavior of photosensitizer in a $\mathrm{pH} 4$ medium at room temperature using different concentrations of DTAB demonstration the monomer-dimer equilibrium.. 57

Figure 19: Spectra showing the effect of different concentrations of DTAB on the photosensitizer at $\mathrm{pH} 6$.

Figure 20: Spectra showing the behavior of the photosensitizer in different phosphate $\mathrm{pH}$ buffers $(0.05 \mathrm{M})$ and $40 \mathrm{mM}$ DTAB, at room temperature.

Figure 21: ${ }^{1} \mathrm{O}_{2}$ emission intensity of $4.5 \times 10^{-5} \mathrm{M}$ methylene blue (calibrant) under $\mathrm{pH} 7$ in the absence of DTAB.

Figure 22: ${ }^{1} \mathrm{O}_{2}$ emission intensity from an aqueous solution of methylene blue (calibrant) in the absence of DTAB. Singlet oxygen decay spectrum data fit to an active curve assuming first order decay. Conditions: Methylene blue $4.5 \times 10^{-5} \mathrm{M}$, Milli-Q distilled water (pH 7). The solid line is a best-fit of eqn. 13 .

Figure 23: ${ }^{1} \mathrm{O}_{2}$ generation from Methylene Blue in aqueous medium and the photosensitizer in different water-alkaline $\mathrm{pH}$ media $(\mathrm{pH} 9, \mathrm{pH} 10$ and $\mathrm{pH} 11)$. Conditions: Photosensitizer: 0.037-0.041 mM. 65 
Figure 24: ${ }^{1} \mathrm{O}_{2}$ generation from Methylene Blue and the photosensitizer in a pH 11 wateralkaline medium with the presence and absence of DTAB. Conditions: Photosensitizer in the presence of DTAB: $0.036-0.140 \mathrm{mM}$, photosensitizer in the absence of DTAB: $0.033-$ 0.041 mM. Methylene blue: 0.0035-0.056 mM. 66

Figure 25: Photobleaching of the photosensitizer under visible light irradiation (intensity $=166 \mathrm{klux})$, at $22^{\circ} \mathrm{C}$, in an oxygen saturated, $\mathrm{pH} 11$ aqueous solution.

Figure 26: Bleaching of the photosensitizer (Q-band $\lambda=696 \mathrm{~nm}$ ) with irradiation time in an oxygen saturated $[\mathrm{A}] \mathrm{pH} 11$ solution and $[\mathrm{B}] \mathrm{pH} 10$ borax buffer solution. Conditions:

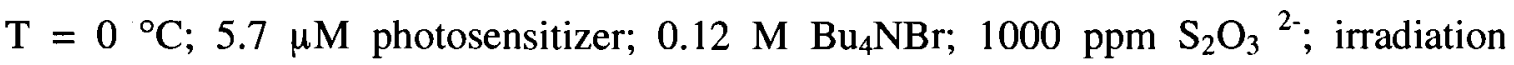
intensity 166 klux 72

Figure 27: Photobleaching of the $\mathrm{Zn}$ phthalocyanine photosensitizer in the presence of Triton X-100 at critical micelle concentration. Conditions: $\mathrm{T}=0{ }^{\circ} \mathrm{C}$, oxygen saturated

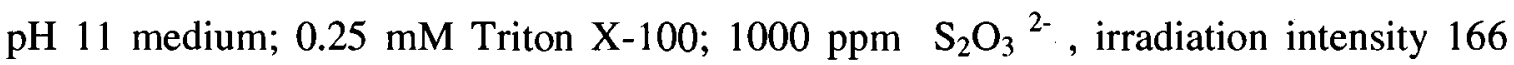
klux.

Figure 28: Bleaching of the photosensitizer (Q-band $\lambda=696 \mathrm{~nm}$ ) with irradiation time in oxygen saturated A) TBAB $(0.12 \mathrm{M})$ and B) CTAB $(1 \mathrm{mM}) \mathrm{pH} 11$ water-alkaline solution. Conditions: $\mathrm{T}=22{ }^{\circ} \mathrm{C} ; 5.7 \mu \mathrm{M}$ photosensitizer; $1000 \mathrm{ppm} \mathrm{S}_{2} \mathrm{O}_{3}{ }^{2-}$; irradiation intensity 166 klux 75

Figure 29: Bleaching of the photosensitizer ( $Q$-band $\lambda=696 \mathrm{~nm}$ ) during the SOOT experiment with irradiation time in an oxygen saturated CTAB (1 mM) pH 11 wateralkaline solution. Conditions: $\mathrm{T}=0{ }^{\circ} \mathrm{C} ; 5.7 \mu \mathrm{M}$ photosensitizer; $1000 \mathrm{ppm} \mathrm{S}_{2} \mathrm{O}_{3}{ }^{2-}$; irradiation intensity 166 klux. 77

Figure 30: Bleaching of the photosensitizer (Q-band $\lambda=696 \mathrm{~nm}$ ) during the SOOT experiment with irradiation time in an oxygen saturated DTAB $(16 \mathrm{mM}) \mathrm{pH} 11$ wateralkaline solution. Conditions: $5.7 \mu \mathrm{M}$ photosensitizer; $1000 \mathrm{ppm} \mathrm{S}_{2} \mathrm{O}_{3}{ }^{2-}$; irradiation intensity $166 \mathrm{klux}$. 80

Figure 31: Bleaching of the photosensitizer (Q-band $\lambda=696 \mathrm{~nm}$ ) during the SOOT experiment at $22^{\circ} \mathrm{C}$ with irradiation time in an oxygen saturated DTAB (16 mM) and DTAC (16 mM) pH 11 water-alkaline solution. Conditions: $5.7 \mu \mathrm{M}$ the photosensitizer; $1000 \mathrm{ppm} \mathrm{S}_{2} \mathrm{O}_{3}{ }^{2-}$ irradiation intensity $166 \mathrm{klux}$. 83 


\section{LIST OF REACTION SCHEMES}

Reaction Scheme 1: Proposed mechanism for the Zinc octacarboxylate phthalocyanine following the protocol outlined by Kuznetsova et al........................................................ 40 Reaction Scheme 2: Proposed structure for the dimer sodium salt of Zinc carboxylate phthalocyanine. .43

Reaction Scheme 3: Mechanism for the synthesis of sodium salt of Zinc 2,3,9,10,16,17(hexacarboxylate)-23,24-(dicarboximide) phthalocyanine sodium salt, the photosensitizer. .48 


\section{LIST OF ABBREVIATIONS}

FT-IR

UV-vis

$\mathrm{HCl}$

PMD

DMF

TCB

BA

$\mathrm{TBAB}$ or $\mathrm{Bu}_{4} \mathrm{NBr}$

CTAB

DTAB

DTAC

SDS

SOOT

CMC

$\mathrm{Q}_{\mathrm{s}}$

The photosensitizer
Fourier Transform Infrared Spectroscopy

Ultraviolet-visible Spectroscopy

Hydrochloric Acid

Pyromellitic Dianhydride

Dimethyl Formamide

Tetracyanobenzene

N-butylamine

Tetrabutylammonium Bromide

CetylTrimethylAmmonium Bromide

DodecylTrimethylAmmonium Bromide

DodecylTrimethylAmmonium Chloride

Sodium Dodecyl Sulfate

Singlet Oxygen Oxidation of Thiosalts

Critical Micelle Concentration

Quantum Yield of Singlet Oxygen

Zinc 2,3,9,10,16,17-(hexacarboxylate)-23,24-(dicarboximide)

phthalocyanine sodium salt 


\section{CHAPTER 1}

\section{INTRODUCTION}

\section{$1.1 \quad$ Singlet Oxygen Oxidation of Thiosalts (SOOT) Process}

The milling of sulfide ores forms partially oxidized sulfur oxyanions such as $\mathrm{S}_{2} \mathrm{O}_{3}{ }^{2-}, \mathrm{S}_{3} \mathrm{O}_{6}{ }^{2-}, \mathrm{S}_{4} \mathrm{O}_{6}{ }^{2-}$ etc., which are termed thiosalts. These thiosalts, along with other mining by-products are dissolved in the effluent. The natural oxidation of these thiosalts generates significant acid concentrations, thereby allowing minerals to dissolve in the water and be released where these harmful substances will elicit toxic effects in aquatic life [68].

The problem of thiosalts in mining effluent was the impetus of much research in the Natural Resources Canada (NRCan) laboratories beginning in 1976 and continues to the present day. During the period of 1976-1982, NRCan, in conjunction with university and industrial stakeholders, carried out a project to evaluate the chemistry, generation and treatment of thiosalts in mining effluent. These studies have been summarized in a paper published by Wasserlauf and Durtrizac in 1984 [18]. The first studies examined direct chemical oxidation of thiosalts by the addition of a chemical oxidant $\left(\mathrm{O}_{3}, \mathrm{Cl}_{2}, \mathrm{H}_{2} \mathrm{O}_{2}, \mathrm{ClO}^{-}\right.$ ... etc.) to mining effluent. While oxidation of thiosalts to sulfate was complete when using these methods, the cost of purchasing these industrial oxidants in bulk made these processes uneconomical. In this regard, catalytic processes or those that generate a 
chemical oxidant in situ would seem to hold the greatest potential for an economically viable solution.

Chanda, O'Driscoll and Rempel proposed using a polymer bound copper complex to catalyze the oxidation of thiosalts by molecular oxygen [3]. According to the reaction:

$\mathrm{S}_{2} \mathrm{O}_{3}{ }^{2-}+2 \mathrm{O}_{2}+\mathrm{H}_{2} \mathrm{O} \rightarrow 2 \mathrm{SO}_{4}{ }^{2-}+2 \mathrm{H}^{+}$

However, a preliminary cost estimate yielded a cost of $\$ 2.89 / \mathrm{m}^{3}$ of effluent [19]. This was regarded by the industry as too high (a treatment cost of $\$ 0.30 / \mathrm{m}^{3}$ effluent is the target [4]).

Currently, thiosalts are oxidized in effluent holding ponds using thiobacilli. After the thiosalt levels have reached a threshold $(<10 \mathrm{mg} / \mathrm{L} \mathrm{[29])} \mathrm{in} \mathrm{the} \mathrm{holding} \mathrm{ponds,} \mathrm{the} \mathrm{pH}$ of the effluent can be adjusted to natural levels and the effluent discharged into the water systems (rivers, lakes and oceans). In a 1985 study of the parameters for the operation of thiosalt oxidation ponds [16], the negative effects of lead, copper and low temperatures on thiosalt oxidation were evaluated. The presence of $2 \mathrm{mg} / \mathrm{liter}$ copper or lead reduced the rate of thiosalt oxidation by 55 and $30 \%$ respectively [16]. Dropping the temperature from 30 to $5{ }^{\circ} \mathrm{C}$ decreased the rate of thiosalt oxidation by a factor of 10 [16]. The study emphasized that when dealing with mining effluent at temperatures lower than $2{ }^{\circ} \mathrm{C}$ “...a supplementary method of thiosalt oxidation must be used" [16]. Thus, due to this hindrance mining productivity in the winter is restricted under Metal Mining Effluent Regulations (MMER) [30]. 
Bacterial oxidation of thiosalts was clearly the most economical of all those studied and is presently used to treat effluents by the Brunswick Mining and Smelting Corp., Bathurst, N.B. during fall and summer. Annual operating costs were estimated [18] to be $\$ 430,000$ to treat $1250 \mathrm{ppm}$ thiosalt effluent or $\$ 0.135 / \mathrm{m}^{3}$ effluent.

In 1996, Haque and Dinardo [6] explored the possibility of removing thiosalts from effluent by halide mediated electro-oxidation. The reaction half-equations are [6]:

$$
\begin{aligned}
& 2 \mathrm{NaCl} \rightarrow 2 \mathrm{Na}^{+}(a q)+2 \mathrm{Cl}^{-}(\mathrm{aq}) \\
& 2 \mathrm{Cl}^{-} \rightarrow \mathrm{Cl}_{2} \text { (anode) } \\
& \mathrm{H}_{2} \mathrm{O}+\mathrm{Cl}_{2} \rightarrow \mathrm{HOCl}+\mathrm{HCl} \\
& \mathrm{H}_{2} \mathrm{~S}_{2} \mathrm{O}_{3}+4 \mathrm{HOCl}+\mathrm{H}_{2} \mathrm{O} \rightarrow 2 \mathrm{H}_{2} \mathrm{SO}_{4}+4 \mathrm{Cl}^{-}+4 \mathrm{H}^{+}
\end{aligned}
$$

The preliminary operating cost estimate based on reagents (rock salt, etc.) and power consumption was $\$ 0.45 / \mathrm{m}^{3}$ effluent [6]. Capital costs were not included in this estimate and so while the electro-oxidation method appeared promising, an even more economical alternative was desired.

Due to the discussion above, there has been an increased interest by government and academic researchers to remedy this situation so that mining restrictions may be minimized with little or no harm to aquatic species. Recent studies have shown that thiosalts in the holding ponds may be oxidized by singlet oxygen. 


\subsection{Singlet Oxygen}

It is known that the ground electronic state $\left({ }^{3} \Sigma_{\mathrm{g}}\right)$ of molecular oxygen contains two unpaired electrons. The two electronic excited singlet states which arise from the same electron configuration but with different spin pairing (Figure 1) in the $\pi$ antibonding orbitals of the two electrons are ${ }^{1} \Delta_{\mathrm{g}}$ and ${ }^{1} \Sigma \mathrm{g}^{+}$states that lie 94 and $157 \mathrm{~kJ}$ $\mathrm{mol}^{-1}$ respectively above the ground state [32]. The ${ }^{1} \Sigma_{\mathrm{g}}{ }^{+}$state is very short lived and rapidly relaxes to the lowest lying excited ${ }^{1} \Delta_{\mathrm{g}}$ state. The transition from ${ }^{1} \Delta_{\mathrm{g}}$ state to ${ }^{3} \Sigma_{\mathrm{g}}$ state is spin forbidden; therefore, ${ }^{1} \Delta_{g}$ state of oxygen is a long lived specie (45 min [33]). Due to the meta-stability of ${ }^{1} \Delta_{\mathrm{g}} \mathrm{O}_{2}$ and its excited state energy ( $\left.0.98 \mathrm{~V}\right)$, it is used in many photobiological and photochemical reactions $[34,35]$.

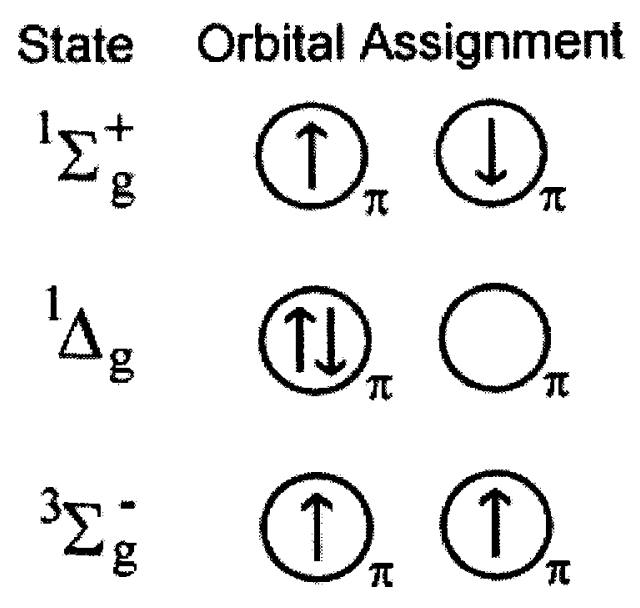

Figure 1: Primitive representations of molecular oxygen lowest singlet and triplet states. [33]

Oxygen by itself (i.e., $\mathrm{O}_{2}$ ) is not a very good oxidant as demonstrated by its calculated reduction potential of $-0.137 \mathrm{~V}$ (using NHE standard) [57]. In contrast, singlet oxygen is a powerful oxidant [54], as shown by Saito et. al., [54] and Eriksen et. al., [56], where the emission energy of singlet oxygen is added to the reduction potential of $\mathrm{O}_{2}$ to 
determine the reduction potential of singlet oxygen. Hence, the reduction potential for singlet oxygen was calculated to be $0.84 \mathrm{~V}$.

Singlet oxygen is an electrophilic molecule and has been shown to oxidize phenols as well as sulfides and thiosalts [7]. It is also been linked to the process responsible for killing cancer cells under photodynamic therapy [7]. Recently, Iliev et. al., [14] examined the photocatalyzed oxidation of sulfides and thiosulfate. They showed that it was possible to completely convert $4.2 \mathrm{mmol}$ of $\mathrm{Na}_{2} \mathrm{~S}$ to sulfate over a period of approximately 3 hours when irradiating an aqueous reaction solution containing $1.7 \mu \mathrm{mol}$ of Zinc tetracarboxylate phthalocyanine ( $\mathrm{pH}$ of 9.2 , temperature $25^{\circ} \mathrm{C}$ ) [14]. In addition, of the photosensitizer's studied (photo-semiconductor powders and Zinc tetracarboxylate phthalocyanine); only Zinc tetracarboxylate phthalocyanine photocatalyzed the oxidation of thiosulfate to sulfate [14].

There are many ways by which singlet oxygen can be produced [34], but it is most commonly produced by photosensitization. Ground state triplet oxygen $\left({ }^{3} \mathrm{O}_{2}\right)$ can be photosensitized to an excited singlet state $\left({ }^{1} \mathrm{O}_{2}\right)$ by energy transfer from a photosensitizer (Sens) possessing a long lived triplet excited state $\left({ }^{3}\right.$ Sens). The triplet excited state of the photosensitizer transfers its energy to the ground state of oxygen generating the oxygen excited state $\left({ }^{1} \mathrm{O}_{2}\right)$ :

$$
\begin{aligned}
& \text { Sens }+h v \rightarrow{ }^{\prime} \text { Sens } * \rightarrow{ }^{3} \text { Sens } * \\
& { }^{3} \text { Sens }{ }^{*}+{ }^{3} \mathrm{O}_{2} \rightarrow \text { Sens }+{ }^{\prime} O_{2}
\end{aligned}
$$


Superoxide can be formed from the oxidation of thiosulfate by singlet oxygen. In an aqueous solution, superoxide is not stable and forms peroxide ions according to the disproportionation reaction given below:

$$
\mathrm{H}_{2} \mathrm{O}+2 \mathrm{O}_{2}^{-} \rightarrow \mathrm{HO}_{2}^{-}+\mathrm{OH}+\mathrm{O}_{2}
$$

and thus leads to chemical oxidation of thiosulfates by peroxides [18]:

$$
4 \mathrm{HO}_{2}+\mathrm{S}_{2} \mathrm{O}_{3}{ }^{2-} \rightarrow \mathrm{H}_{2} \mathrm{O}+2 \mathrm{SO}_{4}{ }^{2-}+2 \mathrm{OH}^{-}
$$

This research project evaluates the effectiveness of singlet oxygen oxidation of thiosalts (SOOT), by photosensitization in a basic medium at temperatures where biological oxidation is inefficient $\left(<0^{\circ} \mathrm{C}\right)$ [7]. It also keeps in mind the demand by industry to create a cheap and widely available methodology that ideally costs less than the biological system while being more effective year around.

\subsection{Photosensitizers}

Photosensitizers are organic or oganometallic macromolecules that have the ability to absorb light forming a long lived triplet excited state [33]. These photosensitizers have the unique ability to photocatalyze chemical reactions which promotes their use in many different industries [21].

Phthalocyanines are a class of photosensitizers with a cage-type structure [10]. These photoactive systems are unique as they are stable, easy to use due to their strong 
adsorption of light and easy to quantify due to their high color intensity. The first phthalocyanine was synthesized in 1907 by Braun and Tcherniac who heated ocyanobenzamide at a high temperature [1]. The structure of this metal free, unsubstituted phthalocyanine was determined only a quarter of a century later by Linstead et. al. [2] and Robertson et. al. [13], while examining both metal-free and metallophthalocyanines [10].

A simplified Jablonski diagram for a photosensitizer is shown below in which a photosensitizer is excited to its triplet state. If oxygen $\left({ }^{3} \mathrm{O}_{2}\right)$ is in close proximity, energy transfer between the triplet states may occur resulting in the formation of singlet oxygen $\left({ }^{1} \mathrm{O}_{2}\right)$. The number of ${ }^{1} \mathrm{O}_{2}$ molecules generated for each photon absorbed by a photosensitizer is called the quantum yield of singlet oxygen formation $\left(Q_{s}\right)$.

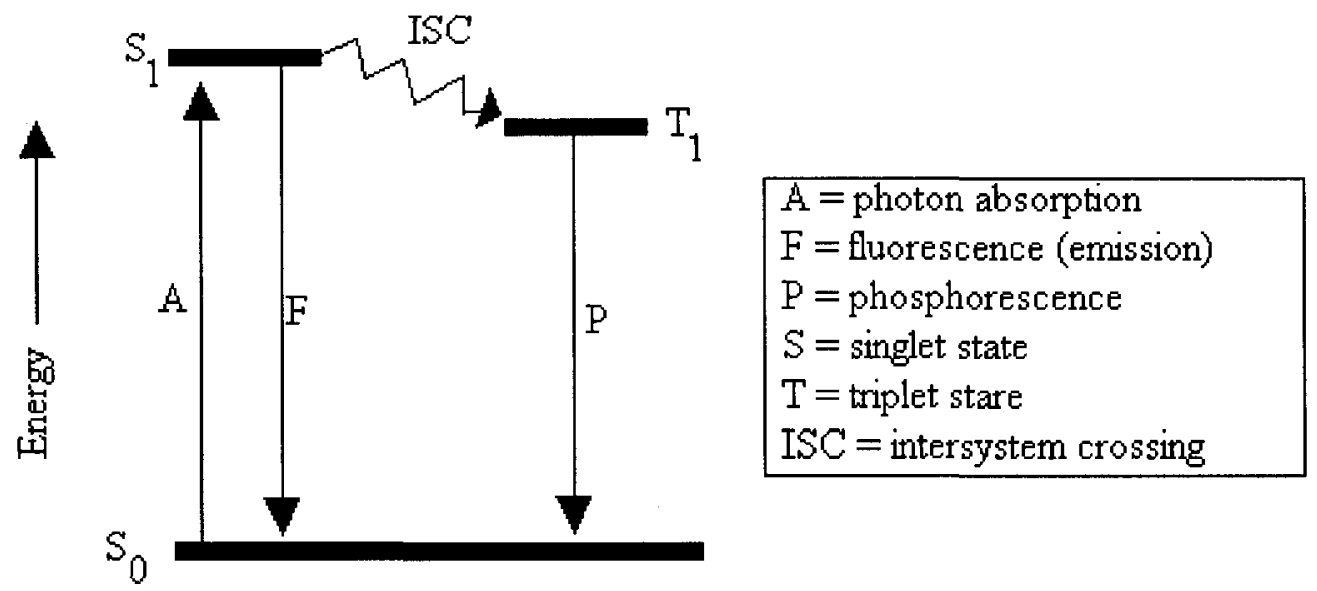

Electronic ground state

Figure 2: A simplified Jablonski diagram for the photosensitizer. 


\subsubsection{Energy Transfer Mechanisms}

Forster transfer is described as the transfer of excitation energy from an excited donor molecule to a ground state acceptor molecule via long distance dipole-dipole interaction [45] that is capable of transferring excitation energy from donor to an acceptor over a separation distance as long as $100 \AA$ [44].

According to Forster et. al. [45], the rate of energy transfer, $\mathrm{k}_{\mathrm{ET}}$, is given by:

$$
k_{E T}=\frac{1}{\tau_{d}}\left(\frac{R_{0}}{r}\right)^{6}
$$

where $\mathrm{r}$ is the distance between the donor molecule (i.e., $\mathrm{ZnPc}$ ) and the acceptor molecule (i.e., ${ }^{3} \mathrm{O}_{2}$ ), $\tau_{\mathrm{d}}$ is the lifetime of the donor molecule in the absence of the acceptor and $\mathrm{R}_{0}$ is the Forster distance [45].

The Dexter mechanism is another dynamic energy quenching mechanism occurring as a result of electron exchange. It is a short range mechanism, with the distance between donor and acceptor typically less than $10 \AA$ [52] and requires that the orbitals of donor overlap with the orbitals of the acceptor since the electrons are exchanged. This is shown by the Dexter equation below, where the energy transfer is dependant upon the distance between the donor-acceptor $\left(\mathrm{r}_{\mathrm{DA}}\right)$ and the orbital overlap (K). As seen from the equation 11 , as the distance of the donor-acceptor gets larger, the rate of energy transfer is expected to decrease exponentially [52]. Therefore, it is evident that Dexter mechanism only hold true for molecules in close proximity. 
According to the Dexter equation $[69,45]$, the rate of energy transfer $\left(\mathrm{k}_{\mathrm{ET}}\right)$ is given by:

$$
k_{E T}=\frac{2 \pi}{h} K J e^{\left(\frac{-2 r_{D A}}{L}\right)}
$$

where $\mathrm{K}$ is the orbital overlap depending on the specific orientations of the donor molecule (i.e., $\mathrm{ZnPc}$ ) and the acceptor molecule (i.e., ${ }^{3} \mathrm{O}_{2}$ ), $\mathrm{L}$ is the sum of van der Waals radii, $\mathbf{J}$ is the Dexter constant and $r_{D A}$ is the donor-acceptor separation relative to their van der Waals radii [41].

\subsection{Photobleaching}

The photosensitizer may react with singlet oxygen or peroxide and lose its ability to absorb visible light. Thus, this decomposition reaction is commonly referred to as photobleaching. Photobleaching results in a reduction in the production of the singlet oxygen and hence the oxidation of thiosalts in the mining effluent. There are many modifications that can reduce the rate of photobleaching [11] some of which are discussed later (i.e., surfactants), but these modifications must not adversely affect the photosensitizer excited state properties. In order to catalyze the formation of singlet oxygen, a sensitizer in its triplet excited state should have a lifetime that permits bimolecular reaction (at least $1 \mu \mathrm{s}$ ) and be energetically capable of energy transfer to the ground state of dioxygen to form singlet oxygen. Photosensitizers whose triplet excited 
state is formed with a large quantum yield will also result in increased singlet oxygen production.

\subsection{Dimerization}

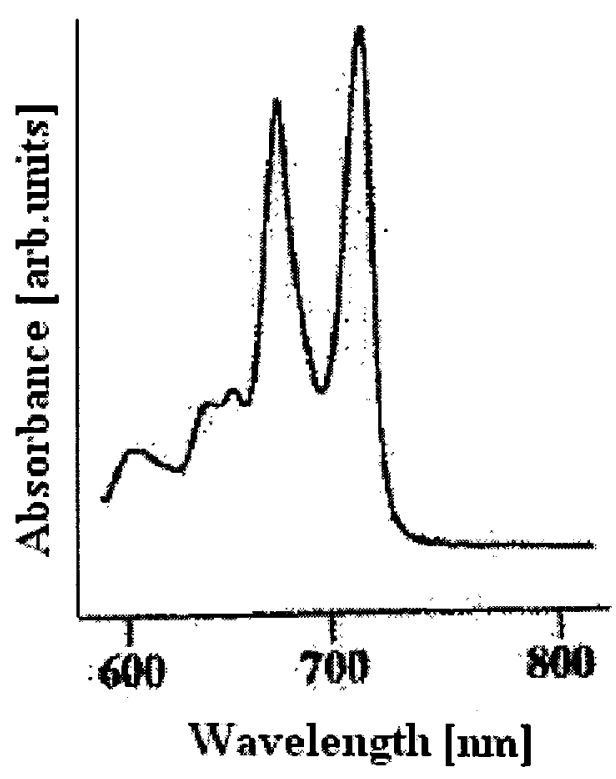

(a)

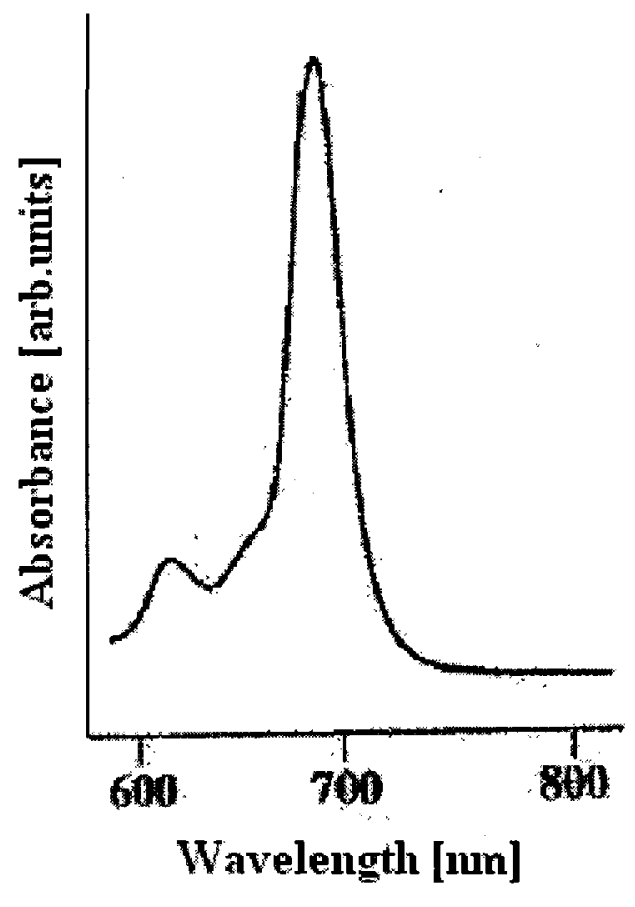

(b)

Figure 3: From ref 12, the visible absorption spectrum of solutions of (a) $\mathrm{H}_{2} \mathrm{Pc}$ and (b) $\mathrm{CuPc}$ in chloroform as the solvent.

The characteristic solution visible absorption spectrum for $\mathrm{H}_{2} \mathrm{Pc}$ and $\mathrm{CuPc}$ is given in Figure 3. In both cases there is a strong absorption between $670 \mathrm{~nm}$ and $690 \mathrm{~nm}$, termed Q-band [12]. In addition there is a strong absorption band in the ultra-violet region between $320 \mathrm{~nm}$ and $370 \mathrm{~nm}$ [12], which has been designated the B-band (or Soret band). The former absorption is responsible for the characteristic intense blue-green 
colour of the compound [12]. A typical value of the extinction coefficient of the intense Q-band is $2 \times 10^{5} \mathrm{~cm}^{-1} \mathrm{M}^{-1}$ for mononuclear phthalocyanine complexes of high purity [12]. The weak absorption bands at about $600 \mathrm{~nm}$ are vibrational overtones of the Q-band.

It has been noted by many researchers $[10,21]$ that phthalocyanine complexes form aggregates (dimer, trimer, etc) in solution as shown in eqn. 12:

$$
2 \mathrm{ZnPc} \leftrightarrow(\mathrm{ZnPc})_{2}
$$

Phthalocyanines tend to aggregate because their planar geometry optimizes $\pi-\pi$ interactions. Figure 4 is an experiment that illustrates how the monomer-dimer equilibrium in $\mathrm{pH} 10$ aqueous solution is affected by the presence of $\mathrm{Bu}_{4} \mathrm{NBr}$. The intense Q-band seen above in Figure $3 \mathrm{~b}$ is diagnostic of having mostly monomer species in solution. Comparing Figure $4 b$ to Figure $3 b$, there is no significant difference observed in the spectra suggesting that the phthalocyanine in the presence of $\mathrm{Bu}_{4} \mathrm{NBr}$ is mostly a monomer specie (i.e. equilibrium in eqn. 12 is mostly to the left). On the other hand, when $\mathrm{Bu}_{4} \mathrm{NBr}$ is not present a new band appears at $620 \mathrm{~nm}$ in the absorption spectrum (Figure 4a) and the Q-band has lost so much intensity that it now appears as a shoulder. We associate the growth of the band at $620 \mathrm{~nm}$ as diagnostic of dimer formation which is to be avoided. Excitation of the dimer creates excimers (an excited dimer) whose photophysical properties of these excimers are not appropriate for photosensitization of singlet oxygen. 


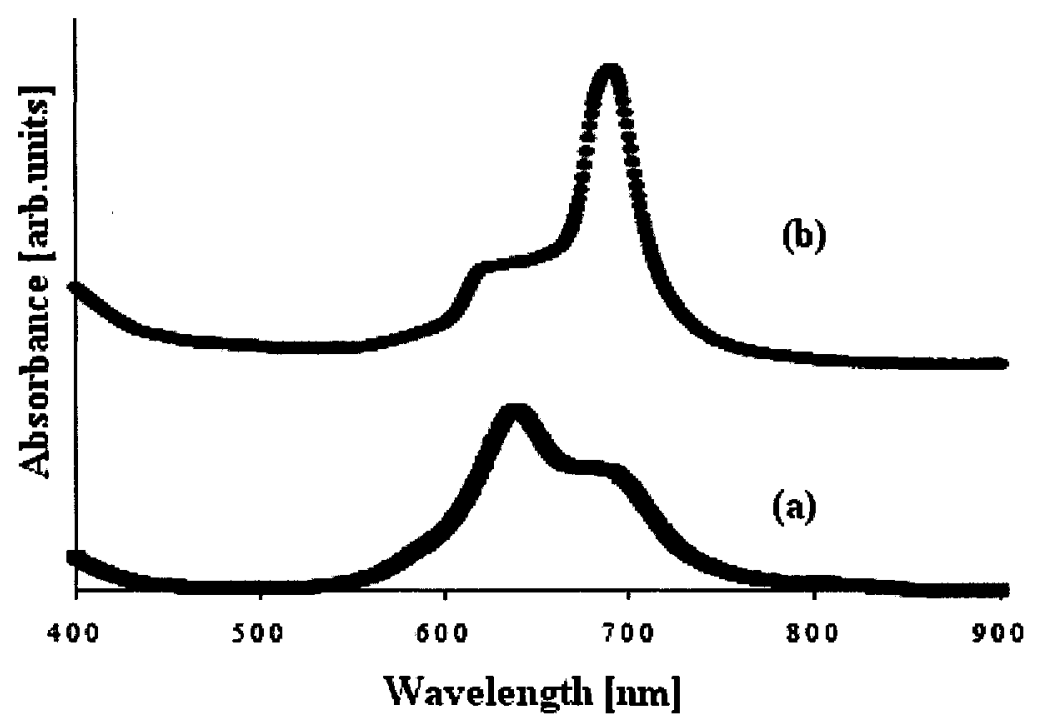

Figure 4: Electronic absorption spectrum of $\mathrm{ZnPc}(\mathrm{COONa})_{4}$ in the presence of $\mathrm{Bu}_{4} \mathrm{NBr}$ (b), and the $\mathrm{ZnPc}(\mathrm{COONa})_{4}$ aggregate (a), both in aqueous solution, $\mathrm{pH} 10$ borax buffer.

Research carried out by Brian MacLean (a former postdoctoral fellow in Dr. Crutchley's lab) indicated successful conversion of thiosalts to sulfates but only in the presence of $\mathrm{Bu}_{4} \mathrm{NBr}$ which limited dimerization of the photosensitizer (see Figure $4 \mathrm{~b}$ ) [21]. Unfortunately, the high concentrations of $\mathrm{Bu}_{4} \mathrm{NBr}$ that were required to reduce dimerization made the SOOT reaction expensive and uneconomical. An alternative to $\mathrm{Bu}_{4} \mathrm{NBr}$ was surfactants.

\subsection{Surfactants}

Surfactants find their uses amongst a myriad of industries (.e.g., soaps, oils, pharmaceuticals, etc). Recently, surfactants have become the subject of intense 
investigation by researchers in the fields of chemical kinetics and biochemistry because of the unusual properties of the supramolecular form (micelle) of these materials [10].

A surfactant is a surface-active agent that, when present at low concentrations in a system, has the property of adsorbing onto the surfaces or interfaces of the system and of altering the surface or interfacial free energies of those surfaces (or interfaces). The term interface indicates a boundary between any two immiscible phases, and the term surface indicates an interface where one phase is a gas, usually air [10].

The interfacial and solution behaviour of surfactants leads to the key surfaceactive properties of surfactants such as wetting/re-wetting, emulsification/ demulsification, foaming, dispersing, defoaming, detergency and solubilising.

\subsubsection{Structure of a Surfactant}

The general structure of a surfactant consists of a structural group that has very little attraction for the solvent (lyophobic group), along with a group that has strong attraction for the solvent (lyophilic group). This is known as an amphipathic structure [15]. Surfactants are called amphiphiles because they possess 2 distinct regions with extreme differences in physicochemical properties. When a surfactant is dissolved in a solvent, the presence of lyophobic groups in the interior of the solvent causes a distortion of the solvent liquid structure, therefore increasing the free energy of the system [15]. In case of water being the solvent, the tail of the surfactant molecule (lyophobic group), is referred to as a hydrophobic group and the head (lyophilic group) as a hydrophilic group as illustrated below. 
Hydrophobic tail

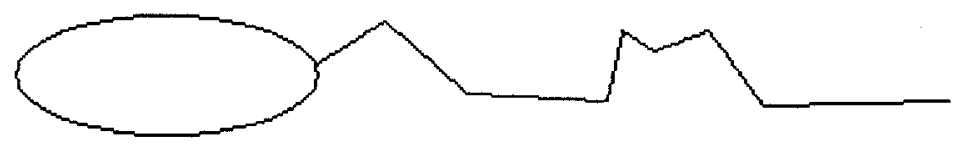

Hydrophilic head group

Figure 5: Schematic illustration of a surfactant molecule.

\subsubsection{Types of Surfactants}

Surfactants are classified according to their dissociation in water. They are divided in four groups, anionic surfactants, non-ionic surfactants, cationic surfactants and amphoteric surfactants.

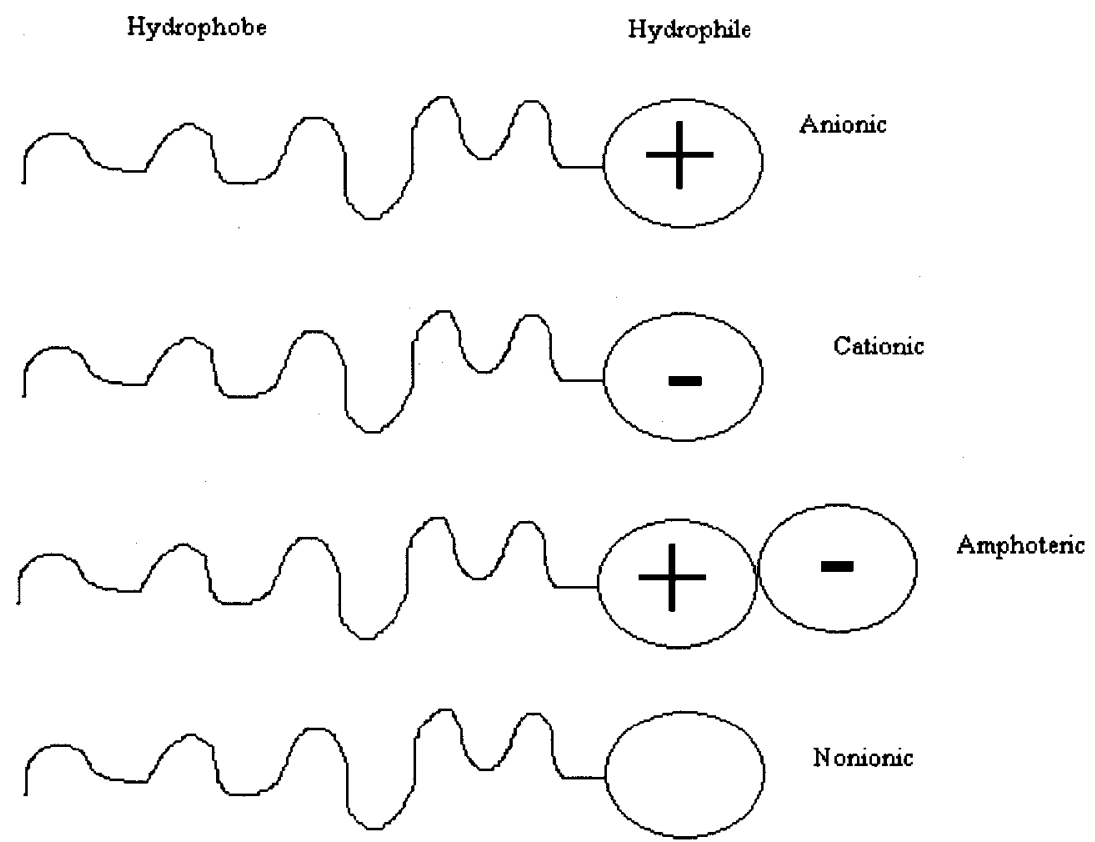

Figure 6: Demonstration of charges on different types of surfactants. 
Anionic surfactants are used in laundry and hand dishwashing detergents, household cleaners, and personal cleansing products. They ionize (are converted to charged particles) in solution, carry a negative charge, and have excellent cleaning properties. Alcohol sulphates, phosphate esters and sulphonated fatty acids are some examples of the anionic surfactants.

Nonionic surfactants are low sudsing and are typically use in laundry and automatic dishwasher detergents and rinse aids. Because they do not ionize in solution and thus have no electrical charge, they are resistant to water hardness and clean well on most soils. Alkyl phenol ethoxylates, fatty amine ethoxylates and sorbitan esters are some examples of nonionic surfactants.

Cationic surfactants are used in fabric softeners and in fabric-softening laundry detergents. Other cationics are the disinfecting/sanitizing ingredient in some household cleaners. They ionize in solution and have a positive charge. Imidazolinium salts, cetyltrimethylammonium bromide and dodecyltrimethylammonium chloride are some examples of cationic surfactants.

Amphoteric surfactants are used in personal cleansing and household cleaning products for their mildness, sudsing and stability. They have the ability to be anionic (negatively charged at low $\mathrm{pH}$ conditions), cationic (positively charged at high $\mathrm{pH}$ conditions) or nonionic (no charge at neutral $\mathrm{pH} \sim 7$ ) in solution. Betains and Imidazolines are some examples of amphoteric surfactants. 


\subsubsection{Critical Micelle Concentration (CMC)}

A fundamental property of surfactants is that they tend to form aggregates in solution, called micelles. The concentration at which micelles start to form is called the Critical Micelle Concentration, or CMC. The exact structure of micelles formed and some details of the process of micellization are issues that are still debated [15]. For our purpose, it is sufficient to indicate that in a non-aqueous solvent the hydrophobic tails tend to orient themselves towards the outside, and the hydrophilic heads form the interior of the micelle, hence ensuring that the surfactant is soluble in that solvent (Figure 7A). On the other hand, having water as the solvent, the hydrophilic heads orient themselves in the opposite direction, i.e., towards the outside, and the hydrophobic tails form the interior of the micelle. This orientation is responsible for the formation of a reverse micelle (Figure 7B).

Furthermore, if a negatively charged complex is introduced in an aqueous solvent, both micelle orientations (Figure 7A and 7B) will be seen with a single surfactant specie. Firstly, a layer of surfactant molecules will orient themselves to interact with the anionic compound (such as Figure 7A) after which another coordinating layer of surfactant molecules will orient themselves around the first layer of the surfactant in a manner similar to Figure 7B to form a soluble micelle in water (Figure 7C). 


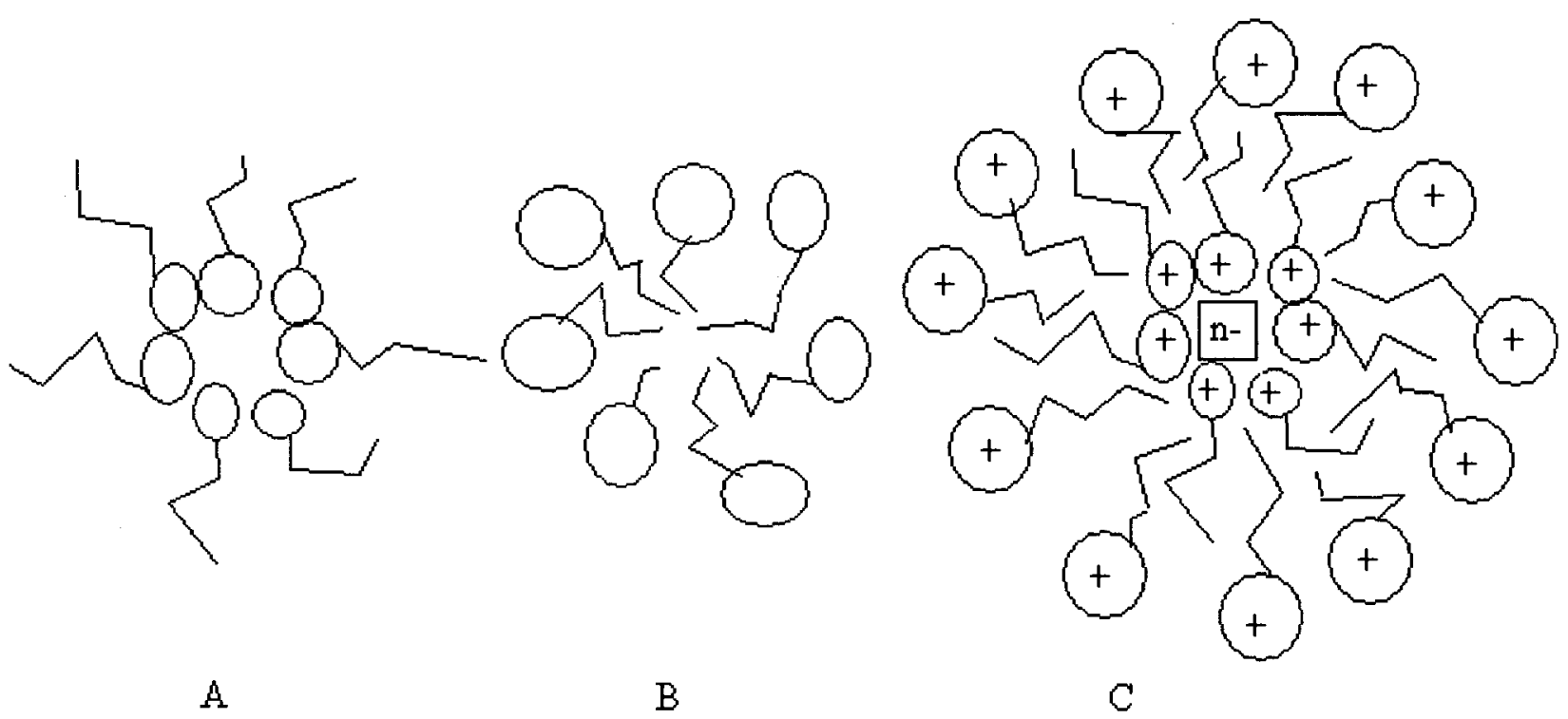

Figure 7: Illustration of a spherical micelle in A) non-aqueous solvent, B) aqueous solvent, C) aqueous solution containing a negatively charged complex and cationic surfactant molecules.

\section{$1.7 \quad$ Temperature Dependence}

Studies by Dr. MacLean showed that $\mathrm{ZnPc}(\mathrm{COONa})_{4}$ photocatalyzed the oxidation of $\mathrm{S}_{2} \mathrm{O}_{3}{ }^{2-}$ to $\mathrm{SO}_{4}{ }^{2-}$ at several temperatures and the data is summarized in Figure 8. His results showed that the oxidation of thiosulfate ions to produce sulfate, while slower, was still significant at lower temperatures. Dr. MacLean noticed an approximately two-fold drop in the production of sulfate with decreasing temperature from 14.2 to $0{ }^{\circ} \mathrm{C}$. Nevertheless, the sulfate produced after 12 hours at $0{ }^{\circ} \mathrm{C}$ corresponded to almost $24 \%$ conversion of thiosulfate to sulfate ion, thus giving a preliminary indication that this approach was better than the ones used by industry (i.e., thiobacilli). The sulfate production levelled off at longer times. This behaviour was attributed to photobleaching of the photosensitizer by singlet oxygen generated during the reaction. As 
the photosensitizer is degraded with time, less is available to convert the remaining thiosulfate.

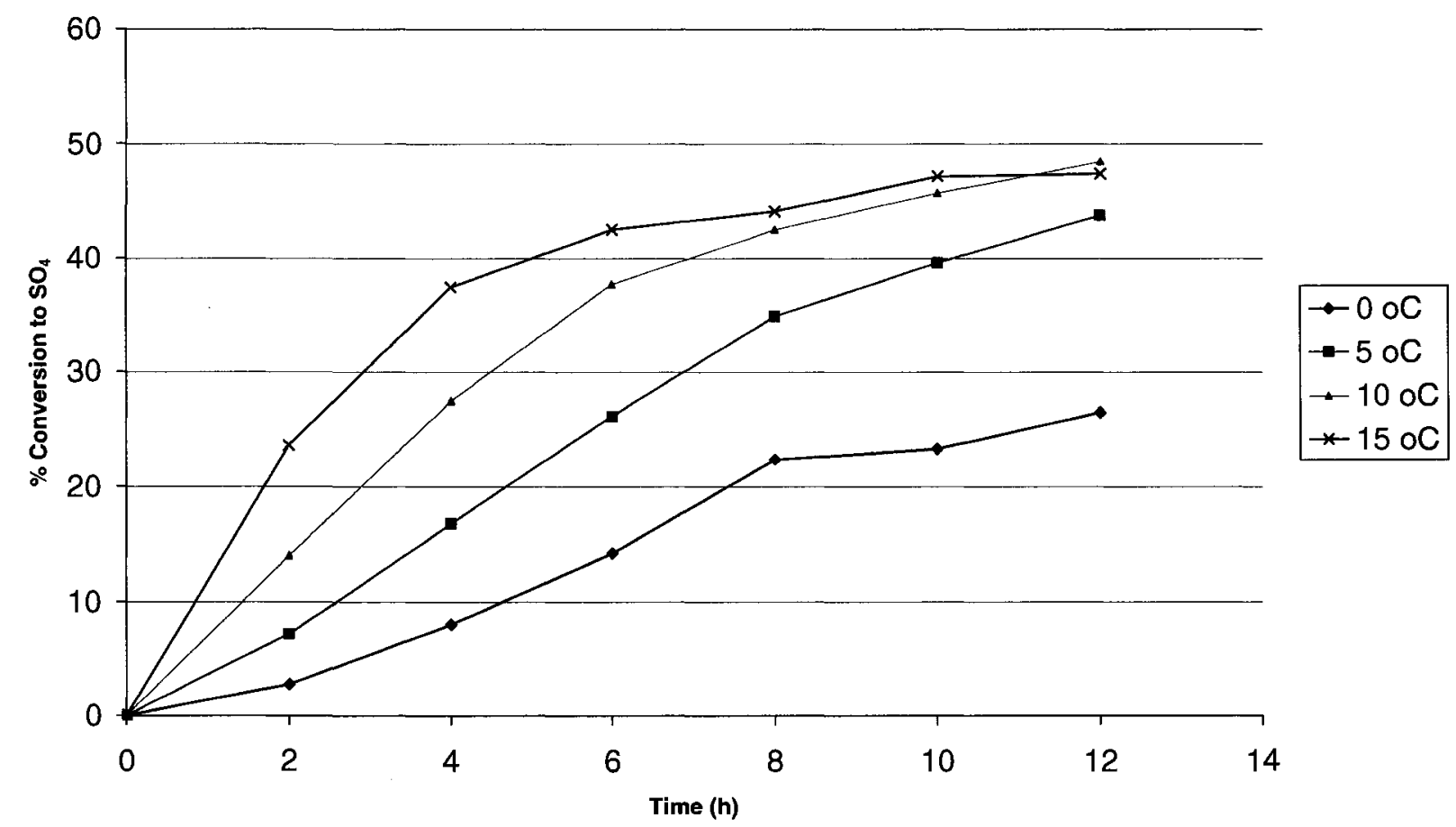

Figure 8: Temperature dependent SOOT experiment using $\mathrm{ZnPc}(\mathrm{COONa})_{4}$ as a photosensitizer. Conditions: $\mathrm{S}_{2} \mathrm{O}_{3}{ }^{2-} 1000 \mathrm{ppm}, \mathrm{ZnPc}(\mathrm{COONa})_{4} 5.7 \mu \mathrm{M}, \mathrm{Bu}_{4} \mathrm{NBr} 0.12 \mathrm{M}$, $\mathrm{pH}=10.0$ borax buffer, irradiation intensity $120 \mathrm{klux}$.

\section{$1.8 \quad$ Proposed Research}

This current research will evaluate the effectiveness of a photosensitizer system to convert thiosalts to sulfates in the presence of conditions that are typically seen at a mining effluent holding pond.

Firstly, an octacarboxylate phthalocyanine complex will be synthesized (see below) and fully characterized via spectrophotometry and elemental analysis. 


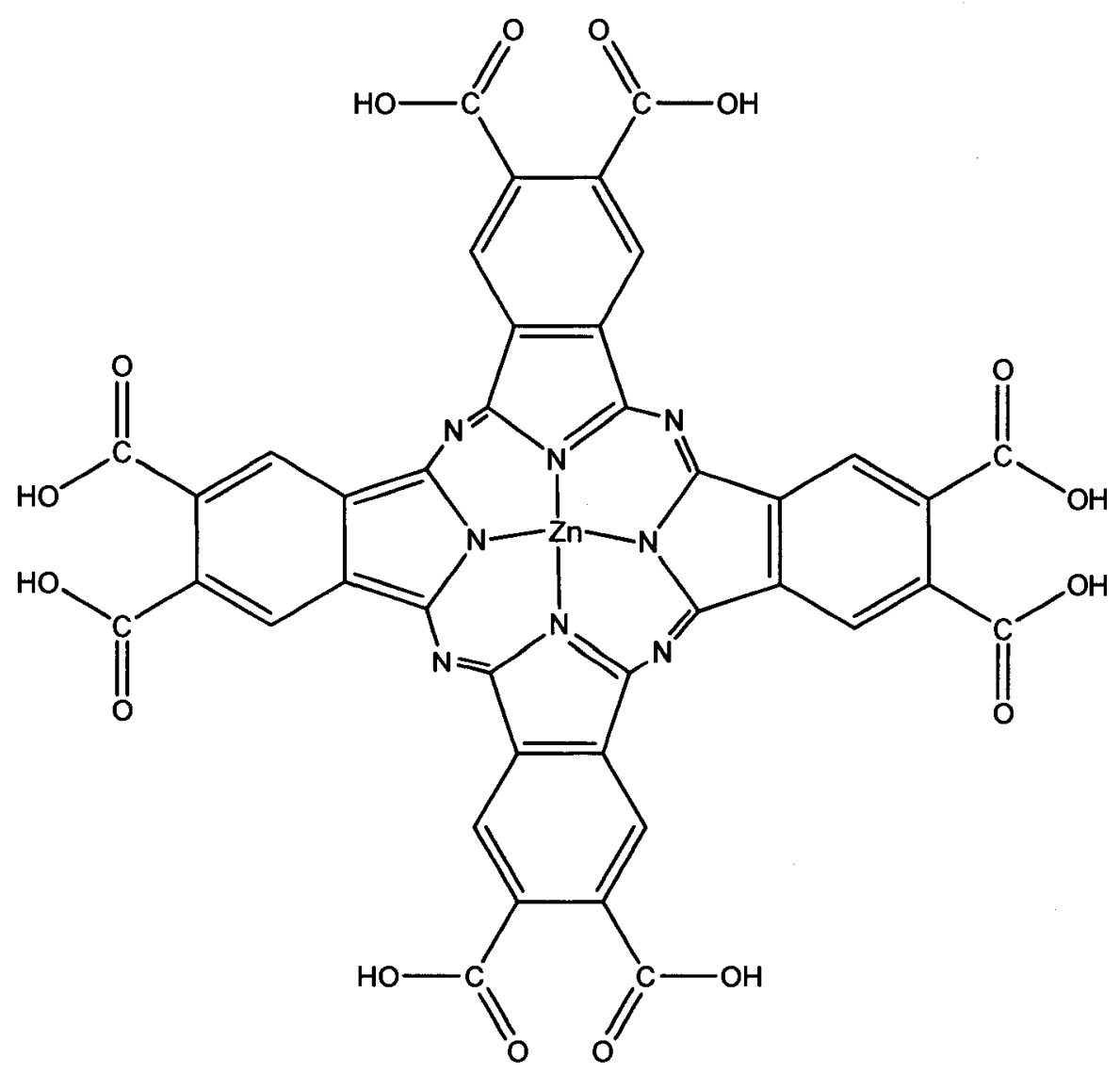

zinc octacarboxy phthalocyanine

Octasubstituted phthalocyanines are symmetrical compounds that contain two substituents in each benzo ring. These systems are less soluble in polar solvents due to the decrease in polarity based on the symmetrical nature of these compounds [1]; however, they can be solubilized by the generation of their corresponding salts. Also, these complexes have higher repulsion with each other in solution thus minimizing the effect of dimerization. The nature of the monomer/dimer equilibrium will be explored under various $\mathrm{pH}$ conditions. SOOT studies will be performed at an environmentally relevant $\mathrm{pH}$ and at different temperatures to mimic summer and winter conditions of the holding ponds. 
Surfactants will be used to keep the photosensitizer in its monomeric form during the SOOT experiments. The optimum concentration of surfactant will be evaluated for the SOOT experiments using spectrophotometry. As an alternative to the uneconomical tetrabutylammonium bromide (i.e., high concentration of $0.12 \mathrm{M}$ ), surfactants such as cetyltrimethylammonium bromide $\mathrm{C}_{19} \mathrm{H}_{42} \mathrm{~N} \cdot \mathrm{Br}$ (CTAB, cationic surfactant), sodium dodecyl sulfate $\mathrm{C}_{12} \mathrm{H}_{26} \mathrm{O}_{4} \mathrm{~S}$.Na (SDS, anionic surfactant), Triton X-100 $\left(\mathrm{C}_{2} \mathrm{H}_{4} \mathrm{O}\right)_{n} \mathrm{C}_{14} \mathrm{H}_{22} \mathrm{O}$ (non-ionic surfactant), Tween 20 (non-ionic surfactant), dodecyltrimethylammonium bromide $\mathrm{C}_{15} \mathrm{H}_{34} \mathrm{~N}$.Br (DTAB, cationic surfactant) and dodecyltrimethylammonium chloride $\mathrm{C}_{15} \mathrm{H}_{34} \mathrm{~N} . \mathrm{Cl}$ (DTAC, cationic surfactant) will be evaluated in the SOOT process.

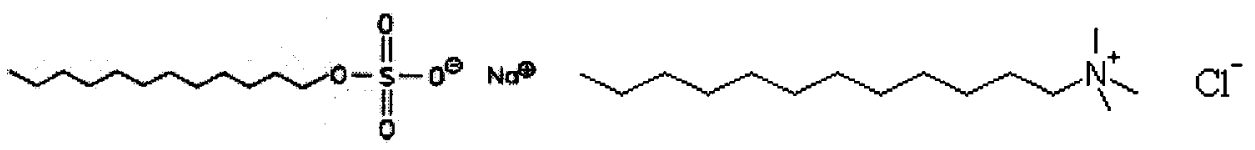

Sodium Dodecylsulfate (SDS) Dodecyltrimethylammonium Chloride (DTAC)

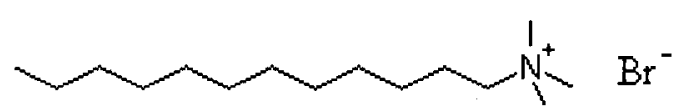

Dodecyltrimethylammonium Bromide (DTAB)

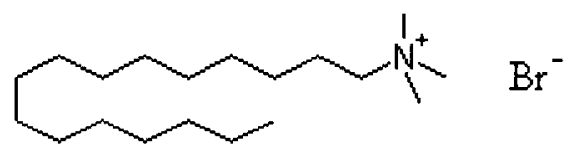

Cetyltrimethylammonium Bromide (CTAB)

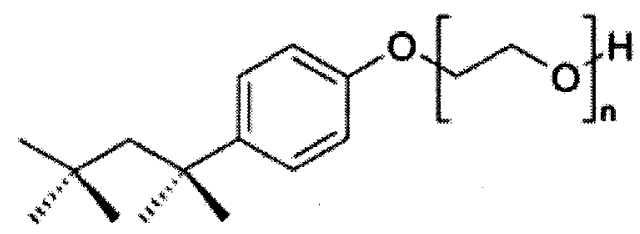

Polyethylene glycol p-(1,1,3,3-tetramethylbutyl)-phenyl ether (Triton X)

Figure 9: Structure of different surfactants, used to evaluate the SOOT process. 
The effectiveness of the photosensitizer system (i.e., with and without cationic surfactants; at different $\mathrm{pH}$ conditions) will be evaluated by quantum yield experiments. The orientation of the cationic surfactant around the photosensitizer can be seen in Figure 7C. Studies will be carried out at the University of Ottawa to determine the singlet oxygen generated by the quenching of the triplet (excited) state of the photosensitizer. The ground state photosensitizer $\left(\right.$ Sen $\left._{0}\right)$ will be irradiated with visible light generating excited singlet state $\left(\right.$ Sens $\left._{l}\right)$. Sens 1 can relax back to an excited state $\mathrm{T}_{1}$, generating singlet oxygen. All measurements of quantum yield of singlet oxygen formation $\left(\mathrm{Q}_{s}\right)$ will be scaled to a reference substance (Methylene Blue in aqueous medium, $\mathrm{Q}_{s}=0.52$ [33]). 


\section{CHAPTER 2}

\section{EXPERIMENTAL}

\subsection{Physical Measurements}

Electronic spectra were acquired on a CARY 5 UV-vis near IR spectrophotometer, using quartz cells with path lengths of $0.2,1$ and $5 \mathrm{~cm}$. Infrared spectroscopy was performed using a BOMEM Michelson 120 FT-IR spectrophotometer on $\mathrm{KBr}$ discs $\left(\mathrm{KBr}\right.$ was dried at $\left.102{ }^{\circ} \mathrm{C}\right)$. Elemental analysis was performed by the Canadian Micro Analytical Service Ltd.

\section{$\underline{2.2}$ Solvents and Reagents}

Distilled Acetone, ethanol (anhydrous, Commercial Alcohols), methanol (spectrograde, Caledon), ethylene glycol (Aldrich), conc. HCl (Anachemia), Phosphate buffer solutions $0.05 \mathrm{M}$ for $\mathrm{pH} 4, \mathrm{pH} \mathrm{6,pH} \mathrm{7,} \mathrm{pH} \mathrm{9,} \mathrm{pH} 10$ and $\mathrm{pH} 11$ (VWR), 1,2,4,5Tetracyanobenzene (TCB) (97\%, Aldrich), anhydrous zinc acetate (99.9\%, Aldrich), sodium chloride $(\mathrm{NaCl})(98 \%$, reagent grade, Aldrich), hydrochloric acid and sodium hydroxide $(\mathrm{NaOH})$ (Anachemia).

Tetrabutylammonium bromide $\left(\mathrm{Bu}_{4} \mathrm{NBr}\right.$ ) (Aldrich), $\mathrm{Na}_{2} \mathrm{~S}_{2} \mathrm{O}_{3} .5 \mathrm{H}_{2} \mathrm{O}$ (Anachemia) $\mathrm{BaCl}_{2} .2 \mathrm{H}_{2} \mathrm{O}$ (Anachemia), sodium tetraphenyl borate (99\%, Lancaster), Cetyltrimethylammonium bromide (CTAB) (Aldrich), sodium dodecyl sulfate (SDS) 
(Fluka), Tween 20 (Aldrich), Triton X-100 (Aldrich), dodecyltrimethylammonium bromide (DTAB) (Aldrich) and dodecyltrimethylammonium chloride (DTAC) (Aldrich).

\section{$\underline{2.3 \quad \text { SOOT Instrumentation }}$}

The experimental setup to carry out the SOOT process employed a Techne constant temperature bath equipped with a circulator and a TE-10D temperature regulator. The bath was cooled with copper coils that were in turn cooled by a Neslab LT-50 low temperature refrigerated circulating bath set at $-35{ }^{\circ} \mathrm{C}$. An Agrosun Gold metal halide lamp was (Hydrofarm, MH1000W) was mounted in a ballast fixture with a reflector. This lamp was chosen due to its similarity to the visible light spectrum of the sun. Light intensity was measured to be 166 klux using an International Light radiometer/photometer (model IL 1400-A). The detector had UV and IR cut-offs at 435 $\mathrm{nm}$ and $705 \mathrm{~nm}$, respectively. The samples were saturated with air by constant bubbling. Tests to determine the concentration of dissolved oxygen in solution were conducted with a Cole-Parmer 5949 oxygen meter. The concentration of the dissolved oxygen in the bubbled solution was determined to be $14.2 \mathrm{ppm}$. An ISFET pH meter (model IQ-125) was used to monitor the $\mathrm{pH}$ of the solutions. A schematic diagram of the SOOT instrumentation is shown below. 


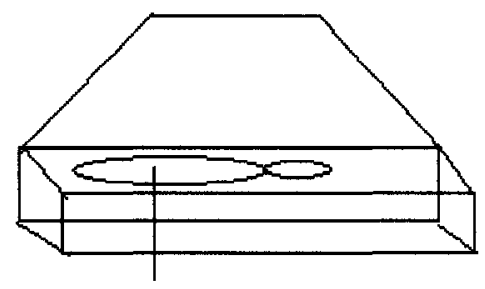

Agrosun Gold metal halide lamp

(Hydrofarm)

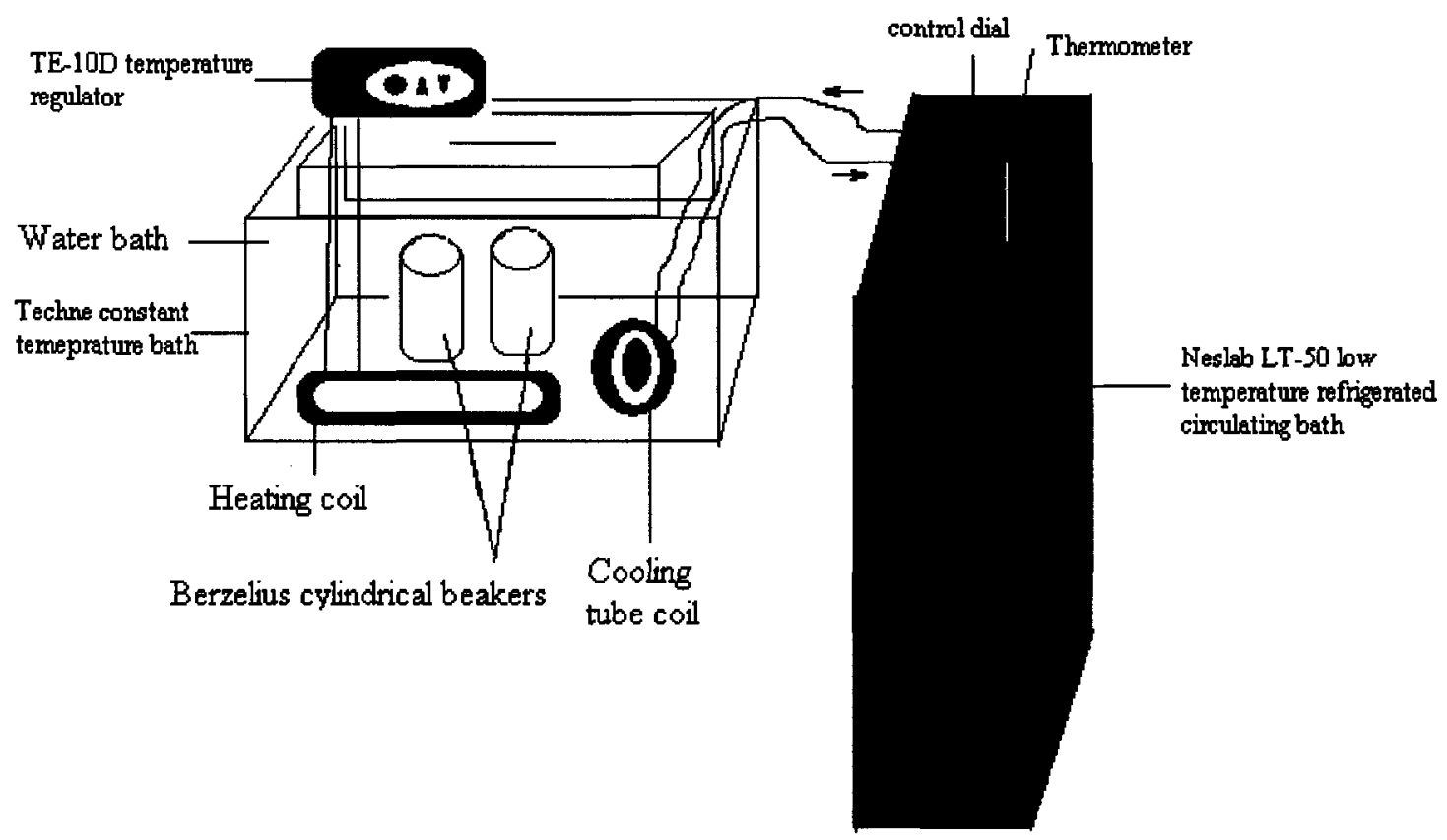

Figure 10: Experimental setup to carry out the SOOT process. 


\subsection{Test Solutions for the SOOT Experiment}

Test solutions for the SOOT experiment were made up of $\mathrm{Na}_{2} \mathrm{~S}_{2} \mathrm{O}_{3} \cdot 5 \mathrm{H}_{2} \mathrm{O}(1000$ ppm), Zinc 2,3,9,10,16,17-(hexacarboxylate)-23,24-(dicarboximide) phthalocyanine sodium salt $(5.7 \mu \mathrm{M})$ with either $\mathrm{Bu}_{4} \mathrm{NBr}(0.12 \mathrm{M})$, CTAB $(1 \mathrm{mM})$, DTAB $(16 \mathrm{mM})$ or DTAC (16 mM) in pH 11 water-alkaline solution (final volume $300 \mathrm{ml}$ ). Solutions were placed in $500 \mathrm{ml}$ cylindrical beakers (Berzelius), giving a solution depth of approximately $7 \mathrm{~cm}$. The solutions were bubbled with air throughout the experiment. Previous studies demonstrated that there were no other oxidation products of thiosulfate other than $\mathrm{SO}_{4}{ }^{2-}$. On this basis, the amount of $\mathrm{SO}_{4}{ }^{2-}$ generated was determined gravimetrically by precipitation of its barium salt.

$\mathrm{CTA}^{+}$and $\mathrm{DTA}^{+}$ions co-precipitate with $\mathrm{BaSO}_{4}$ and had to be separated from the $\mathrm{SO}_{4}{ }^{2-}$ ions prior to the addition of $\mathrm{BaCl}_{2}$ solution. This was achieved by the addition of 10 $\mathrm{ml}$ of $0.03 \mathrm{M}$ sodium tetraphenyl borate which precipitated the $\mathrm{CTA}^{+}$or $\mathrm{DTA}^{+}$ions as a $\mathrm{BPh}^{-}$salt. After filtration, the $\mathrm{pH}$ of the filtrate was lowered from $\mathrm{pH} 11$ to $\mathrm{pH} 4$ by adding $0.1 \mathrm{M} \mathrm{HCl}$ dropwise, monitored by a $\mathrm{pH}$ meter, to avoid the production of $\mathrm{BaCO}_{3}$. $15 \mathrm{ml}$ of $0.5 \mathrm{M} \mathrm{BaCl}_{2}$ solution was then added precipitating $\mathrm{BaSO}_{4}$. The solution was allowed to stand in the dark overnight before filtration. The $\mathrm{BaSO}_{4}$ precipitate was collected on an ultrafine glass frit filters $(4-5.5 \mu \mathrm{m}$ porosity $)$, dried for 12 hours $\left(120^{\circ} \mathrm{C}\right)$ and weighed to a constant mass. 


\subsubsection{Sample Calculation for the Percentage Conversion of Thiosulfate to Sulfate in the SOOT Experiment Carried Out in the Presence of DTAB at $22^{\circ} \mathrm{C}$.}

Table 1: Illustration of the Weight in Grams of Barium Sulfate in the SOOT Experiment Carried Out for 8 hours in the Presence of DTAB.

\begin{tabular}{|c|c|}
\hline 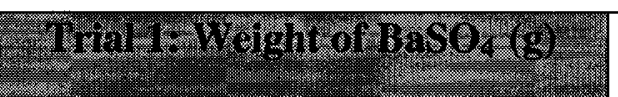 & 0.551 \\
\hline Trial-2. Weight of BaSO4 (o) & 0.530 \\
\hline 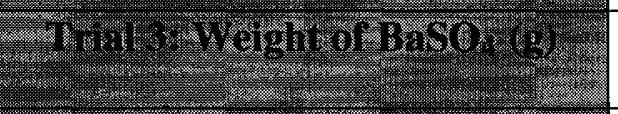 & 0.481 \\
\hline A rerage Weight & 0.521 \\
\hline
\end{tabular}

1. $\frac{\text { Weight of } \mathrm{BaSO}_{4}(\mathrm{~g})}{\mathrm{Molecular}_{\text {weight of } \mathrm{BaSO}_{4}(\mathrm{~g} / \mathrm{mol})}}=$ Moles of $\mathrm{BaSO}_{4}(\mathrm{~mol})=\mathrm{Moles} \mathrm{SO}_{4}^{2-}(\mathrm{mol})$

2. $\frac{\text { Moles of suffate }(\mathrm{mol})}{2 \mathrm{x} \text { moles of } \mathrm{Na}_{2} \mathrm{~S}_{2} \mathrm{O}_{3}(\mathrm{~mol})} \times 100=\% \mathrm{Na}_{2} \mathrm{~S}_{2} \mathrm{O}_{3}$ converted to $\mathrm{SO}_{4}^{2-}$

1. $\frac{0.521 \mathrm{~g}}{233 \mathrm{~g} / \mathrm{mol}}=0.00223 \mathrm{~mol}$ of $\mathrm{SO}_{4}^{2-}$

2. $\frac{0.00223 \mathrm{~mol}}{2 \times 1.21 \times 10^{-3} \mathrm{~mol}} \times 100=92.6 \%$ of $\mathrm{SO}_{4}^{2-}$ 


\subsection{Singlet Oxygen Quantum Yield Determination}

Singlet oxygen quantum yield measurements were conducted in the labs of Dr. Tito Scaiano (University of Ottawa). A Nd:YAG laser was used to irradiate an aqueous solution of the photosensitizer. This formed the triplet excited state $\left({ }^{3}\right.$ Sens $)$ of the photosensitizer which then transferred its energy to triplet oxygen $\left({ }^{3} \mathrm{O}_{2}\right)$ causing the formation of singlet oxygen $\left({ }^{1} \mathrm{O}_{2}\right)$. A Hamamatsu NIR PMT Module, Model H10330-75 was used to detect singlet oxygen emission [20] and the output was amplified and converted to a voltage pulse using a high speed current preamplifier (model SR445). A multichannel scaler (model SR430) connected to a personal computer was used for the time resolved single photon counting. A schematic diagram of the instrument is shown below.

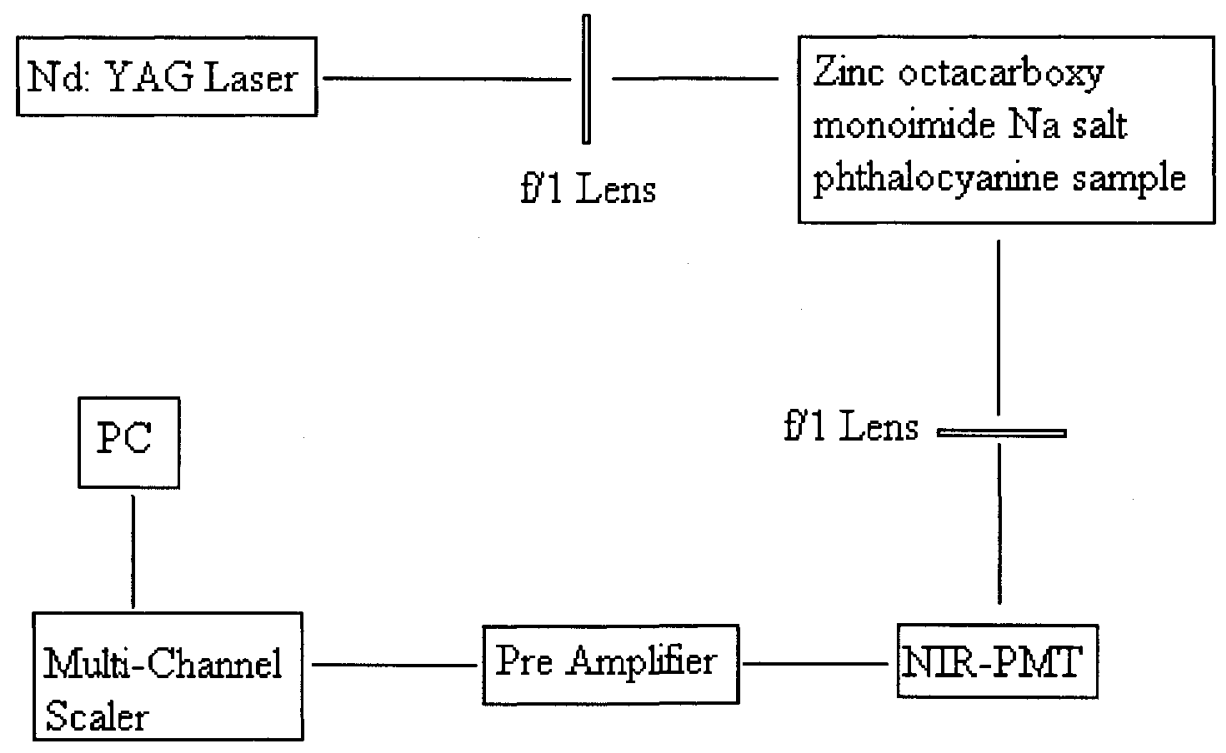

Figure 11: The experimental setup at University of Ottawa, for singlet oxygen quantum yield and lifetime measurements. Band width: $\pm 20 \mathrm{MHz}$, time: $25 \mu$ s, wavelength: 650 $\mathrm{nm}$, phosphorescence of singlet oxygen: $1270 \mathrm{~nm}$. 


\subsection{Test Solutions for Determining the Quantum Yield of Singlet Oxygen}

\subsubsection{Determining the Quantum Yield in the Absence of Surfactant}

The following concentrations of photosensitizer were used: $3.3 \times 10^{-5} \mathrm{M}, 1.6 \times 10^{-5}$ $\mathrm{M}, 8.2 \times 10^{-5} \mathrm{M}$ and $4.1 \times 10^{-5} \mathrm{M}$. Each sample was diluted in a $\mathrm{pH} 9, \mathrm{pH} 10$ and $\mathrm{pH} 11$ water-alkaline solution (final volume $50 \mathrm{ml}$ ). The $\mathrm{pH}$ of each solution was determined using a $\mathrm{pH}$ meter before running the samples. The calibration standard used was Methylene Blue in $\mathrm{pH} 7$ aqueous solution. UV-vis spectra of the samples were taken before and after laser irradiation to ensure that no photo-degradation had taken place.

\subsubsection{Determining the Quantum Yield in the Presence of Surfactant}

The following concentrations of photosensitizer were used: $1.4 \times 10^{-4} \mathrm{M}, 1.1 \times 10^{-4}$ $\mathrm{M}, 7.2 \times 10^{-5} \mathrm{M}$ and $3.6 \times 10^{-5} \mathrm{M} .16 \mathrm{mM}$ of DTAB was added in each sample. Each sample was diluted in a $\mathrm{pH} 11$ water-alkaline solution (final volume $50 \mathrm{ml}$ ). The $\mathrm{pH}$ of each solution was determined using a $\mathrm{pH}$ meter before running the samples. The calibration standard used was Methylene Blue in $\mathrm{pH} 11$ water-alkaline solution. UV-vis spectra of the samples were taken before and after laser irradiation to ensure that no photodegradation had taken place.

\subsection{Attempted Synthesis of the Photosensitizer}

The synthesis of pure phthalocyanines can be extremely difficult and attempts to prepare pure $\mathrm{ZnPc}(\mathrm{COOH})_{8}$ by following the procedures outlined by V. Iliev et. al., [21] 
and N.A. Kuznetsova et. al., [36] was unsuccessful. In Section 2.7 these synthetic attempts are described in detail together with additional purification procedures. The purity of $\mathrm{ZnPc}$ purity was evaluated by the extinction coefficient of the Q band which for pure metal phthalocyanines should be ca. $2 \times 10^{5} \mathrm{M}^{-1} \mathrm{~cm}^{-1}[37]$.

\subsubsection{Iliev and A. Mihaylova's Protocol}

The Zinc carboxy tetraimide phthalocyanine compound was synthesized following the procedures outlined by V. Iliev and A. Mihaylova [21]. $3.93 \mathrm{~g}$ of pyromellitic dianhydride (PMD), $19.8 \mathrm{~g}$ of urea, $4.50 \mathrm{~g}$ of zinc acetate and $0.04 \mathrm{~g}$ of ammonium molybdate were refluxed at $240{ }^{\circ} \mathrm{C}$ for 3 hours in a flask immersed in silicon oil forming the Zinc tetraimide phthalocyanine compound. The mixture was cooled and washed with water and acetone after which it was air dried. The dried product was stirred with $500 \mathrm{ml}$ of $6 \mathrm{M}$ hydrochloride acid for 12 hours at room temperature. The acid was removed by filtration and the solid product was washed with hot water until a neutral $\mathrm{pH}$ was reached. The crude sample [1.08 $\mathrm{g}$, extinction coefficient $(635 \mathrm{~nm})$ in DMF: $800 \mathrm{M}^{-}$ ${ }^{1} \mathrm{~cm}^{-1}, \mathrm{Zn}\left(\mathrm{C}_{40} \mathrm{H}_{12} \mathrm{~N}_{12} \mathrm{O}_{8}\right)$ ] was hydrolyzed using $2 \mathrm{M}$ sodium hydroxide and $80 \mathrm{~g}$ of sodium chloride and stirred for 5 hours at $90{ }^{\circ} \mathrm{C}$ forming the carboxy phthalocyanine compound. The sample was filtered, after which it was acidified with $2 \mathrm{M}$ hydrochloride acid and washed with water up to $\mathrm{pH} 7$. The solid product was heated three times for 30 minutes at $90^{\circ} \mathrm{C}$ with $100 \mathrm{ml}$ of a dimethylformamide (DMF) - water solution $(5: 1 \mathrm{v} / \mathrm{v})$. The weight of the dry carboxy sample was measured at $0.64 \mathrm{~g}$. A UV-vis spectrum was obtained for the phthalocyanine complex, and the extinction coefficient $(681 \mathrm{~nm})$ was determined to be $1000 \mathrm{M}^{-1} \mathrm{~cm}^{-1}$ in distilled water $\left[\mathrm{Zn}\left(\mathrm{C}_{40} \mathrm{H}_{15} \mathrm{~N}_{9} \mathrm{O}_{14}\right)\right]$. 


\subsubsection{N.A Kuznetsova et al.'s Protocol}

The Zinc carboxy tetraimide phthalocyanine compound was synthesized following the protocols outlined by N.A. Kuznetsova et. al., [36]. $23.5 \mathrm{~g}$ of pyromellitic dianhydride (PMD), $63.6 \mathrm{~g}$ of urea, $9.72 \mathrm{~g}$ of zinc acetate, $46 \mathrm{~g}$ of sodium sulphate, $25 \mathrm{ml}$ of 1-bromonapthalene and $0.5 \mathrm{~g}$ of ammonium molybdate were refluxed at $235^{\circ} \mathrm{C}$ for 4 hours, forming the Zinc tetraimide phthalocyanine compound. The cooled reaction mixture was filtered and the precipitate was washed with benzene, followed by an acid/base $\left(\mathrm{HCl} / \mathrm{NH}_{4} \mathrm{OH}\right)$ precipitation for purification of the tetraimide compound (16.7 g). The tetraimide sample [5 g, extinction coefficient $(632 \mathrm{~nm})$ in DMF: $1500 \mathrm{M}^{-1} \mathrm{~cm}^{-1}$, $\mathrm{Zn}\left(\mathrm{C}_{40} \mathrm{H}_{12} \mathrm{~N}_{12} \mathrm{O}_{8}\right)$ ] was hydrolyzed using $21.6 \mathrm{~g}$ of potassium hydroxide $(\mathrm{KOH})$ and 127 $\mathrm{ml}$ of triethylene glycol and stirred for 2 hours at $135^{\circ} \mathrm{C}$ in an argon flow. The carboxy phthalocyanine solution was cooled, acidified with $2 \mathrm{M}$ hydrochloric acid $(\mathrm{HCl})$ and filtered. The precipitate was washed with $2 \mathrm{M} \mathrm{HCl}$ and water until a neutral $\mathrm{pH}(7)$ was reached. The weight of the dry carboxy phthalocyanine sample was measured at $0.5 \mathrm{~g}$. A UV-vis spectrum was obtained for the phthalocyanine complex, and the extinction coefficient $(684 \mathrm{~nm})$ was determined to be $7300 \mathrm{M}^{-1} \mathrm{~cm}^{-1}$ in distilled water $\left[\mathrm{Zn}\left(\mathrm{C}_{40} \mathrm{H}_{15} \mathrm{~N}_{9} \mathrm{O}_{14}\right)\right]$. The carboxy phthalocyanine was converted into its sodium salt by using a $1 \% \mathrm{NaOH}$ solution. The weight of the dry phthalocyanine salt sample was measured at $0.4 \mathrm{~g}$. A UV-vis spectrum was obtained for the phthalocyanine complex, and the extinction coefficient $(691 \mathrm{~nm})$ was determined to be $11,000 \mathrm{M}^{-1} \mathrm{~cm}^{-1}$ in distilled water $\left[\mathrm{Zn}\left(\mathrm{C}_{40} \mathrm{H}_{8} \mathrm{~N}_{8} \mathrm{O}_{16} \mathrm{Na}_{8}\right]\right.$. 


\section{$\underline{\text { 2.7.3 Soxhlet Extraction Purification }}$}

The crude Zinc carboxy tetraimide phthalocyanine compound was synthesized following the process outlined in section 2.7 .2 . The reaction mixture was filtered and the precipitate was washed with benzene, followed by an acid/base $\left(\mathrm{HCl} / \mathrm{NH}_{4} \mathrm{OH}\right)$ precipitation for purification of the tetraimide compound by removing the unreacted reagents like urea and PMD from the reaction mass. Soxhlet extraction was utilized as a means to further purify the tetraimide substance. The tetraimide complex $[11.0 \mathrm{~g}$, extinction coefficient in DMF: $1500 \mathrm{M}^{-1} \mathrm{~cm}^{-1}, \mathrm{Zn}\left(\mathrm{C}_{40} \mathrm{H}_{12} \mathrm{~N}_{12} \mathrm{O}_{8}\right)$ ] was placed inside a thimble, made from thick filter paper, located in the main chamber of the soxhlet extractor. The tetraimide complex was dissolved in DMF and collected in the distillation flask. After 10 hours the tetraimide compound was recovered from the distillation flask $(5.4 \mathrm{~g})$. The UV-vis spectrum for the tetraimide phthalocyanine compound showed an extinction coefficient $(639 \mathrm{~nm})$ of $10,000 \mathrm{M}^{-1} \mathrm{~cm}^{-1}, \mathrm{Zn}\left(\mathrm{C}_{40} \mathrm{H}_{12} \mathrm{~N}_{12} \mathrm{O}_{8}\right) .5 \mathrm{~g}$ of the sample was further hydrolyzed and converted to the sodium salt (via $1 \% \mathrm{NaOH}$ solution using the procedure outlined in section 2.7.2). The extinction coefficient $(691 \mathrm{~nm})$ of the final salt product was calculated in water at $21,000 \mathrm{M}^{-1} \mathrm{~cm}^{-1}\left[\mathrm{Zn}\left(\mathrm{C}_{40} \mathrm{H}_{8} \mathrm{~N}_{8} \mathrm{O}_{16} \mathrm{Na}_{8}\right]\right.$.

\subsubsection{Flash Chromatography Purification}

The crude Zinc carboxy tetraimide phthalocyanine compound was synthesized following the process outlined in section 2.7.2. The reaction mixture was filtered and the precipitate was washed with benzene, followed by an acid/base $\left(\mathrm{HCl} / \mathrm{NH}_{4} \mathrm{OH}\right)$ precipitation for purification of the tetraimide compound by removing the unreacted reagents like urea and PMD from the reaction mass. To further purify the tetraimide 
compound, a slurry of silica gel $(70 \mathrm{~g})$ in DMF $(150 \mathrm{ml})$ was poured into a column. $1 \mathrm{~g}$ of the tetraimide phthalocyanine complex [extinction coefficient (632 nm) in DMF: $1500 \mathrm{M}^{-}$ $\left.{ }^{\prime} \mathrm{cm}^{-1}, \mathrm{Zn}\left(\mathrm{C}_{40} \mathrm{H}_{12} \mathrm{~N}_{12} \mathrm{O}_{8}\right)\right]$ was dissolved in $45 \mathrm{ml}$ DMF and poured down the column to create a darkly colored band. Air pressure was applied to aid in the elution of the sample through the column at a steady rate (sample started to elute after 5.5 hours). After the complex had eluted, the solution was solvent stripped to dryness, after which it was left to dry overnight. The weight of the dry sample was measured at $0.4 \mathrm{~g}$. The UV-vis of the dry sample gave an extinction coefficient $(639 \mathrm{~nm})$ of $18,000 \mathrm{M}^{-1} \mathrm{~cm}^{-1}$ in DMF $\left[\mathrm{Zn}\left(\mathrm{C}_{40} \mathrm{H}_{12} \mathrm{~N}_{12} \mathrm{O}_{8}\right)\right] .0 .4 \mathrm{~g}$ of the tetraimide sample was further hydrolyzed and converted to the sodium salt by following the process outlined in section 2.7.2. The extinction coefficient $(691 \mathrm{~nm})$ of the final salt product was calculated in water at $32,000 \mathrm{M}^{-1} \mathrm{~cm}^{-1}$ $\left[\mathrm{Zn}\left(\mathrm{C}_{40} \mathrm{H}_{8} \mathrm{~N}_{8} \mathrm{O}_{16} \mathrm{Na}_{8}\right]\right.$.

\subsubsection{Modifications to Kuznetsova et al.'s Protocol}

$10.0 \mathrm{~g}$ of PMD, $4.0 \mathrm{~g}$ of anhydrous zinc acetate, $26.0 \mathrm{~g}$ of urea, $0.2 \mathrm{~g}$ of ammonium molybdate and $10 \mathrm{ml}$ of 1-bromonaphthalene were stirred in a round bottom flask $(250 \mathrm{ml})$ and refluxed at $190{ }^{\circ} \mathrm{C}$ for 4 hours, after which it was cooled to room temperature. The crude tetraimide sample was dissolved in DMF and refluxed for an additional 30 minutes. The solution was filtered to remove any solid impurities and solvent stripped to dryness. The dry tetraimide product was boiled in $2 \mathrm{M} \mathrm{HCl}(50 \mathrm{ml})$ solution and filtered. This cycle was repeated six times or until the yellow colour completely disappeared from the filtrate. The dry tetraimide weighed $8.42 \mathrm{~g}$. The UV-vis spectrum for the tetraimide phthalocyanine compound gave an extinction coefficient (638 
$\mathrm{nm})$ in DMF of $27,000 \mathrm{M}^{-1} \mathrm{~cm}^{-1}\left[\mathrm{Zn}\left(\mathrm{C}_{40} \mathrm{H}_{12} \mathrm{~N}_{12} \mathrm{O}_{8}\right)\right]$. For further purification, $0.5 \mathrm{~g}$ of the sample was dissolved in $25 \mathrm{ml}$ of DMF and eluted through a silica column as previously discussed in section 2.7.4. The eluted sample was filtered, dried, weighed $(0.2 \mathrm{~g})$ and the extinction coefficient $(636 \mathrm{~nm})$ in DMF was measured at $45,000 \mathrm{M}^{-1} \mathrm{~cm}^{-1}$ $\left[\mathrm{Zn}\left(\mathrm{C}_{40} \mathrm{H}_{12} \mathrm{~N}_{12} \mathrm{O}_{8}\right)\right]$

$0.1 \mathrm{~g}$ of the purified tetraimide compound (by flash chromatography) was added to a solution of $10.0 \mathrm{~g} \mathrm{NaCl}$ in $50 \mathrm{ml} \mathrm{NaOH}$ to hydrolyze. The solution was stirred for 1.5 hours at $80^{\circ} \mathrm{C}$. After cooling, the carboxy phthalocyanine complex was neutralized with dilute $\mathrm{HCl}(2 \mathrm{M})$ and filtered. The weight of the dry sample was measured at $0.07 \mathrm{~g}$. UVvis in water gave an extinction coefficient $(689 \mathrm{~nm})$ of $117,000 \mathrm{M}^{-1} \mathrm{~cm}^{-1}$ $\left[\mathrm{Zn}\left(\mathrm{C}_{40} \mathrm{H}_{15} \mathrm{~N}_{9} \mathrm{O}_{14}\right)\right]$

$0.07 \mathrm{~g}$ of the carboxy phthalocyanine compound was suspended in $100 \mathrm{ml}$ of distilled water. $1 \% \mathrm{NaOH}$ w/w was added to the suspension (sample in water) to convert the sample to its sodium salt. The salt was filtered and solvent stripped to dryness. The pure sample was washed with acetone and dried. The weight of the dry sample was measured at $0.05 \mathrm{~g}$. UV-vis for the phthalocyanine compound gave an extinction coefficient $(695 \mathrm{~nm})$ in water of $119,000 \mathrm{M}^{-1} \mathrm{~cm}^{-1}$. The elemental analysis of the purified phthalocyanine complex is shown in Table 2. 
Table 2: Comparison of the Calculated and Found Elemental Analysis (C, $\mathrm{H}$ and $\mathrm{N}$ ) for Kuznetsova's $\mathrm{ZnPc}(\mathrm{COONa})_{8}$ Product $\left[\mathrm{Zn}\left(\mathrm{C}_{40} \mathrm{H}_{8} \mathrm{~N}_{8} \mathrm{O}_{16} \mathrm{Na}_{8}\right), \mathrm{FW}=1105.84 \mathrm{~g} / \mathrm{mol}\right]$.

\begin{tabular}{|c|c|c|}
\hline Element & Calculated $(\%)$ & Found $(\%)$ \\
\hline Carbon $(\mathbf{C})$ & 43.45 & 39.78 \\
\hline Hydrogen $(\mathbf{H})$ & 0.73 & 1.20 \\
\hline Nitrogen $(\mathbf{N})$ & 10.13 & 10.20 \\
\hline
\end{tabular}

\subsection{Synthesis of Zinc 2,3,9,10,16,17-(Hexacarboxylate)-23,24-(Dicarboximide)}

\section{Phthalocyanine Sodium Salt}

The Zinc carboxy tetraimide phthalocyanine compound was synthesized following the protocols outlined by D.R. Boston and J.C. Bailer [38], where the tetraimide was hydrolyzed with $18 \mathrm{M} \mathrm{KOH}$ for 9 hours at $100^{\circ} \mathrm{C}$. These harsh conditions for hydrolysis led to the decomposition of $\mathrm{ZnPc}$. To get a higher yield of $\mathrm{ZnPc}$ and to minimize decomposition, milder hydrolysis conditions were followed as described below.

$1.78 \mathrm{~g}$ of TCB, $0.85 \mathrm{~g}$ of anhydrous zinc acetate and $40 \mathrm{ml}$ of ethylene glycol were stirred and refluxed at $198{ }^{\circ} \mathrm{C}$ for 5 hours (the solution started to show signs of colour change at $160^{\circ} \mathrm{C}$ and became dark green at $175^{\circ} \mathrm{C}$ ), after which it was cooled at room temperature. $100 \mathrm{ml}$ of distilled water was added to the suspension and stirred for an additional 15 minutes. The mixture was filtered using a Buchner funnel $(40-60 \mu \mathrm{m}$ porosity), and the residue was washed with acetone $(50 \mathrm{ml})$. This washing was repeated twice. The crude tetraimide sample was air dried overnight the weight was measured at $3.01 \mathrm{~g}$. 
The crude solid was crushed and placed in a beaker. A solution of $35 \mathrm{ml}$ of water and $65 \mathrm{ml}$ of acetone was prepared and added to the beaker containing the sample. The suspension was stirred at room temperature for 0.5 hours, after which it was filtered using a Buchner funnel (40-60 $\mu \mathrm{m}$ porosity) and the dry weight determined as $2.98 \mathrm{~g}$. FT-IR spectrum of the crude sample was obtained in $\mathrm{KBr}$ and two distinctive peaks were observed ( $\mathrm{OH}$-stretch and the $\mathrm{C}=\mathrm{O}$ stretch at $3740 \mathrm{~cm}^{-1}$ and $1772 \mathrm{~cm}^{-1}$ respectively). This purification procedure was repeated until the yellow colour completely disappeared from the filtrate (approximately five washings). The final weight of the sample was recorded as $2.81 \mathrm{~g}$.

After air drying, the tetraimide complex was placed in a beaker containing $100 \mathrm{ml}$ of $0.01 \mathrm{M} \mathrm{HCl}$. The solution was stirred at room temperature for 15 minutes, and then filtered through a glass frit (10-15 $\mu \mathrm{m}$ porosity). The precipitate was washed with acetone; air dried and weighed (2.75 g). This procedure was repeated twice (or repeated until the filtrate became colourless). Final weight of the purified tetraimide sample was determined to be $2.63 \mathrm{~g}$. UV-vis absorption spectrum [extinction coefficient $(639 \mathrm{~nm})$ was calculated in DMF to be $\left.122,000 \mathrm{M}^{-1} \mathrm{~cm}^{-1}, \mathrm{Zn}\left(\mathrm{C}_{40} \mathrm{H}_{12} \mathrm{~N}_{12} \mathrm{O}_{8}\right) .8 \mathrm{H}_{2} \mathrm{O}\right]$ and IR spectrum ( $\mathrm{OH}$-stretch and the $\mathrm{C}=\mathrm{O}$ stretch at $3439 \mathrm{~cm}^{-1}$ and $1702 \mathrm{~cm}^{-1}$ respectively) were obtained for the dried pure sample.

$1 \mathrm{~g}$ of the purified Zinc octa-4,5-carboxyphthalocyanine tetraimide was added to a solution of $200 \mathrm{ml}$ of $2 \mathrm{M} \mathrm{NaOH}$ and $80 \mathrm{~g}$ of $\mathrm{NaCl}$, which was stirred for 3.5 hours at 70 ${ }^{\circ} \mathrm{C}$. The hot mixture was diluted with $100 \mathrm{ml}$ of water and allowed to cool. The cold solution was filtered through a glass frit (10-15 $\mu \mathrm{m}$ porosity) and acidified with $262 \mathrm{ml}$ of $\mathrm{HCl}(1.0 \mathrm{M} ; \sim \mathrm{pH} 2)$ and left to sit for $\sim 12$ hours. The precipitate was filtered using a 
Buchner funnel (10-15 $\mu \mathrm{m}$ porosity) and washed with $50 \mathrm{ml}$ of $0.1 \mathrm{M} \mathrm{HCl}$ and $\sim 100 \mathrm{ml}$ of distilled water, until the filtrate was neutral as monitored by $\mathrm{pH}$ measurements (approximately six times). The weight of the wet sample was measured at $725 \mathrm{mg}$. This sample was vacuum dried and had a dry weight of $610 \mathrm{mg}$. UV-vis spectrum in distilled water for the Zinc 2,3,9,10,16,17-(hexacarboxylate)-23,24-(dicarboximide) phthalocyanine gave an extinction coefficient $(689 \mathrm{~nm})$ of $181,000 \mathrm{M}^{-1} \mathrm{~cm}^{-}$ ${ }^{\prime}\left[\mathrm{Zn}\left(\mathrm{C}_{40} \mathrm{H}_{15} \mathrm{~N}_{9} \mathrm{O}_{14}\right) \cdot 8 \mathrm{H}_{2} \mathrm{O}\right]$.

$0.5 \mathrm{~g}$ of Zinc 2,3,9,10,16,17-(hexacarboxylate)-23,24-(dicarboximide) phthalocyanine was suspended in $100 \mathrm{ml}$ of distilled water. $10 \mathrm{ml}$ of $1 \% \mathrm{NaOH}(\mathrm{w} / \mathrm{w})$ was added to the suspension, which was allowed to sit for 2 hours. The solution was filtered through a glass frit (4-5.5 $\mu \mathrm{m}$ porosity) and solvent stripped to dryness. The dry sample was washed with acetone and air dried (weight $=0.45 \mathrm{~g}$, percentage yield $=17 \%$ ). UV-vis for Zinc 2,3,9,10,16,17-(hexacarboxylate)-23,24-(dicarboximide) phthalocyanine sodium salt, hereafter called the photosensitizer, gave an extinction coefficient $(696 \mathrm{~nm})$ of $191,000 \mathrm{M}^{-1} \mathrm{~cm}^{-1}$ in water $\left[\mathrm{Zn}\left(\mathrm{C}_{40} \mathrm{H}_{9} \mathrm{~N}_{9} \mathrm{O}_{14}\right) \mathrm{Na}_{6} \cdot 8 \mathrm{H}_{2} \mathrm{O}\right]$. Elemental analysis is given in Table 3. 
Table 3: Calculated and Found Elemental Analysis ( $\mathrm{C}, \mathrm{H}$ and $\mathrm{N}$ ) for Zinc 2,3,9,10,16,17(Hexacarboxylate)-23,24-(Dicarboximide) Phthalocyanine. $\left[\mathrm{Zn}\left(\mathrm{C}_{40} \mathrm{H}_{15} \mathrm{~N}_{9} \mathrm{O}_{14}\right) \cdot 8 \mathrm{H}_{2} \mathrm{O}\right.$, $\mathrm{FW}=1055.11 \mathrm{~g} / \mathrm{mol}]$.

\begin{tabular}{|c|c|c|}
\hline Element & Calculated (\%) & Found (\%) \\
\hline Carbon (C) & 45.53 & 45.15 \\
\hline Hydrogen (H) & 2.96 & 2.11 \\
\hline Nitrogen (N) & 11.95 & 11.76 \\
\hline
\end{tabular}

Note: The molecular weight for the $\mathrm{Zn}\left(\mathrm{C}_{40} \mathrm{H}_{15} \mathrm{~N}_{9} \mathrm{O}_{14}\right) \cdot 8 \mathrm{H}_{2} \mathrm{O}$ compound was calculated as $1055.11 \mathrm{~g} / \mathrm{mol}$ and all concentrations of the Zinc 2,3,9,10,16,17-(hexacarboxylate)-23,24(dicarboximide) phthalocyanine solutions were calculated based on this molecular weight. 


\section{CHAPTER 3}

\section{SYNTHESIS AND PROPERTIES OF THE PHOTOSENSITIZER}

\subsection{Synthesis of the Photosensitizer, Zinc 2,3,9,10,16,17-(hexacarboxylate)-23,24-}

\section{(dicarboximide) phthalocyanine sodium salt}

The first synthetic procedure followed was that of V. Iliev and A. Mihaylova [21] who claimed to have synthesized the octacarboxy tetraimide zinc phthalocyanine by reacting pyromellitic anhydride with zinc acetate and ammonium molybdate in the presence of excess urea. The carboxy product of this reaction was very impure as judged by its electronic absorption spectrum which showed a Q-band extinction coefficient (681 $\mathrm{nm})$ of only $1000 \mathrm{M}^{-1} \mathrm{~cm}^{-1}$ in distilled water $\left[\mathrm{Zn}\left(\mathrm{C}_{40} \mathrm{H}_{15} \mathrm{~N}_{9} \mathrm{O}_{14}\right)\right]$, and it was concluded that this method was inefficient to produce a pure phthalocyanine compound.

The second synthetic procedure followed was that of Kuznetsova et. al. [36]. Kuznetsova et. al., reacted pyromellitic dianhydride, excess urea, zinc acetate, sodium sulphate, 1-bromonapthalene and ammonium molybdate to form the tetraimide compound. Sodium sulfate was used to absorb excess water from the reaction mixture. 1bromonapthalene solvent was used to create a partially homogenous reaction mixture (i.e. dissolve some of the pyromellitic acid, zinc salt and ammonia). Attempts to reproduce the monomer phthalocyanine complex using the same method as described by Kuznetsova et. al., was unsuccessful as indicated by the low extinction coefficient value $(691 \mathrm{~nm})$ for the salt $\left(11,000 \mathrm{M}^{-1} \mathrm{~cm}^{-1}\right.$ in distilled water $)$. 

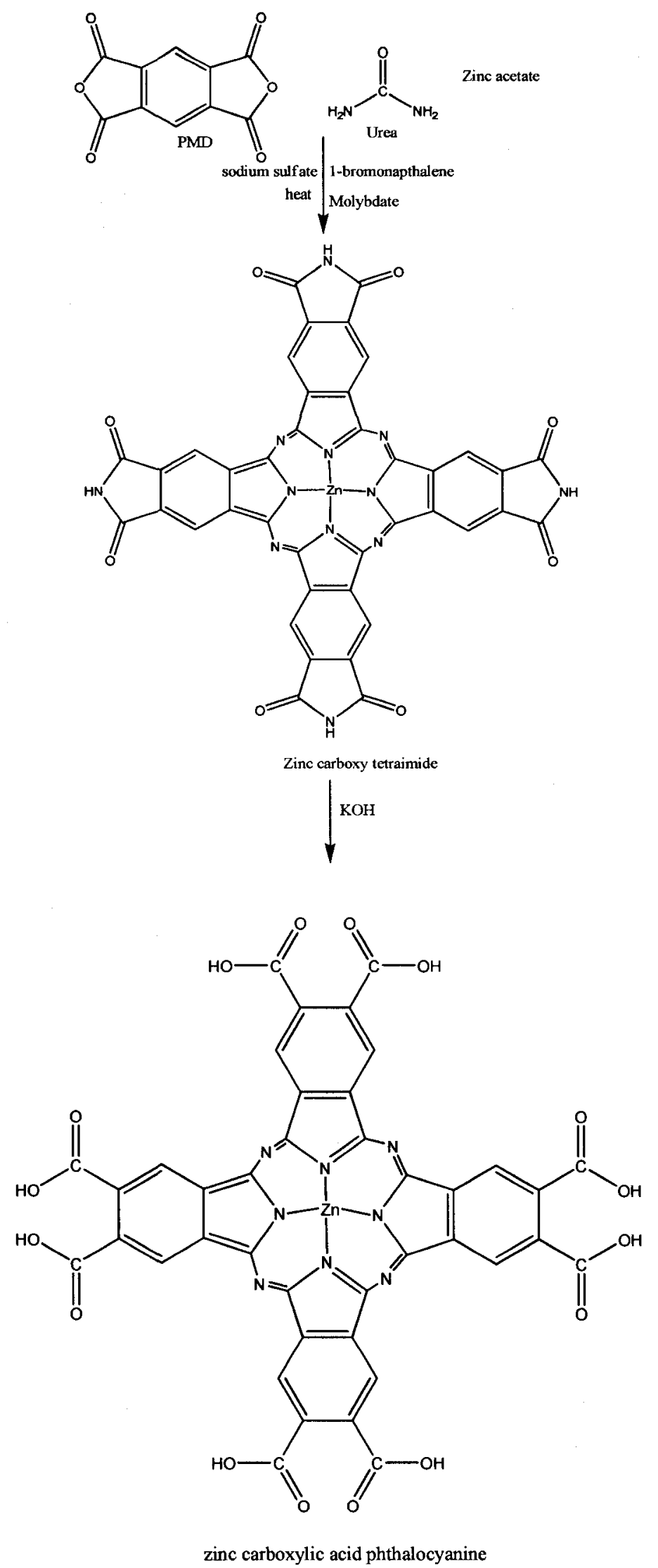


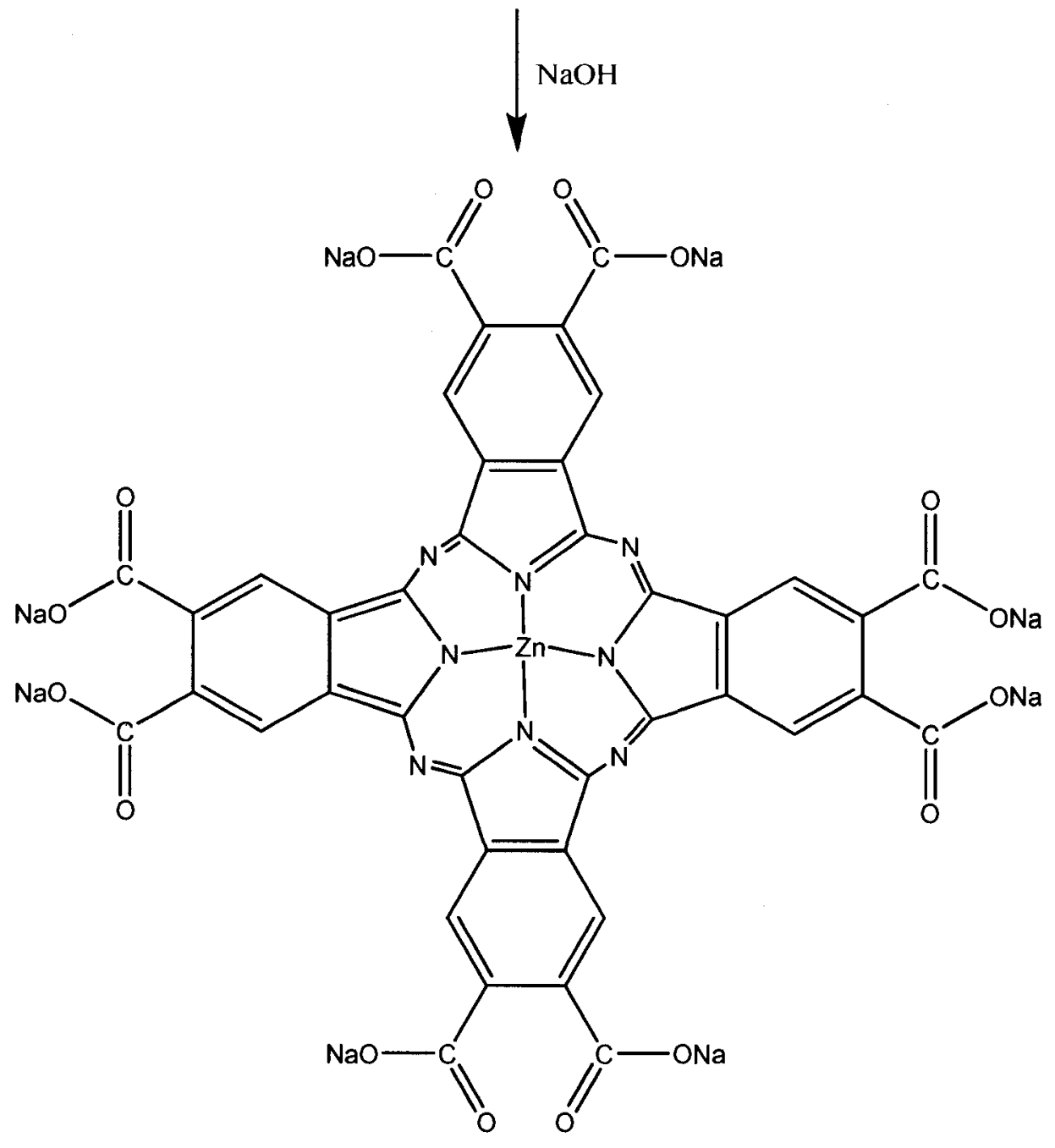

zinc octacarboxy phthalocyanine sodium salt

Reaction Scheme 1: Proposed mechanism for the Zinc octacarboxylate phthalocyanine following the protocol outlined by Kuznetsova et al.

Various techniques were used to purify the Zinc tetraimide phthalocyanine compound synthesized using Kuznetsova et. al.'s protocol. The crude tetraimide sample was washed with benzene in order to remove the unreacted 1-bromonapthalene from the reaction mass and was followed by acid/base $\left(\mathrm{HCl} / \mathrm{NH}_{4} \mathrm{OH}\right)$ precipitation which ensured the removal of water soluble reactants, mostly urea, zinc acetate, sodium sulphate, 
pyromellitic dianhydride and excess metal. Soxhlet extraction was used to further purify the tetraimide substance. The tetraimide compound was hydrolyzed and converted to its salt (via $1 \% \mathrm{NaOH}$ ) by using the literature protocol followed by Kuznetsova et. al. The extinction coefficient $(691 \mathrm{~nm})$ value of the purified salt compound was calculated in water to be only $21,000 \mathrm{M}^{-1} \mathrm{~cm}^{-1}\left[\mathrm{Zn}\left(\mathrm{C}_{40} \mathrm{H}_{8} \mathrm{~N}_{8} \mathrm{O}_{16} \mathrm{Na}_{8}\right]\right.$. Because soxhlet extraction proved ineffective, purification using flash chromatography was attempted. The final product had only a slightly improved extinction coefficient $\left(691 \mathrm{~nm}, 32,000 \mathrm{M}^{-1} \mathrm{~cm}^{-1}\right)$.

It was noted that the high temperature conditions of the Kuznetsova et. al., method seemed to decompose the product. Therefore, synthesis of the tetraimide compound was attempted using milder temperature conditions $\left(190{ }^{\circ} \mathrm{C}\right.$ for 4 hours). The tetraimide phthalocyanine was then hydrolyzed according to Kuznetsova et. al. After the end of hydrolysis, there was evidence of thermal degradation as visually indicated by a color change from dark green to yellowish green along with a measured weight difference. Therefore, milder basic conditions as proposed by V.Iliev and A. Mihaylova [21] were used to hydrolyze the tetraimide compound. Using these milder conditions, there was no visual evidence of discoloration in the reaction mixture at the end of 1.5 hours $\left(80^{\circ} \mathrm{C}\right)$. UV-vis spectrum of the compound was obtained in water and the extinction coefficient $(695 \mathrm{~nm})$ value $\left(119,000 \mathrm{M}^{-1} \mathrm{~cm}^{-1}\right)$ is a significant improvement but still less than the expected value of approximately $200,000 \mathrm{M}^{-1} \mathrm{~cm}^{-1}$ [37].

It was hypothesized that the complexes synthesized using protocols outlined by both V. Iliev and A. Mihaylova and Kuznetsova et. al., were in fact polymers (i.e., dimers, trimers or of higher orders) and that this may have accounted for the difficulty in purification. This was supported by the ratio of carbon to nitrogen from the elemental 
analysis for the synthesized complex (4.55/1) with that the theoretically calculated for polymeric phthalocyanine derivatives provided by W.C Drinkard et. al. [22], (see Table 4).

Table 4: Comparison of the Carbon: Nitrogen (C/N) Ratios for the Synthesized Compound (A), (see Section 2.7.5) with the Calculated $\mathrm{C} / \mathrm{N}$ Ratios of Phthalocyanine Polymers (B).

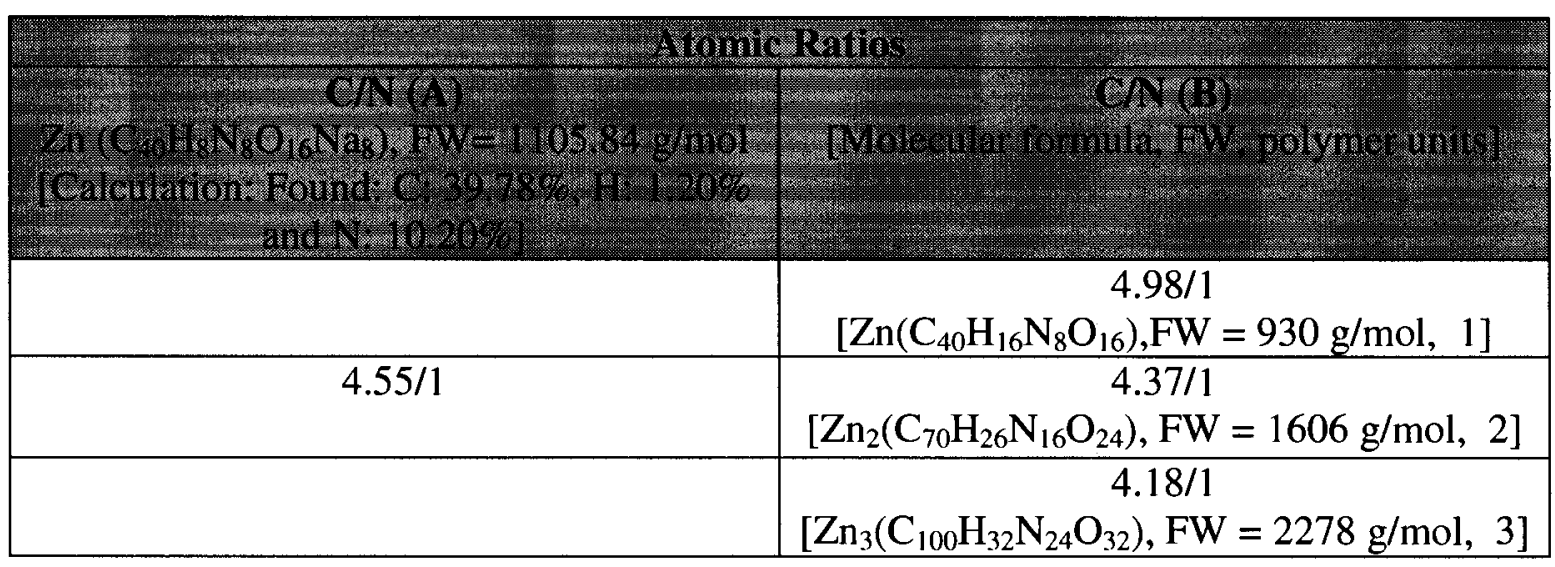

Pyromellitic dianhydride in the presence of excess ammonia (formed by the decomposition of urea at high temperatures) will form dicarboxyimide diimino isoindoline which will readily form two fused phthalocyanine rings as shown in Scheme 2 below. 

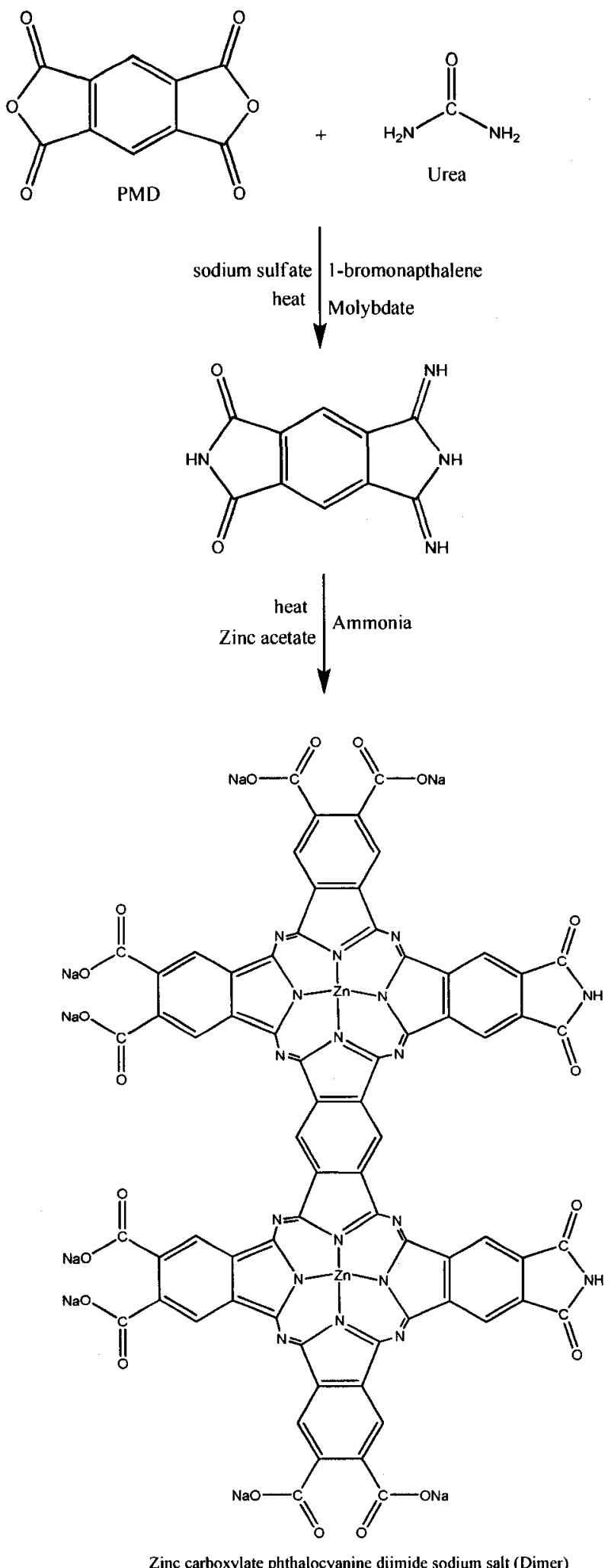

Reaction Scheme 2: Proposed structure for the dimer sodium salt of Zinc carboxylate phthalocyanine. 
The method of D. R. Boston and J. C. Bailer [38] was followed using tetracyanobenzene instead of pyromellitic anhydride and urea. The reaction between zinc acetate and tetracyanobenzene (TCB) in the presence of ethylene glycol is depicted in Scheme 3 below. The hydrolysis of TCB in wet ethylene glycol generated low concentrations of ammonia which in turn induced cyclization of the remaining nitrile groups forming an iminoisoindoline moiety. As shown in Scheme 3 below, continued heating of the isoindoline 4 results in the formation of the desired $\mathrm{ZnPc}$ product 5.

When comparing the infrared spectra of the crude Zinc tetraimide and the purified (by acid washing) Zinc tetraimide complex it was observed that the imide stretch for the impure Zinc tetraimide appeared at $1772 \mathrm{~cm}^{-1}$. The peak was seen to be broad and wide, in contrast with the sharp and intense imide peak that appeared at $1702 \mathrm{~cm}^{-1}$ for the acid washed complex. UV-vis spectrum was determined and the extinction coefficient value $(693 \mathrm{~nm})$ in DMF was calculated to be $122,000 \mathrm{M}^{-1} \mathrm{~cm}^{-1}$.

Table 5: IR Data for Zinc Tetraimide Phthalocyanine Using $\mathrm{KBr}$ Pellets at Room Temperature (see Appendix I).

\begin{tabular}{|c|c|c|}
\hline & \multicolumn{2}{|c|}{${\text { Frequency in } \mathrm{cm}^{1}}^{-1}$} \\
\hline & Impure tetraimide complex & Tetraimide complex after acid/base \\
\hline O-H stretch & 3740 & extraction \\
\hline $\mathrm{C}=\mathrm{O}$ imide stretch & 1772 broad peak & 3439 \\
\hline
\end{tabular}


The next step in synthesis involved the hydrolysis of the Zinc tetraimide phthalocyanine complex 6. Using D. R. Boston and J. C. Bailer's method, the Zinc carboxy phthalocyanine tetraimide compound was hydrolyzed using $18 \mathrm{M} \mathrm{KOH}$. There was evidence of thermal degradation after 8 hours as indicated by a color change from dark green to yellowish green. Also, there was a considerable decrease in recovered weight ( $2.42 \mathrm{~g}$ to $0.20 \mathrm{~g}$; yield $7.58 \%$ ) which was indicative of decomposition during hydrolysis under strong basic conditions $(18 \mathrm{M} \mathrm{KOH})$. This method for hydrolysis was modified using a milder basic conditions as proposed by V. Iliev and A. Mihaylova (2 $\mathrm{M} \mathrm{NaOH}$ ). No discoloration was noticed at the end of the reaction ( 8 hours, yield $23.1 \%$ ). The carboxy phthalocyanine was converted to its sodium salt by using the protocol outlined by Kuznetsova et. al. UV-vis spectrum (Figure 12) of the salt compound 7 was obtained and the extinction coefficient $(696 \mathrm{~nm})$ value in water was determined to be $191,000 \mathrm{M}^{-}$ ${ }^{1} \mathrm{~cm}^{-1}$. The monomeric nature of the compound was confirmed by elemental analysis (below) and further supported by the calculated atomic ratio of carbon to nitrogen (5.0/1). The calculated value for the $\mathrm{C} / \mathrm{N}$ ratio was in agreement with the theoretical values shown in Table 4 for a monomer form of zinc phthalocyanine, thus confirming the monomeric nature of our complex. The calculated elemental analysis of the sodium salt of $\mathrm{ZnPc}\left(\mathrm{COO}^{-}\right)_{8}$ did not agree with that found but could be fitted assuming the hydrated Zinc 2,3,9,10,16,17-(hexacarboxylate)-23,24-(dicarboximide) phthalocyanine sodium salt. The complex purity was judged to be sufficient to carry out quantitative studies due to the high extinction coefficient of the photosensitizer $\left(191,000 \mathrm{M}^{-1} \mathrm{~cm}^{-1}\right)$. 

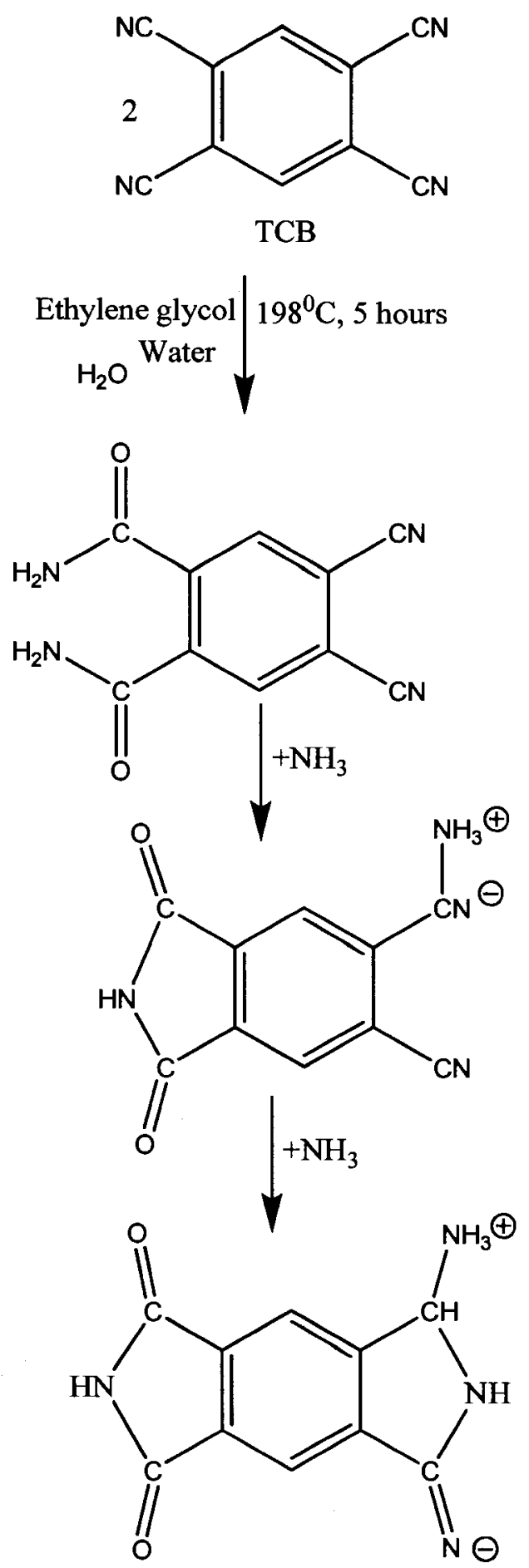

(1)

(2)

(3) 


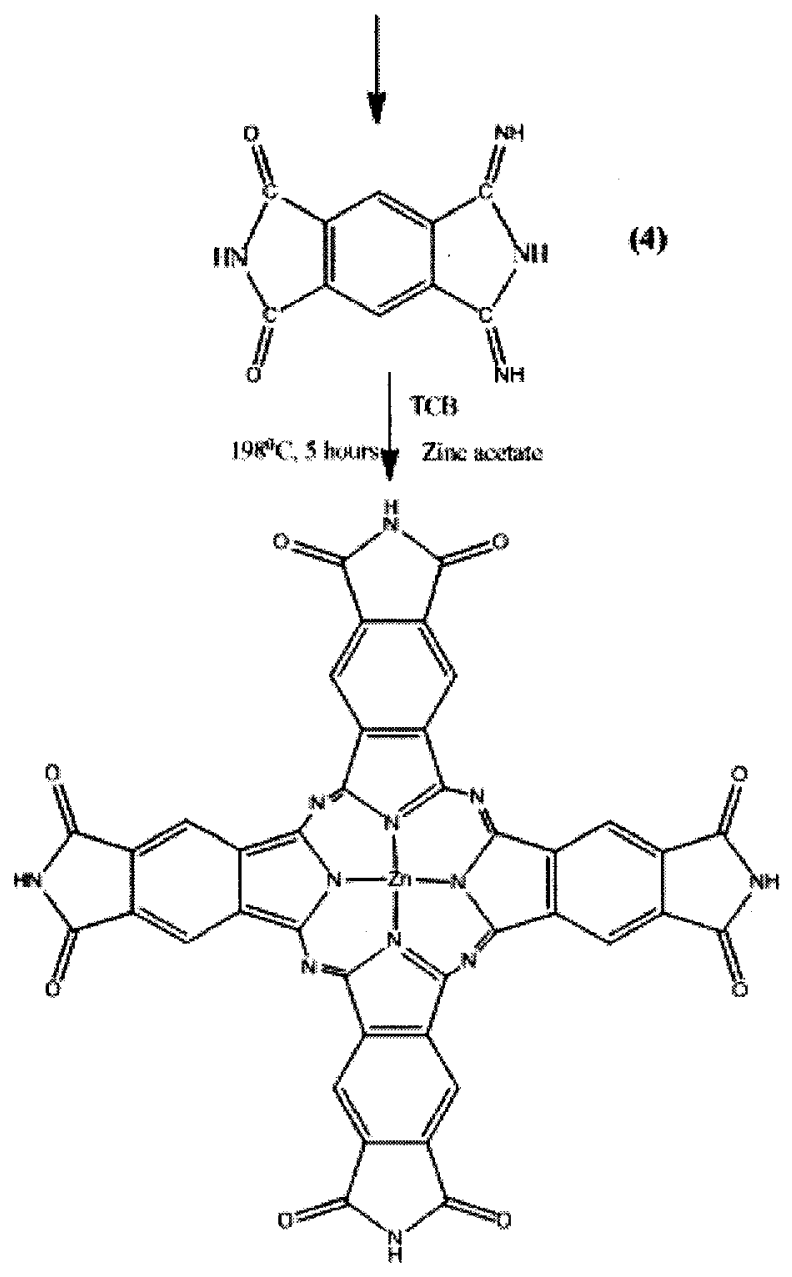

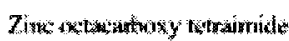

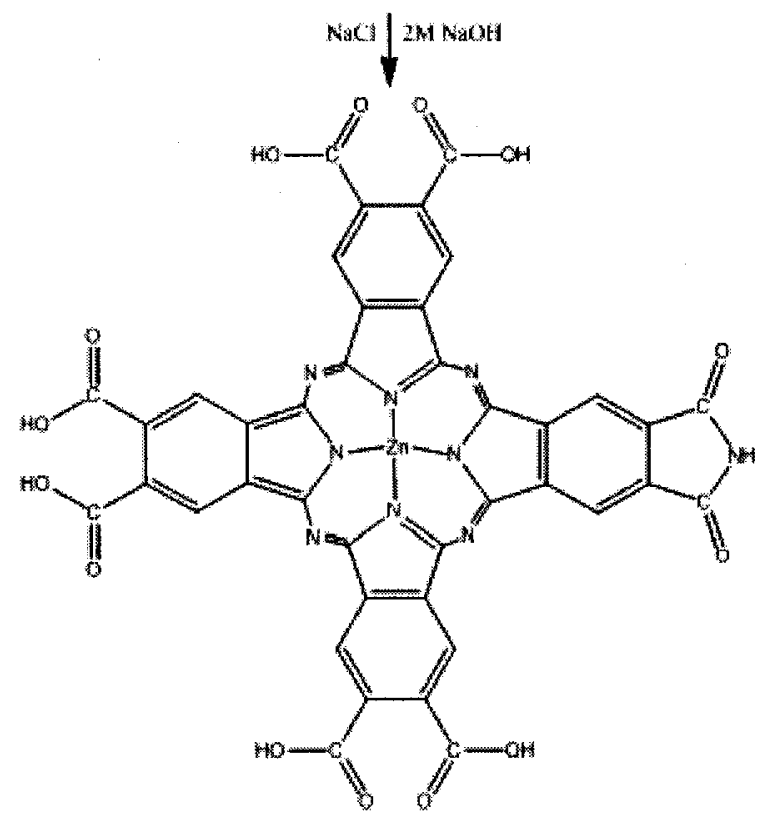

(5) 


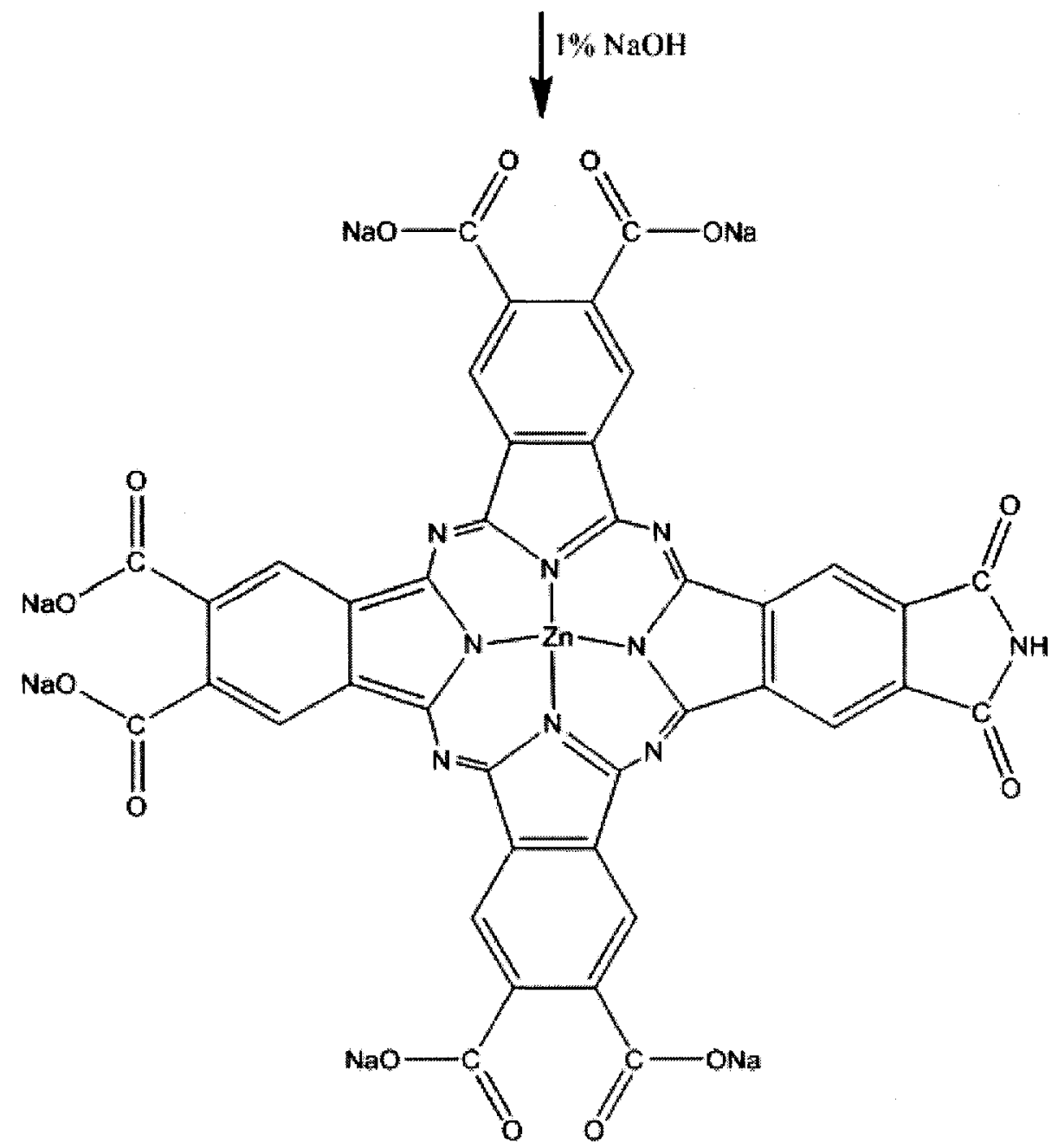

(7)

Zinc 2,3,9,10,16,17-(hexacarboxylate)-23,24-(dicarboximide) phthalocyanine sodium salt

Reaction Scheme 3: Mechanism for the synthesis of sodium salt of Zinc 2,3,9,10,16,17(hexacarboxylate)-23,24-(dicarboximide) phthalocyanine sodium salt, the photosensitizer. 


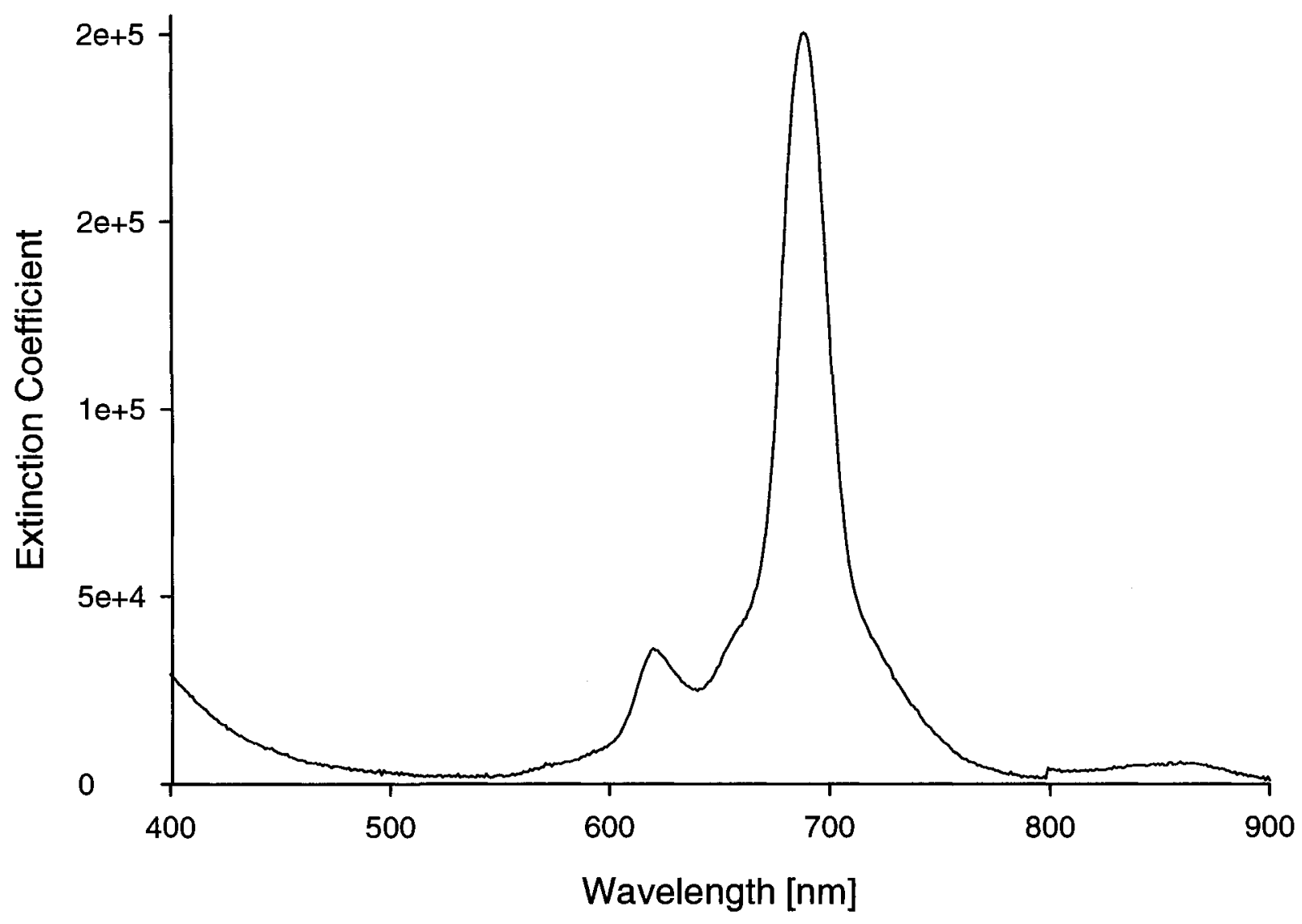

Figure 12: UV-vis spectrum of the photosensitizer in water. 


\subsection{Aggregation of the Photosensitizer from $\mathrm{pH} 4$ to 11}

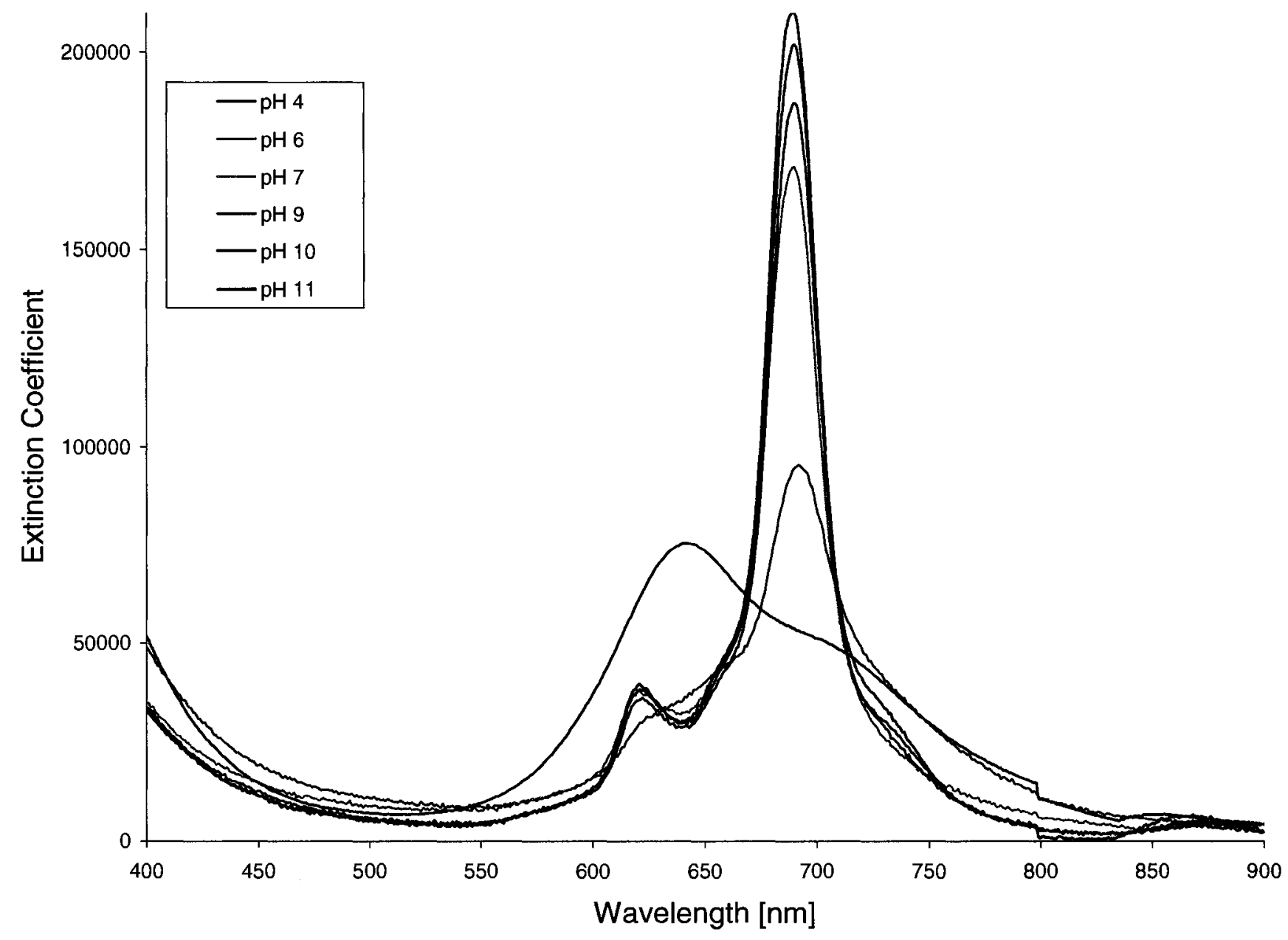

Figure 13: UV-vis spectra showing the behavior of the photosensitizer at room temperature in a $\mathrm{pH}$ 4-11 water-alkaline medium.

The nature of the photosensitizer in solution depends on the degree of ionization of the carboxyl groups of the phthalocyanine [43]. This is illustrated by Figure 13 which shows a change in photosensitizer absorption spectrum with decreasing $\mathrm{pH}$. Under acidic conditions ( $\mathrm{pH} 4$ ), the carboxylic groups are likely protonated and this favours aggregation [10,43]. As discussed previously, these aggregates do not have the 
properties that allow them to form singlet oxygen in their excited state $[28,31]$. To see if the absorption changes seen in Figure 13 were a consequence of the protonation equilibrium of the carboxylate groups, the photosensitizer was dissolved in DMF and to it different concentrations (1drop-10 ml) of N-butylamine were added (Figure 14).

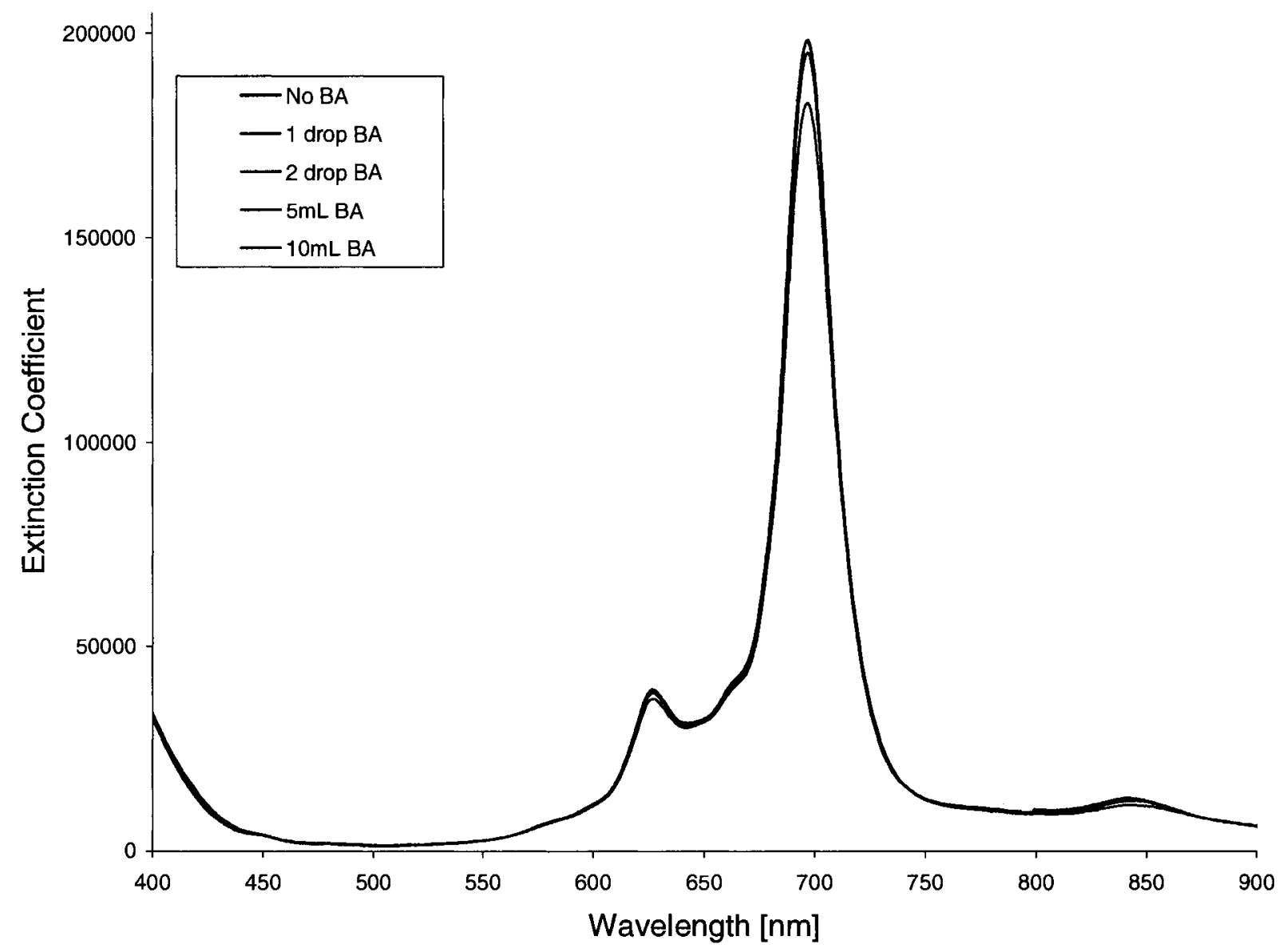

Figure 14: Spectra showing the behavior of the photosensitizer in DMF at room temperature using different concentrations of $\mathrm{N}$-butylamine (BA) in $50 \mathrm{~mL}$ total volume of solution.

N-butylamine $(\mathrm{pKa}=10.7)$ is able to completely deprotonate the peripheral carboxyl substituents in the photosensitizer (pKa 4.8) [41, 43]. As shown by Figure 14, there is practically no change in the photosensitizer absorption spectrum with the addition 
of N-butylamine. It is concluded that electronic transitions responsible for the Q-band of phthalocyanine are unaffected by the protonation equilibrium of the carboxylic groups and that the changes seen in Figure 13 are due to changes in the monomer/aggregate equilibrium.

\subsection{Influence of Concentration on the Monomer-Dimer Equilibrium at pH 11}

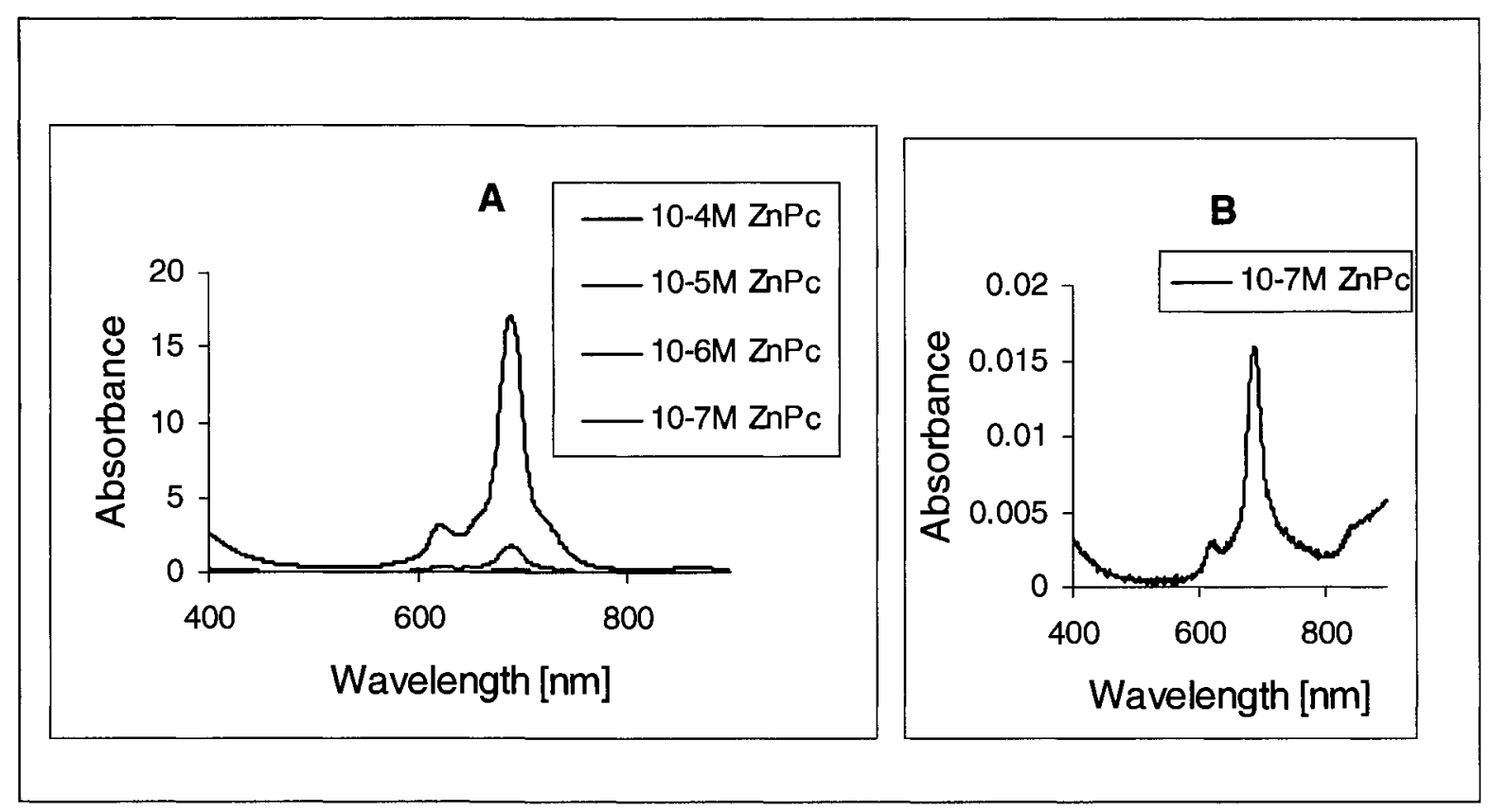




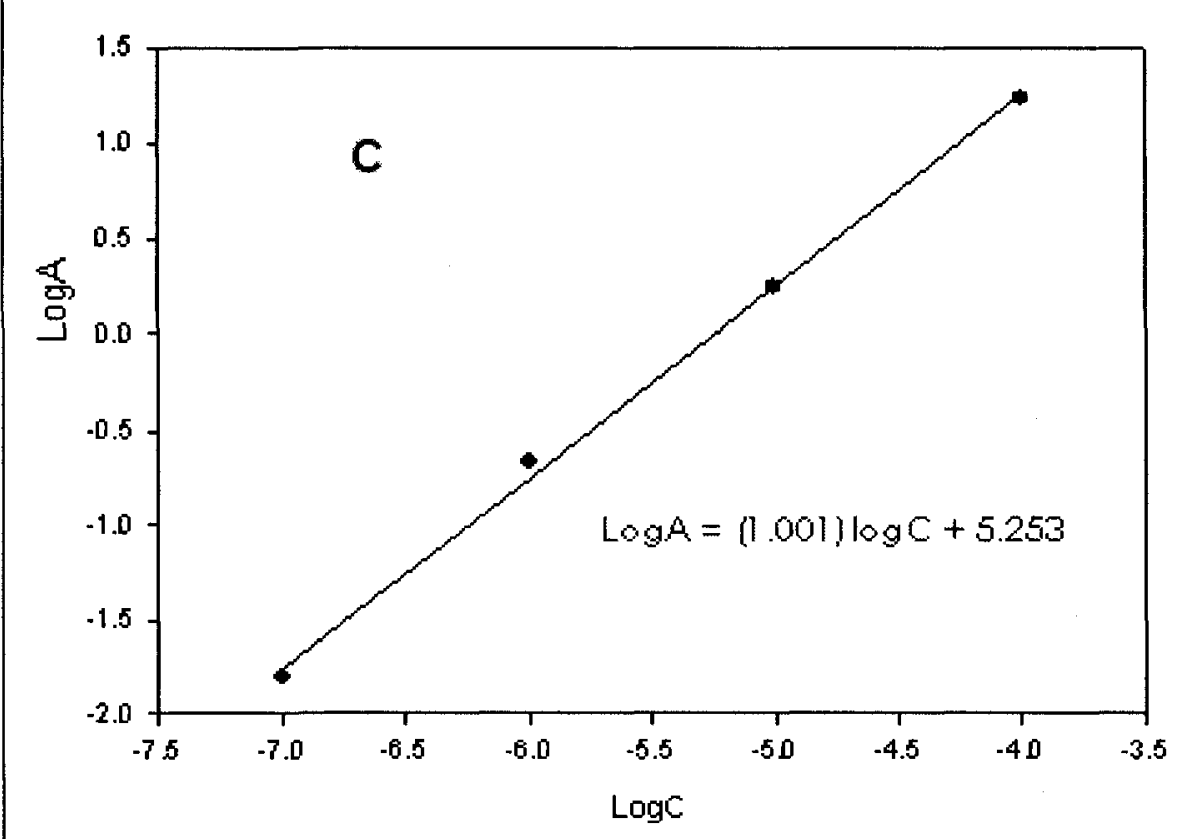

Figure 15: A: Band profiles with respect to the various concentrations of the photosensitizer in a $\mathrm{pH} 11$ water-alkaline solution using different cells in aqueous solution at room temperature. B: Band profile with respect to the lowest concentration $\left(10^{-7}\right)$ of the photosensitizer in a $\mathrm{pH} 11$ medium. C: Plot of the logarithm of absorbance measured at $696 \mathrm{~nm}$ versus the logarithm of the photosensitizer concentration. A Cell with a $5 \mathrm{~cm}$ path length was used for $10^{-6}$ and $10^{-7} \mathrm{M}$ solutions. Cells with $0.2 \mathrm{~cm}$ and 1 $\mathrm{cm}$ path lengths were used for $10^{-4}$ and $10^{-5} \mathrm{M}$ solutions respectively. The absorbance was normalized relative to that of the $1 \mathrm{~cm}$ cell by dividing the measured absorbance by the path length of the cell used in the measurement.

The effect of concentration on the absorption spectra was studied for the photosensitizer in aqueous pH 11 solution and is shown in Figure 15A and 15B. The spectra for the lowest concentration $\left(10^{-7} \mathrm{M}\right)$ and the highest concentration $\left(10^{-4} \mathrm{M}\right)$ of the photosensitizer show an intense peak at $696 \mathrm{~nm}$ with no apparent shoulder, which is consistent with the monomer UV spectrum for the photosensitizer (Figure 12). 
From the intercept of the linear best fit of the data in Figure 15C, an extinction coefficient of $179,000 \mathrm{M}^{-1} \mathrm{~cm}^{-1}$ is calculated, which is lower than that obtained from a solution of the photosensitizer at approx. $10^{-6} \mathrm{M}\left(191,000 \mathrm{M}^{-1} \mathrm{~cm}^{-1}\right)$. This deviation maybe due to the formation of dimer at higher concentrations but considering the 1000 fold change in concentration to produce this effect, the influence of photosensitizer concentration on the monomer-dimer equilibrium must be small.

\subsection{The Equilibrium Studies and Surfactants}

\subsubsection{Anionic and Non-Ionic Surfactants}

Surfactants are classified according to their dissociation in water and are divided into four groups: (1) anionic; (2) nonionic; (3), cationic; and (4) amphoteric. Because the phthalocyanine is anionic, it was hypothesized that a cationic surfactant would be required to prevent aggregations. To confirm our hypothesis and to support our use of cationic surfactants, we decided to perform the SOOT experiments using anionic and nonionic surfactants. As hypothesized these surfactants were unsuccessful in protecting the photosensitizer against photodegradation during the SOOT experiment and thus no further characterization was performed using these classes of surfactants.

\subsubsection{Monomer-Dimer Equilibrium and Cationic Surfactants}

As seen in Figure 13 above, there exists a monomer-aggregate equilibrium where the photosensitizer is mostly an aggregate at low $\mathrm{pH}$ conditions (i.e., $\mathrm{pH} 4$ ). To see if this 
monomer-dimer equilibrium can shift towards mostly monomer species in solution and to study the state of the monomer-dimer equilibrium, the cationic surfactant CTAB was utilized at $\mathrm{pH} 4$.

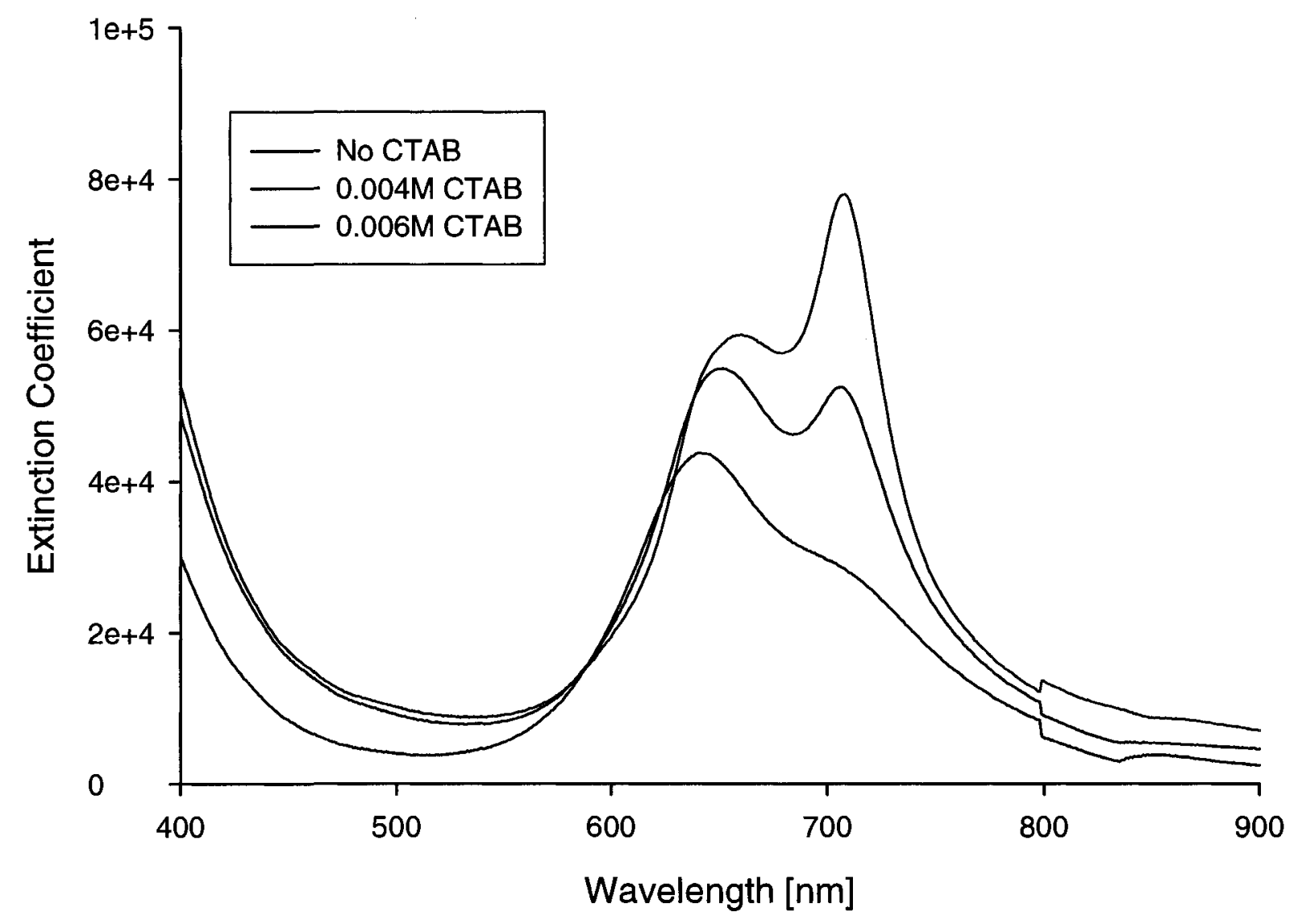

Figure 16: Spectra showing the effect of different concentrations of CTAB on the photosensitizer at $\mathrm{pH} 4$.

Figure 16 shows varying concentrations of CTAB $(0.004 \mathrm{M}-0.006 \mathrm{M})$ complexed with the photosensitizer and its effects on dimerizaton at $\mathrm{pH} 4$ as compared to a control containing only photosensitizer. The dimerization of the phthalocyanine decreases with 
increasing amounts of CTAB. This is indicated by the Q-band shifting from $620 \mathrm{~nm}$ to $690 \mathrm{~nm}$ and the enhancement of its intensity as CTAB concentration increases in solution. Preliminary studies, however, indicated that CTAB precipitated from solution as a sulfate salt during the SOOT experiments, and so this equilibrium was examined with DTAB under the same conditions.

Figures 17 and 18 shows the absorption spectrum behaviour of the photosensitizer in a $\mathrm{pH} 4$ medium at room temperature using different concentrations of DTAB $(0.5 \mathrm{mM}-$ $28 \mathrm{mM}$ ) and is due to changes in the monomer-dimer equilibrium.

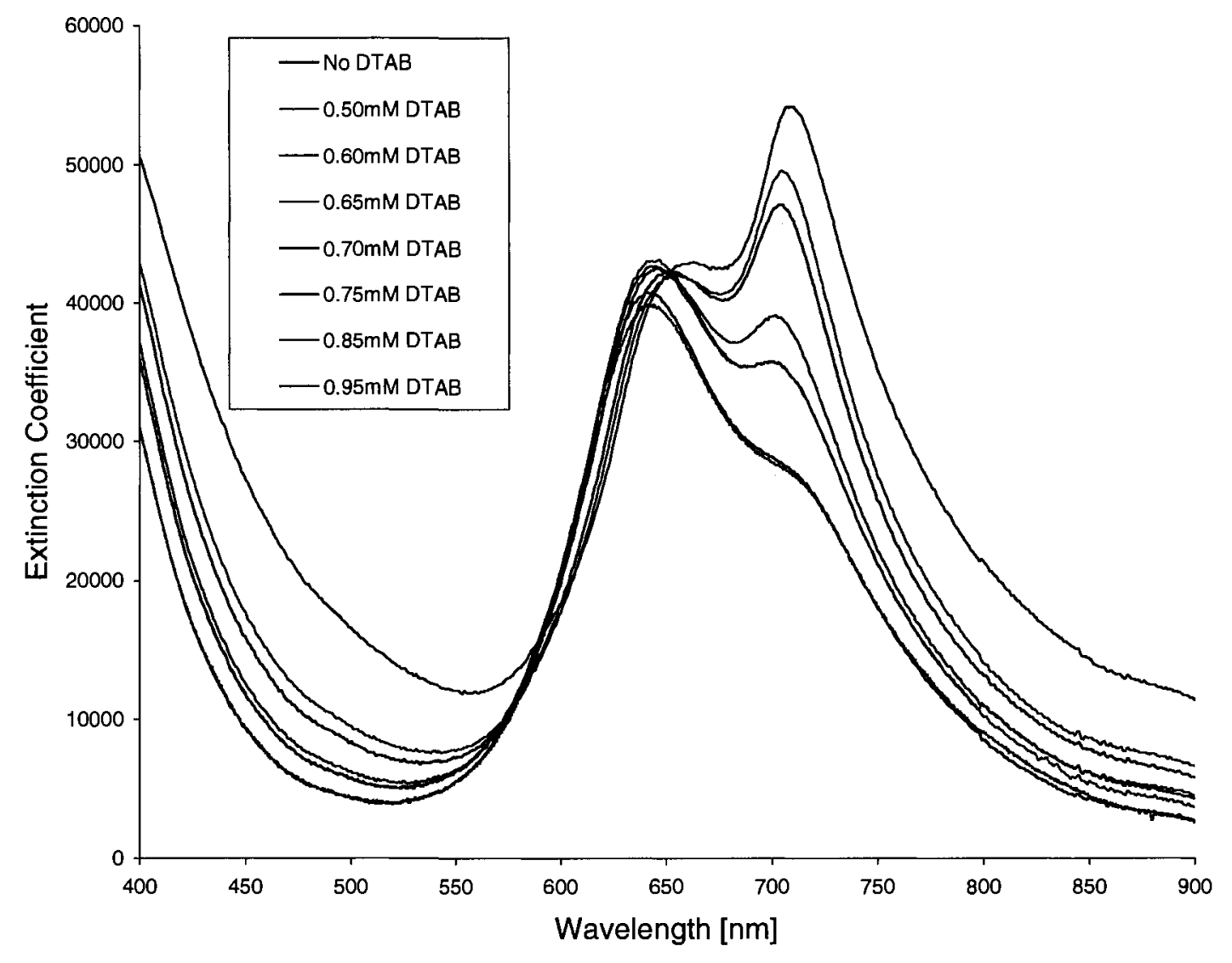

Figure 17: Spectra showing the behavior of photosensitizer in a $\mathrm{pH} 4$ medium at room temperature using different concentrations of DTAB demonstration the monomer-dimer equilibrium. 


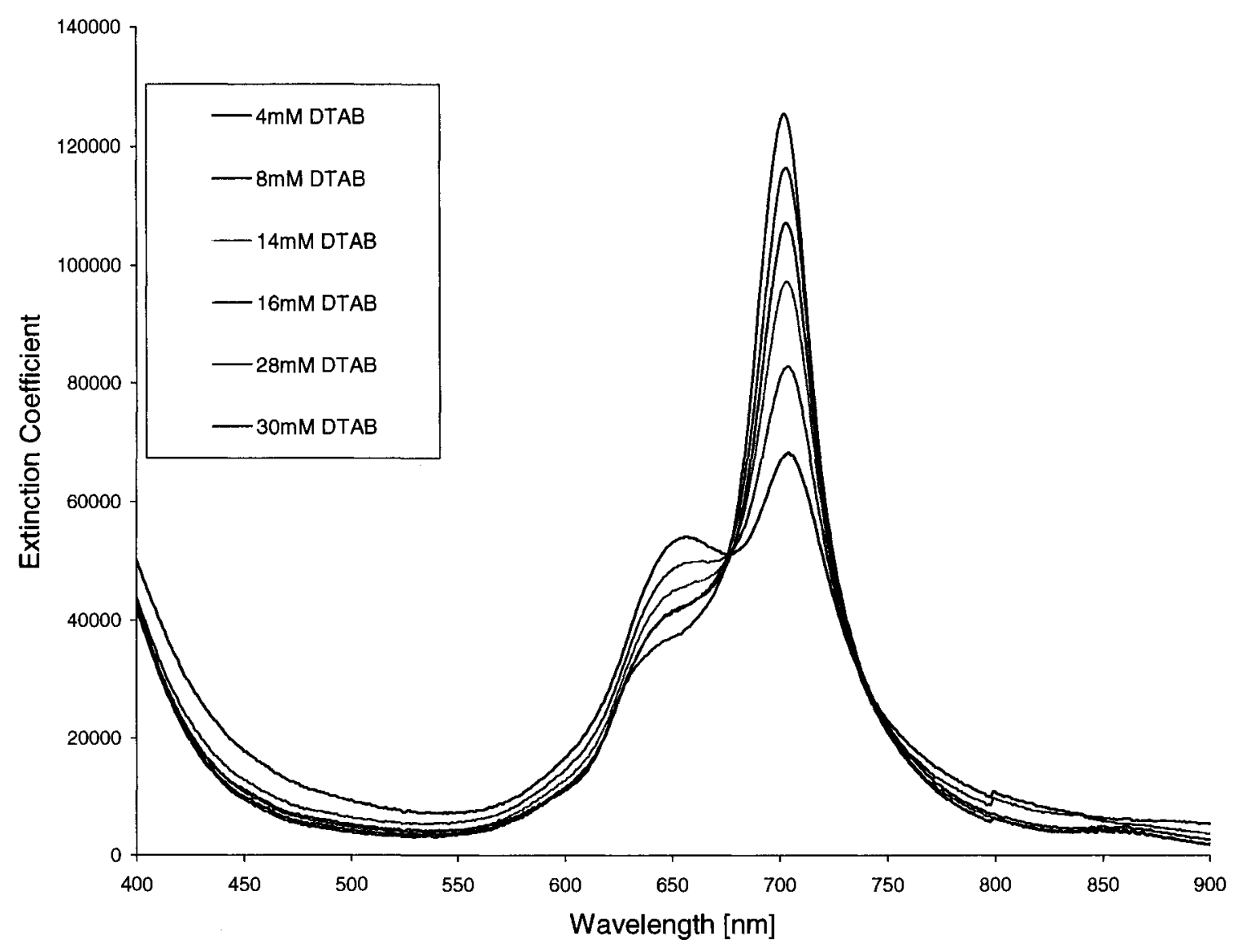

Figure 18: Spectra showing the behavior of photosensitizer in a $\mathrm{pH} 4$ medium at room temperature using different concentrations of DTAB demonstration the monomer-dimer equilibrium.

Because there are multiple sets of isosbestic points in Figures 17 and 18, we concluded that there exist more than two species in solution [42]. The scheme below shows some possible species that may be present in solution containing DTAB. As seen in Figures 17 and 18, there is no spectral change observed in the UV spectra of the sensitizer above the DTAB concentration of $30 \mathrm{mM}$. At the concentrations of photosensitizer and surfactant used in this experiment (see above) along with the fact that at concentrations greater then $4 \mathrm{mM}$, only one set of isosbestic point is observed, it can be 
hypothesized that the equilibrium that exists is simply a micelle encapsulated dimermonomer.

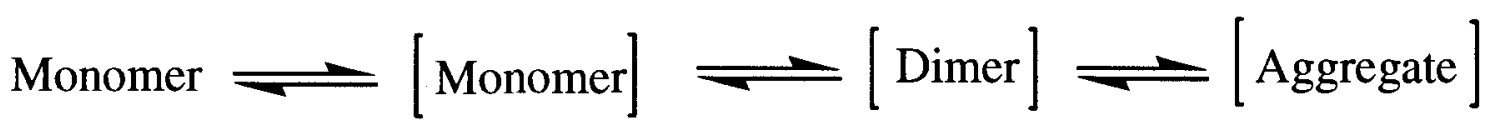

$$
[\rfloor=\text { micelle }
$$

From the scheme presented above, it is suggested that in addition to the monomer species in solution there are also DTAB encapsulated monomer, dimer or aggregate complexes present in the medium above the DTAB concentration of $4 \mathrm{mM}$.

A similar trend was observed as the one seen for CTAB (Figure 16) when the concentration of DTAB was increased in a pH 6 solution from $8 \mathrm{mM}$ to $28 \mathrm{mM}$ (Figure 19). 


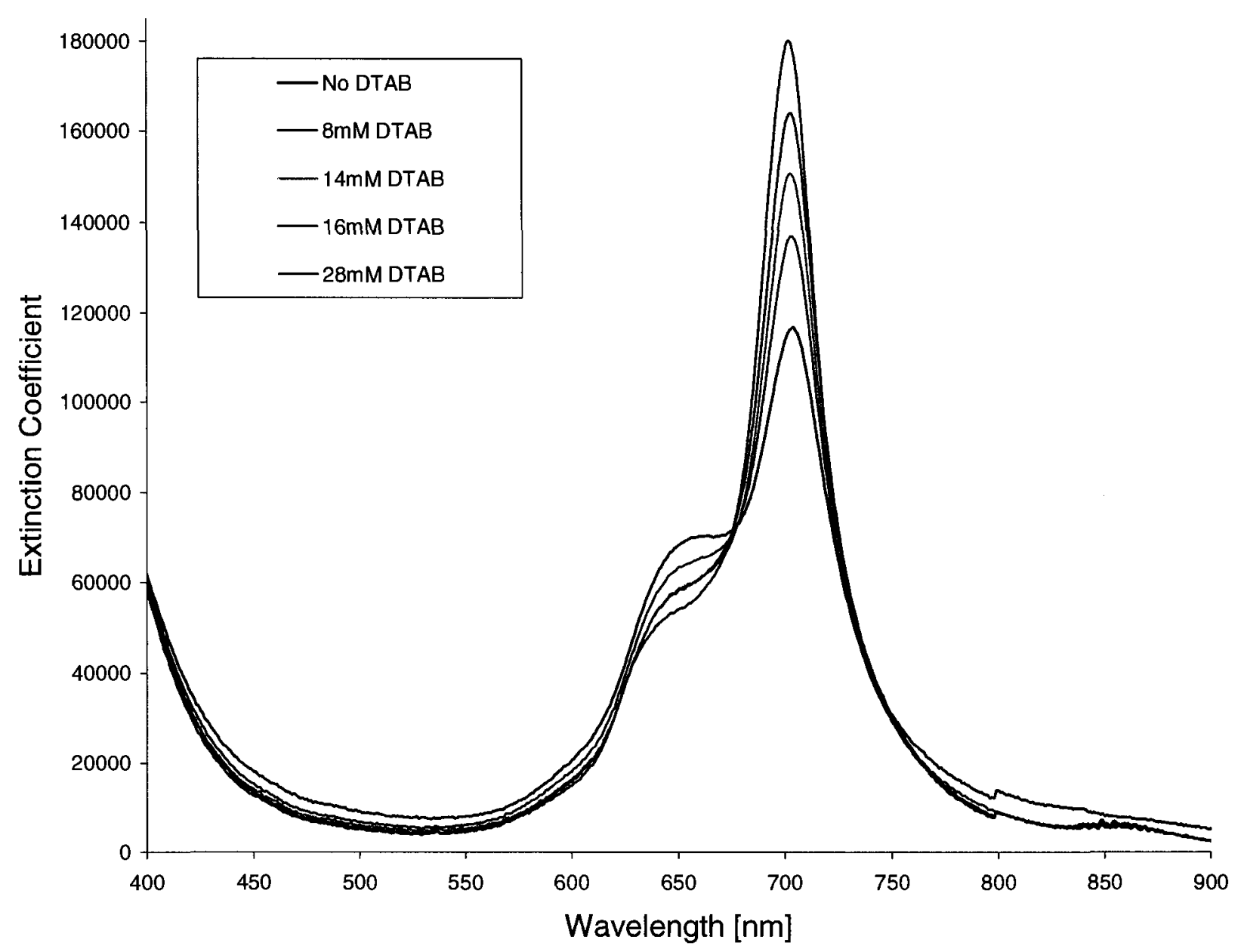

Figure 19: Spectra showing the effect of different concentrations of DTAB on the photosensitizer at $\mathrm{pH} 6$.

There were no significant changes observed in the absorption spectra at higher concentrations of DTAB (above $28 \mathrm{mM}$ ). It was found, with both cationic surfactants (CTAB and $\mathrm{DTAB})$ and at both $\mathrm{pH}$ conditions (pH 4 and $\mathrm{pH}$ 6), the equilibrium shifted towards having more monomer species in solution and the concentration of DTAB required to attain the extinction coefficient that is associated with mostly monomer species in solution appears to be lower at $\mathrm{pH} 6$ when compared to $\mathrm{pH} 4$. 


\subsubsection{Protonation-Deprotonation Equilibrium Studies}

There are two equilibria that occur in an aqueous solution containing the photosensitizer, (1) protonation-deprotonation ( $\mathrm{pH}$ dependent); (2) and monomer-dimer equilibrium (see above).

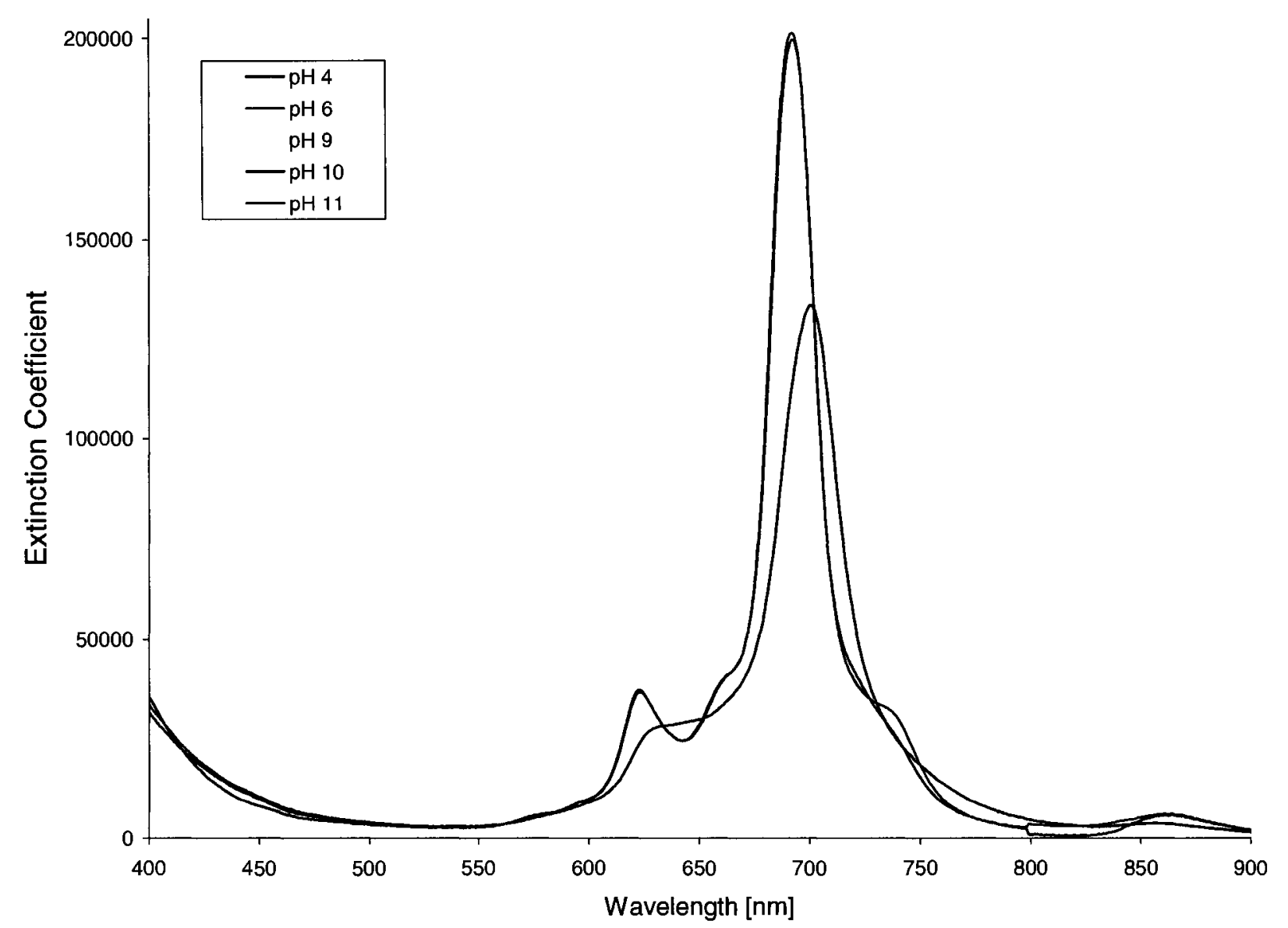

Figure 20: Spectra showing the behavior of the photosensitizer in different phosphate $\mathrm{pH}$ buffers $(0.05 \mathrm{M})$ and $40 \mathrm{mM} \mathrm{DTAB}$, at room temperature. 
Comparing Figures 20 and 13, it can be seen that when using DTAB, the photosensitizer exists mostly as monomer in $\mathrm{pH}$ ranges 6-10 (Figure 20) while when in solution without surfactant there are dimer species present at $\mathrm{pH}$ 6-10 (Figure 13) indicating there is no protonation-deprotonation equilibrium in solution (i.e., Figures 13 and 20 would look similar if there was such an equilibrium). Only at $\mathrm{pH} 4$, is a significant concentration of dimer present under both conditions (with and without surfactant); however, when comparing Figure 20 to Figure 13, there are more monomer species present in solution in the presence of surfactant.

\section{5 pH Dependence on the Singlet Oxygen Quantum Yield}

The number of singlet oxygen molecules produced per photon absorbed by the photosensitizer is given by the value of $\mathrm{Q}_{\mathrm{s}}$, the quantum yield of singlet oxygen formation. The $\mathrm{Q}_{\mathrm{s}}$ value for the photosensitizer was determined by using the method described in Chapter 2, Section 2.5, and using methylene blue as calibrant $\left(Q_{s}=0.52\right.$ [33]) at room temperature in a $\mathrm{pH} 7$ aqueous solution in the absence of DTAB and in a pH 11 water-alkaline solution in the presence of DTAB. The reaction conditions were kept constant throughout the experiment and an excitation wavelength of $650 \mathrm{~nm}$ was used because at this wavelength the absorptivities of methylene blue and the photosensitizer are approximately equivalent. 


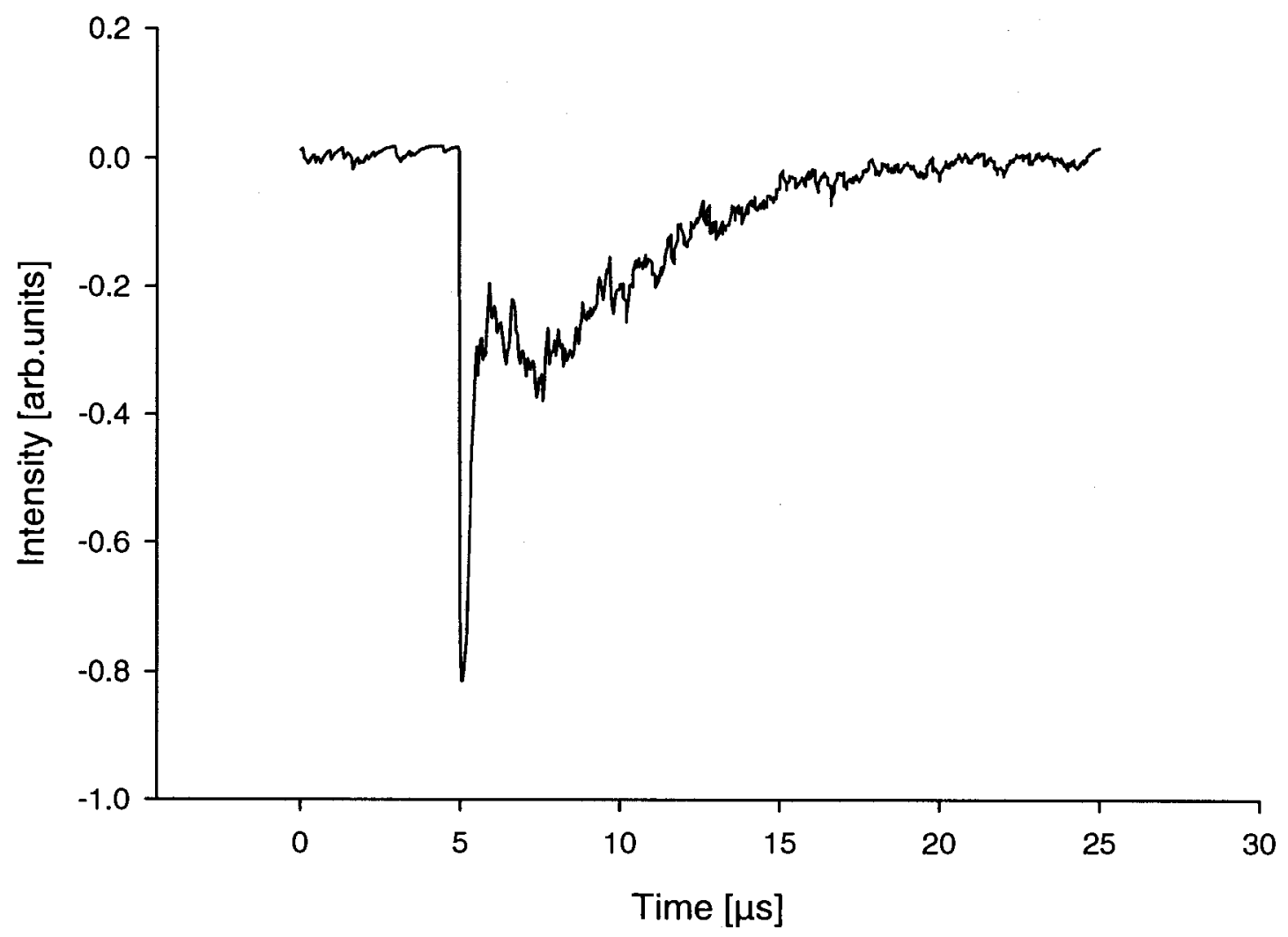

Figure 21: ' $\mathrm{O}_{2}$ emission intensity of $4.5 \times 10^{-5} \mathrm{M}$ methylene blue (calibrant) under $\mathrm{pH} 7 \mathrm{in}$ the absence of DTAB. 


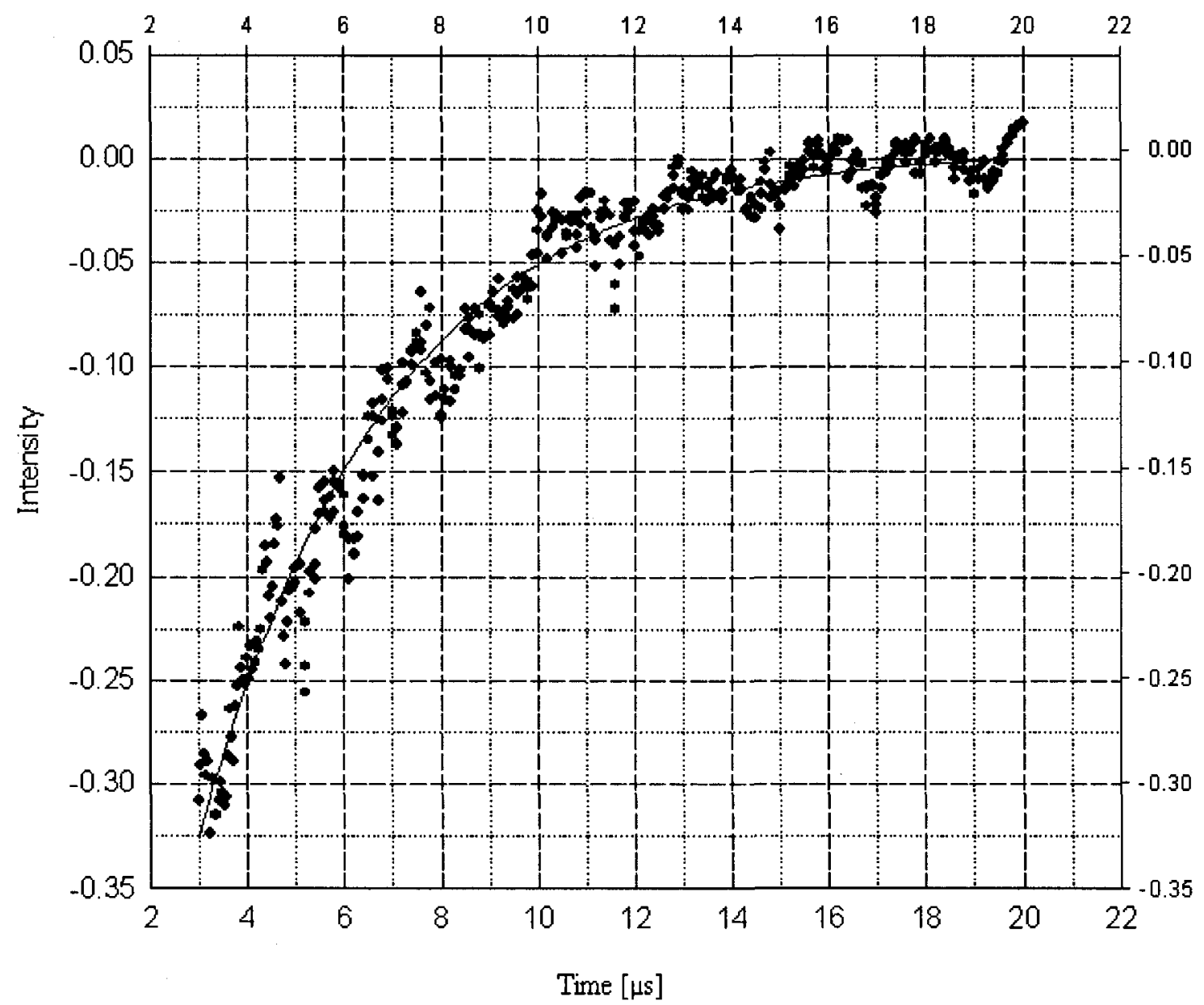

Figure 22: ${ }^{1} \mathrm{O}_{2}$ emission intensity from an aqueous solution of methylene blue (calibrant) in the absence of DTAB. Singlet oxygen decay spectrum data fit to an active curve assuming first order decay. Conditions: Methylene blue $4.5 \times 10^{-5} \mathrm{M}$, Milli-Q distilled water ( $\mathrm{pH} \mathrm{7).} \mathrm{The} \mathrm{solid} \mathrm{line} \mathrm{is} \mathrm{a} \mathrm{best-fit} \mathrm{of} \mathrm{eqn.} 13$.

In both studies we did not find any photodegradation of the phthalocyanine complex or calibrant monitored using UV-vis, indicating good stability under the experimental conditions employed. Figures 21 and 22 illustrate the treatment of the raw data and the results are summarized in Table 6. The ratio of the slope of the test solution to the calibrant times the quantum yield of the calibrant gave the quantum yields of singlet oxygen formation that are compiled below in Tables 6 and 7 . 
As shown in Figure 21, the initial signal at time zero after excitation gave a large signal which did not correspond to the intensity of singlet oxygen emission but was instead due to an electronic artifact. The intensity at time zero was estimated by extrapolation of data after the electronic noise had dissipated ( 3 to 4 microseconds) by assuming first order exponential decay according to the equation below:

$$
I=-A e^{-k t}
$$

Where "I" is the intensity of singlet oxygen emission, "A" is the intensity of emission right after the flash, time zero, $\mathrm{k}$ is the first-order rate of decay $(1 / \mathrm{k}$ is the measure of lifetime for the singlet oxygen) and " $\mathrm{t}$ " is the time in $\mu \mathrm{s}$.

Singlet oxygen signal intensity at time zero, $\mathrm{A}$ in eqn. 13 was plotted versus concentration of methylene blue and the photosensitizer at different $\mathrm{pH}$ in the absence of $\mathrm{DTAB}$ and in the presence of DTAB in a pH 11 medium respectively, giving straight line relationships and these are summarized in Figures 23 and 24. 


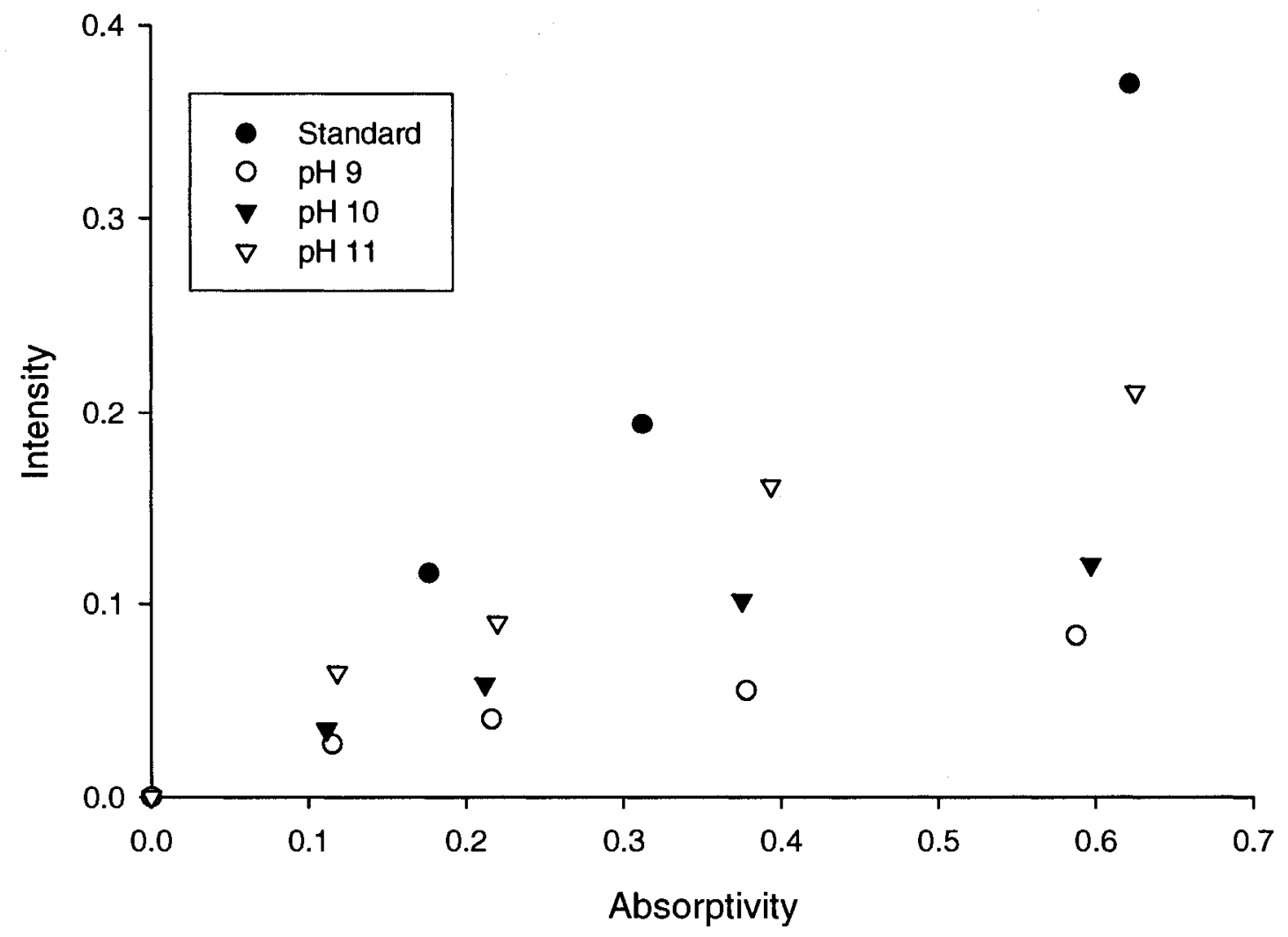

Figure 23: ${ }^{\mathrm{O}} \mathrm{O}_{2}$ generation from Methylene Blue in aqueous medium and the photosensitizer in different water-alkaline $\mathrm{pH}$ media $(\mathrm{pH} 9, \mathrm{pH} 10$ and $\mathrm{pH} 11)$. Conditions: Photosensitizer: 0.037-0.041 mM. 


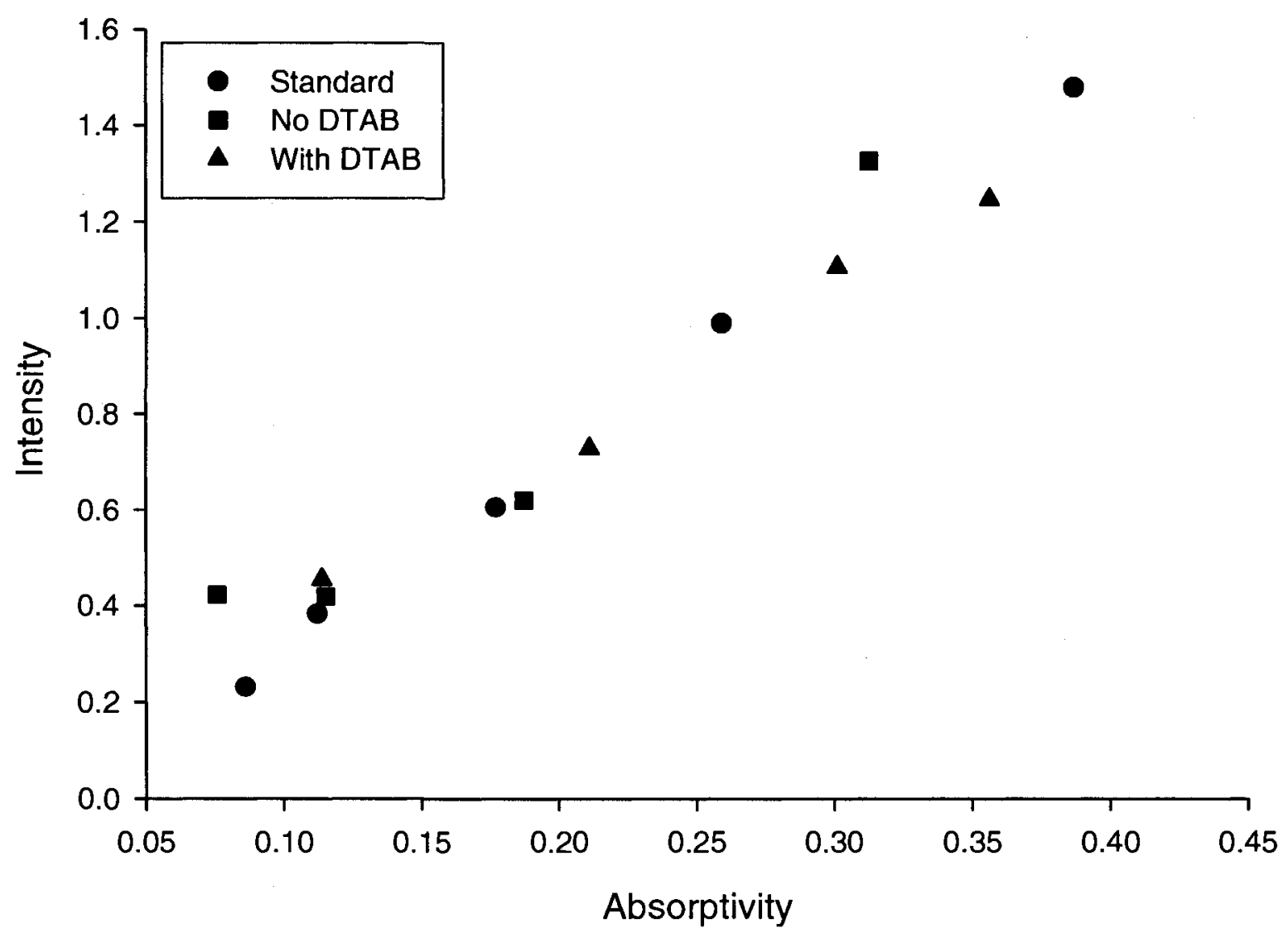

Figure 24: ${ }^{1} \mathrm{O}_{2}$ generation from Methylene Blue and the photosensitizer in a $\mathrm{pH} 11$ wateralkaline medium with the presence and absence of DTAB. Conditions: Photosensitizer in the presence of DTAB: $0.036-0.140 \mathrm{mM}$, photosensitizer in the absence of DTAB: $0.033-$ $0.041 \mathrm{mM}$. Methylene blue: 0.0035-0.056 mM. 


\subsubsection{Calculation of the Ouantum Yield of Singlet Oxvgen Formation $\left(Q_{s}\right)$}

Table 6: Calculated Values of the Quantum Yield of Singlet Oxygen for the Photosensitizer in Different pH Solutions in the Absence of Surfactant.

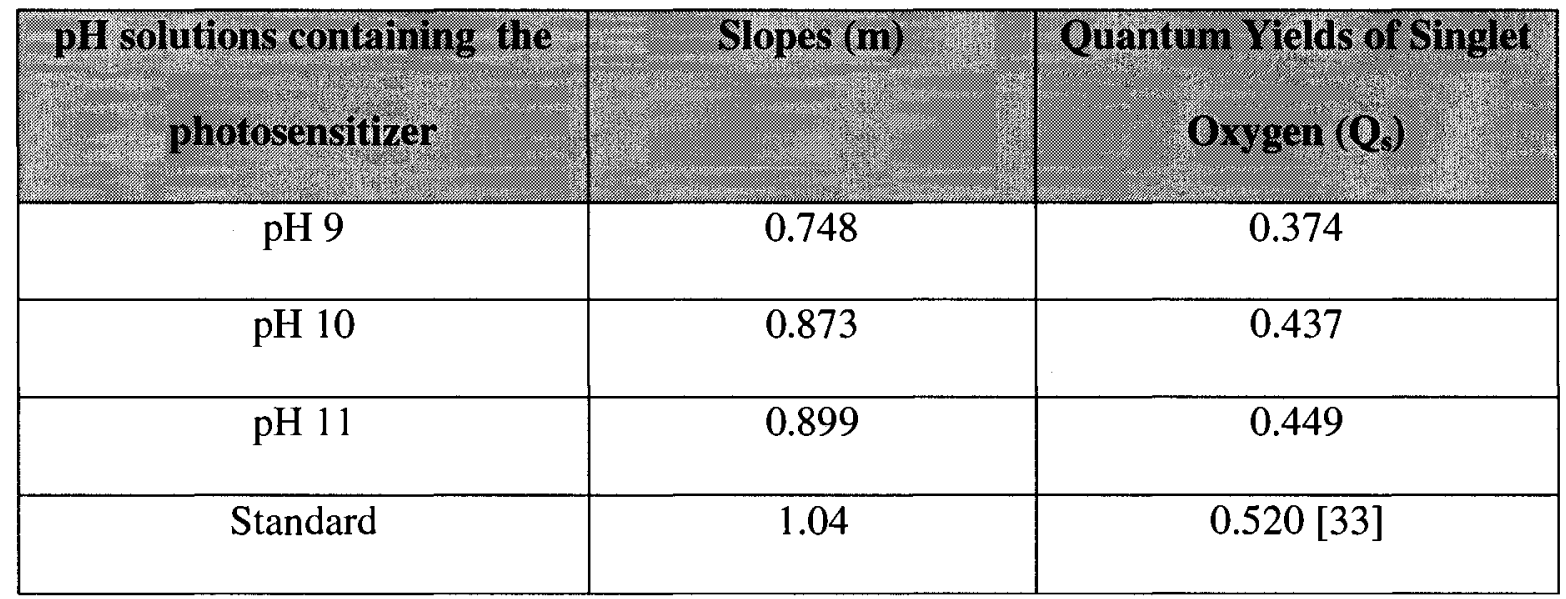

From the data in Table 6 it is clear that decreasing pH decreases the production of singlet oxygen. This is because as the $\mathrm{pH}$ of the solution drops, protonation of the photosensitizer takes place and the equilibrium present in the solution shifts towards the dimer formation as shown in Figure 13. 
Table 7: Calculated Values of the Quantum Yield of Singlet Oxygen for the Photosensitizer in Different pH Solutions in the Presence of Surfactant.

\begin{tabular}{|c|c|c|}
\hline $\begin{array}{c}\text { pH solutions containing the } \\
\text { photosensitizer }\end{array}$ & Slopes $(\mathrm{m})$ & $\begin{array}{c}\text { Quantum Yields of Singlet } \\
\text { Oxygen }\left(\mathbf{Q}_{\mathrm{s}}\right)\end{array}$ \\
\hline $\mathrm{pH} 11$ (Without DTAB) & 3.98 & 0.501 \\
\hline $\mathrm{pH} 11$ (With DTAB) & 3.76 & 0.474 \\
\hline Standard & 4.12 & $0.520[33]$ \\
\hline
\end{tabular}

From Table 7 , it is clear that the singlet oxygen production levels remained approximately the same in the presence and absence of DTAB in a $\mathrm{pH} 11$ medium. This indicates that the surfactant only plays a role in preventing photobleaching/photodegration of the photosensitizer, while having minimal effects on the energy transfer mechanisms to create singlet oxygen.

Of note is that the maximum amount of singlet oxygen generated from the photosensitizer (as seen in Tables 6 and 7) is only slightly below the value measured for methylene blue. This variation, although not characterized, can be partially attributed to (a) difference in intersystem crossing to the triplet state from an excited state; or (b) difference in reaction conditions. 


\section{CHAPTER 4}

\section{SINGLET OXYGEN OXIDATION OF THIOSALTS (SOOT)}

\subsection{Photobleaching}

\subsubsection{Photobleaching in the Absence of Surfactant}

Figure 25 shows the effect of irradiation on the photosensitizer over a period of 90 minutes using the SOOT test solution (see Chapter 2) but without added thiosulfate. A rapid decrease in the absorptivity of the Q-band is apparent indicating decomposition of the photosensitizer.

In an aqueous solution, superoxide ions are not stable and get rapidly converted to peroxide ions and oxygen (see Chapter 1, eqn. 8). These peroxide ions can either lead to (a) the chemical oxidation of thiosalts; or (b) the oxidation of phthalocyanine complex leading to photobleaching according to the reaction seen below:

$\mathrm{H}_{2} \mathrm{O}+\mathrm{HO}_{2}^{-}+2 \mathrm{ZnPc} \rightarrow 2 \mathrm{ZnPc}^{+}+3 \mathrm{OH}^{-}$ 


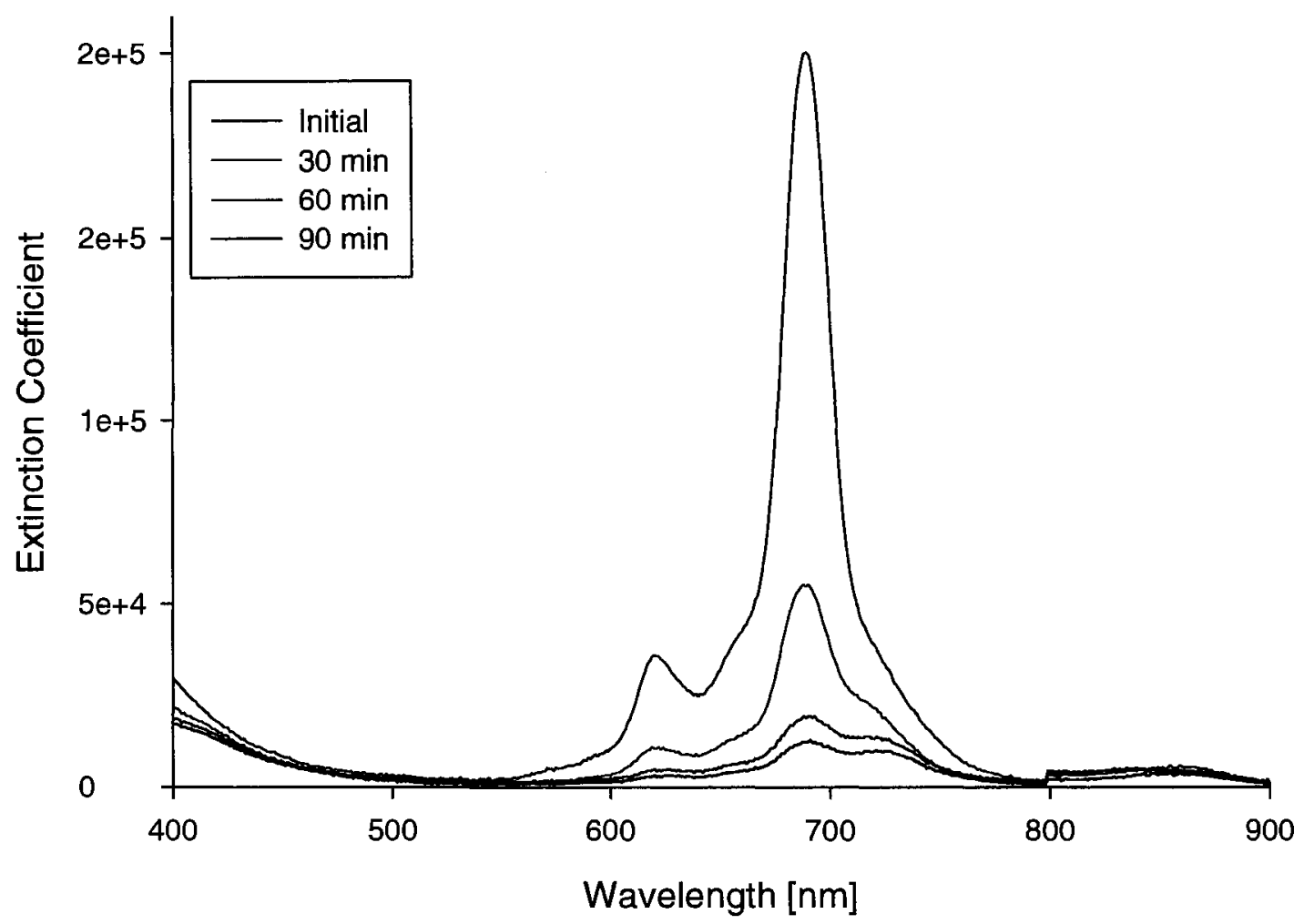

Figure 25: Photobleaching of the photosensitizer under visible light irradiation (intensity $=166 \mathrm{klux}$ ), at $22{ }^{\circ} \mathrm{C}$, in an oxygen saturated, $\mathrm{pH} 11$ aqueous solution.

Figure 25 demonstrates that after $90 \mathrm{~min}$ of irradiation, bleaching of the photosensitizer is close to $95 \%$. Consequently the production of singlet oxygen and hence sulfate ions is reduced by $95 \%$. In previous studies, this problem of photobleaching was overcome by adding $0.12 \mathrm{M}$ tetrabutylammonium bromide $\left(\mathrm{Bu}_{4} \mathrm{NBr}\right)$ to the solutions prior to irradiation in the SOOT experiment [21]. Using such high concentrations of $\mathrm{Bu}_{4} \mathrm{NBr}$ successfully reduced photobleaching but was considered an expensive answer to the problem and therefore, other surfactants and $\mathrm{pH}$ conditions were explored (discussion below). 


\subsubsection{Effect of $\mathrm{pH}$ on the Photobleaching of the Photosensitizer}

In order to mimic environmental conditions such as the ones used in holding ponds of mine effluents, the effect of $\mathrm{pH}$ on the photosensitizer (i.e., photobleaching) was looked at under $\mathrm{pH} 10$ and 11 conditions.

As shown in Figure 26, photobleaching is greater in $\mathrm{pH} 10$ buffer solution compared to a $\mathrm{pH} 11$ solution. This difference is probably due to the greater anion charge of the photosensitizer at $\mathrm{pH} 11$ and the protection afforded to the photosensitizer by being surrounded by a more tightly bound sphere of tetrabutylammonium cations. With the greater loss of photosensitizer in $\mathrm{pH} 10$ solution, sulfate yield at $\mathrm{T}=0^{\circ} \mathrm{C}$ and 4 hours irradiation was only $12 \%$ compared to that of a $\mathrm{pH} 11$ solution, sulfate yield $=$ $22 \%$. 


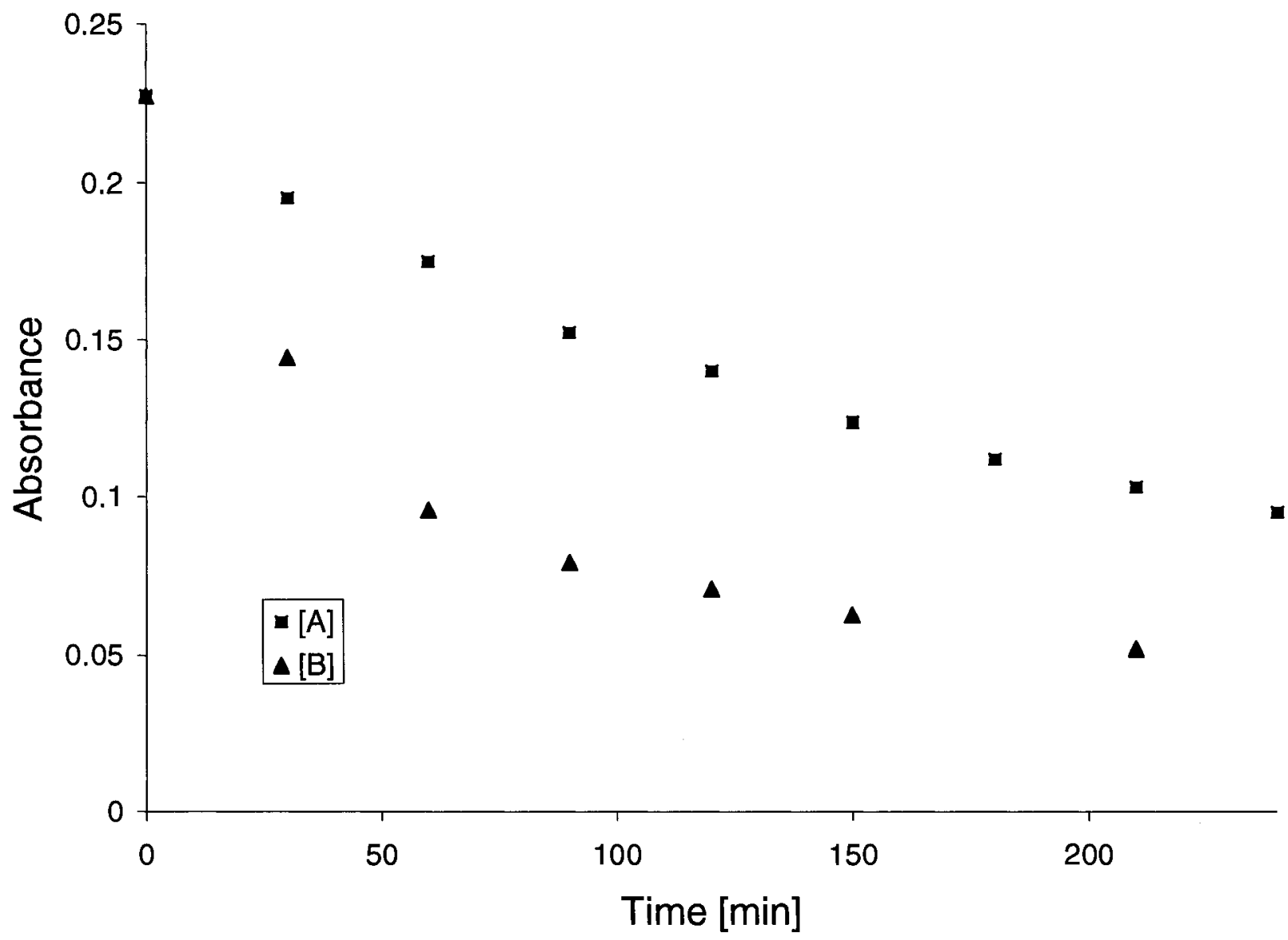

Figure 26: Bleaching of the photosensitizer (Q-band $\lambda=696 \mathrm{~nm}$ ) with irradiation time in an oxygen saturated $[\mathrm{A}] \mathrm{pH} 11$ solution and $[\mathrm{B}] \mathrm{pH} 10$ borax buffer solution. Conditions: $\mathrm{T}=0{ }^{\circ} \mathrm{C} ; 5.7 \mu \mathrm{M}$ photosensitizer; $0.12 \mathrm{M} \mathrm{Bu}_{4} \mathrm{NBr} ; 1000 \mathrm{ppm} \mathrm{S}_{2} \mathrm{O}_{3}{ }^{2-}$; irradiation intensity 166 klux. 


\subsubsection{Effect of Anionic, Non-Ionic and Amphoteric Surfactants on the}

\section{Photosensitizer}

The SOOT experiment was performed under visible light using the photosensitizer in the presence of three surfactants: (a) Triton $X$ (non-ionic surfactant); (b) SDS (anionic surfactant); and (c) Tween 20 (non-ionic surfactant) (see detailed discussion of surfactants in chapter 1).

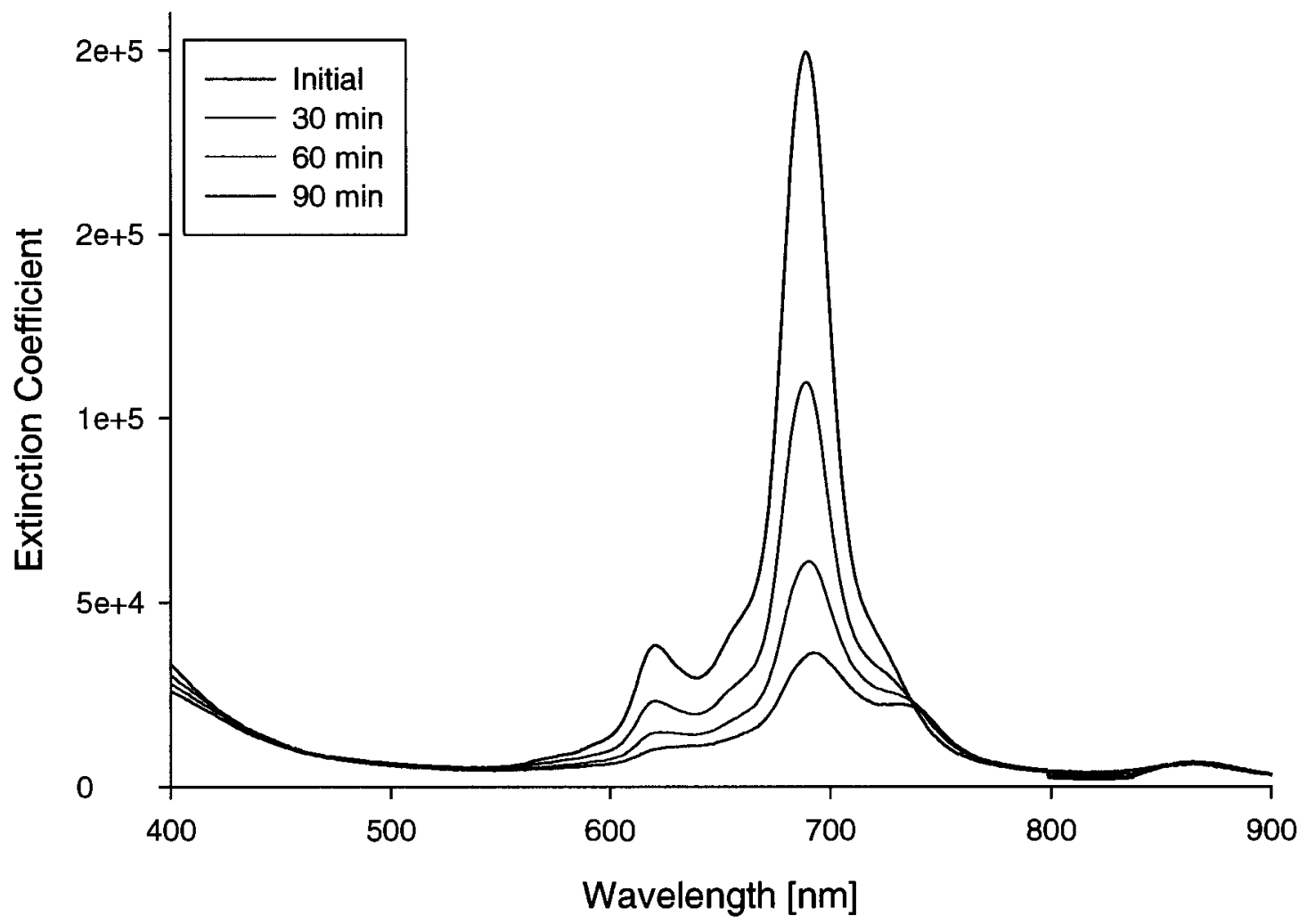

Figure 27: Photobleaching of the $\mathrm{Zn}$ phthalocyanine photosensitizer in the presence of Triton X-100 at critical micelle concentration. Conditions: $\mathrm{T}=0{ }^{\circ} \mathrm{C}$, oxygen saturated pH 11 medium; $0.25 \mathrm{mM}$ Triton $\mathrm{X}-100 ; 1000 \mathrm{ppm} \mathrm{S}_{2} \mathrm{O}_{3}{ }^{2-}$, irradiation intensity 166 klux. 
The spectra for all the three surfactants Tween $20(\mathrm{CMC}=0.059 \mathrm{mM})$, SDS $(\mathrm{CMC}=2.3 \mathrm{mM})$ and Triton $\mathrm{X}-100$ looked similar to the one in Figure 27. It was observed in all three cases that there was a slight decrease in photobleaching when compared to Figure 25, but it was small compared to that of tetrabutylammonium cation. Therefore, from these preliminary tests, it was concluded that these three classes of surfactants were not significantly successful in inhibiting photodegradation and to further the research, the feasibility of cationic surfactants was explored.

\subsubsection{Comparison of Cationic Surfactants CTAB to $\mathrm{Bu}_{4} \mathrm{NBr}$ (TBAB)}

Next, the SOOT experiment was performed under visible light using the photosensitizer in the presence of two cationic surfactants: (A) TBAB; and (B) CTAB. 


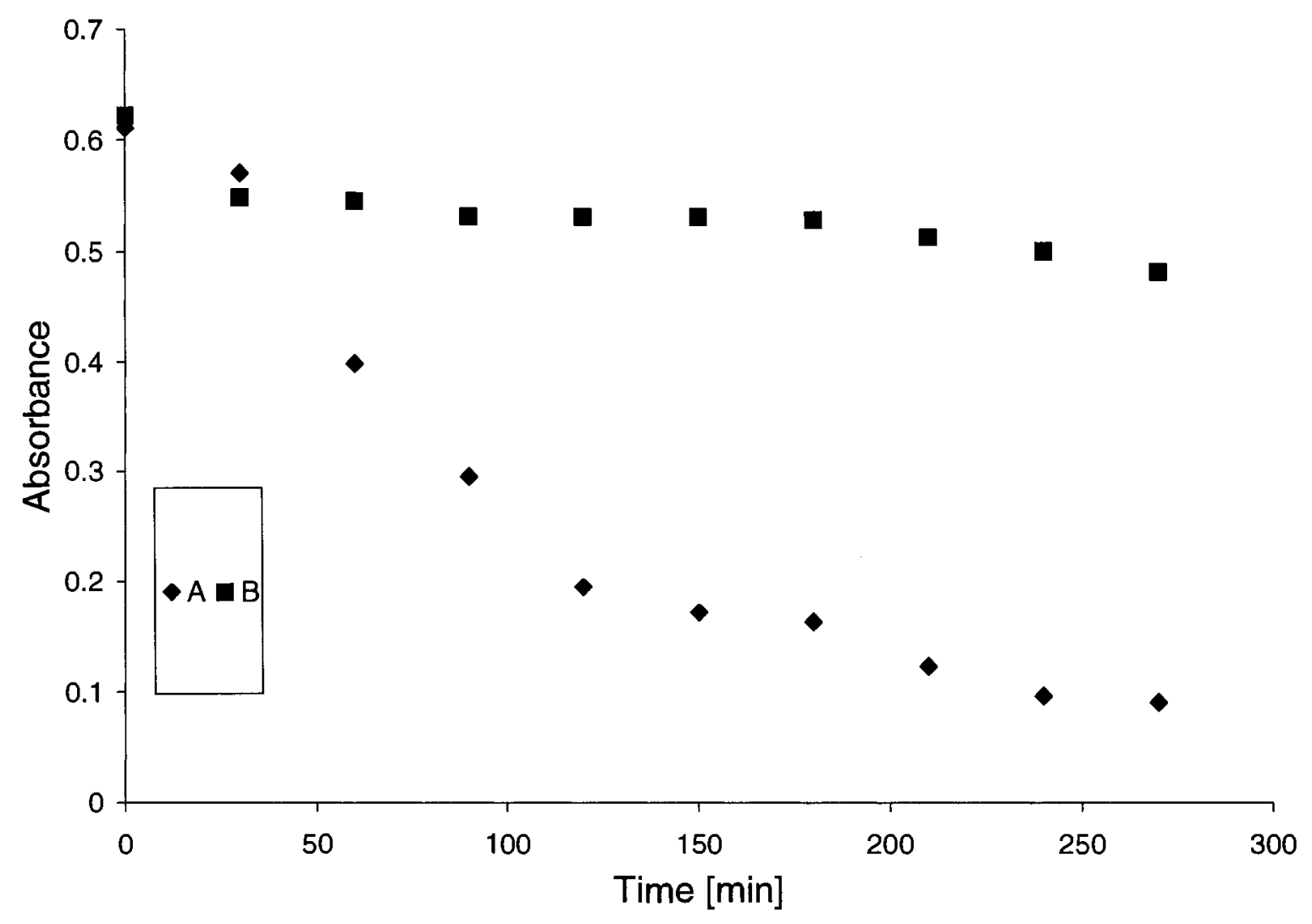

Figure 28: Bleaching of the photosensitizer (Q-band $\lambda=696 \mathrm{~nm}$ ) with irradiation time in oxygen saturated A) TBAB $(0.12 \mathrm{M})$ and B) CTAB $(1 \mathrm{mM}) \mathrm{pH} 11$ water-alkaline solution. Conditions: $\mathrm{T}=22{ }^{\circ} \mathrm{C} ; 5.7 \mu \mathrm{M}$ photosensitizer; $1000 \mathrm{ppm} \mathrm{S}_{2} \mathrm{O}_{3}{ }^{2-}$; irradiation intensity 166 klux.

As shown in Figure 28B, there is only a slight decomposition of the photosensitizer over a period of 5 hours and this is due to the enclosure of the photosensitizer by a cationic micelle. In a SOOT solution, there exist neutral oxygen and anionic superoxide/peroxide species. It has already been shown that there is no significant difference in singlet oxygen generation in the presence or absence of surfactant (Figure 24). This is because neutral oxygen can freely diffuse through a cationic micelle and react with the photosensitizer triplet state to produce singlet oxygen. 
Hydrated peroxide anion, which is able to oxidize the photosensitizer (eqn.14), is repelled by the inner hydrophobic layer of the cationic micelle (see Figure 7C), which encloses the photosensitizer and so oxidation of the photosensitizer is inhibited.

The presence of CTAB with the photosensitizer after 5 hours of irradiation showed higher conversion to sulfate (i.e., $54 \%$ ) at a low concentration (i.e., $[\mathrm{CTAB}]=1$ $\mathrm{mM}$ ) when compared to the percentage conversion to sulfate (i.e., 38\%) when using a higher concentration of $\mathrm{Bu}_{4} \mathrm{NBr}(0.12 \mathrm{M})$.

$\mathrm{CTA}^{+}$performs better than $\mathrm{TBA}^{+}$because $\mathrm{CTA}^{+}\left(\mathrm{C}_{19}\right)$ completely surrounds the photosensitizer by having an organized micelle structure that prevents the peroxide to permeate inside to reach the photosensitizer. $\mathrm{TBA}^{+}\left(\mathrm{C}_{4}\right)$, on the other hand is a smaller molecule and is unable to create an organized micelle around the photosensitizer allowing areas, where the peroxide can permeate through to reach the photosensitizer causing photobleaching.

\subsection{SOOT Experiment with CTAB at $0^{\circ} \mathrm{C}$}

Studies carried out by Silver et. al., in 1985 revealed that the rate of thiosalt oxidation using thiobacilli decreased by a factor of 10 when the temperature of the thiosalt oxidation ponds dropped from 30 to $5^{\circ} \mathrm{C}$. Therefore, it was decided to test what happens to the photosensitizer at lower temperatures $\left(0^{\circ} \mathrm{C}\right)$ when irradiated. 


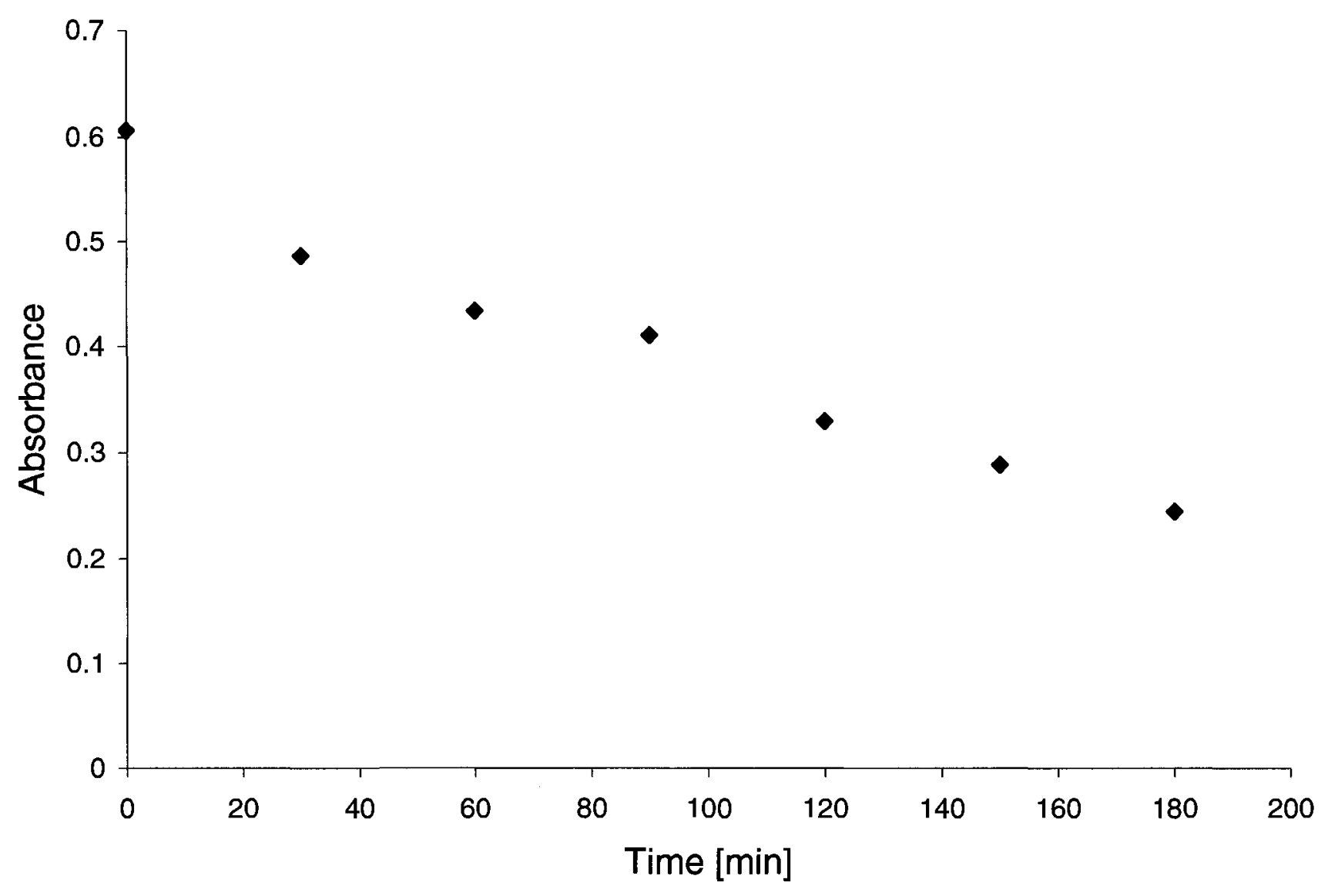

Figure 29: Bleaching of the photosensitizer (Q-band $\lambda=696 \mathrm{~nm}$ ) during the SOOT experiment with irradiation time in an oxygen saturated CTAB $(1 \mathrm{mM}) \mathrm{pH} 11$ wateralkaline solution. Conditions: $\mathrm{T}=0{ }^{\circ} \mathrm{C} ; 5.7 \mu \mathrm{M}$ photosensitizer; $1000 \mathrm{ppm} \mathrm{S}_{2} \mathrm{O}_{3}{ }^{2-}$; irradiation intensity 166 klux.

The absorption spectra of the photosensitizer at $0{ }^{\circ} \mathrm{C}$ in the presence of CTAB (1 $\mathrm{mM}$ ) in a $\mathrm{pH} 11$ water-alkaline solution (Figure 29) showed significantly greater photobleaching compared to the room temperature experiment (Figure 28). A background increase was also observed in the UV spectrum because of the presence of a white precipitate. This precipitate was isolated from the SOOT solution and its IR spectrum (see Appendix I, Figure C) showed the characteristic vibration bands of the sulfate ion 
[65]. The IR spectrum of $[\mathrm{CTA}]_{2} \mathrm{SO}_{4}$, prepared by the addition of CTAB to a concentrated sulfate solution, was identical to that of precipitate isolated from the SOOT solution. At low temperatures, the precipitation of CTA cations from the SOOT solution causes the photosensitizer to become unprotected from the peroxide anion, leading to a significant increase in photobleaching. The percentage conversion of thiosulfate to sulfate for the SOOT experiment in the presence of $\mathrm{CTAB}$ and $\mathrm{Bu}_{4} \mathrm{NBr}$ is given below in Table 8. It is likely that CTA cation precipitated out of aqueous solution at lower temperature because of the 19 carbons in its organic tail that made it less polar and reduced its solubility in water. It was decided to try SOOT experiments at $0{ }^{\circ} \mathrm{C}$ with a surfactant with a smaller carbon backbone (i.e., DTAB).

Table 8: Comparison of the Percentage Conversion of Thiosulfate to Sulfate (Gravimetric Analysis of Barium Sulfate) for the SOOT Experiment Carried Out at $0{ }^{\circ} \mathrm{C}$ and $22{ }^{\circ} \mathrm{C}$ in the Presence of CTAB and $\mathrm{Bu}_{4} \mathrm{NBr}$.

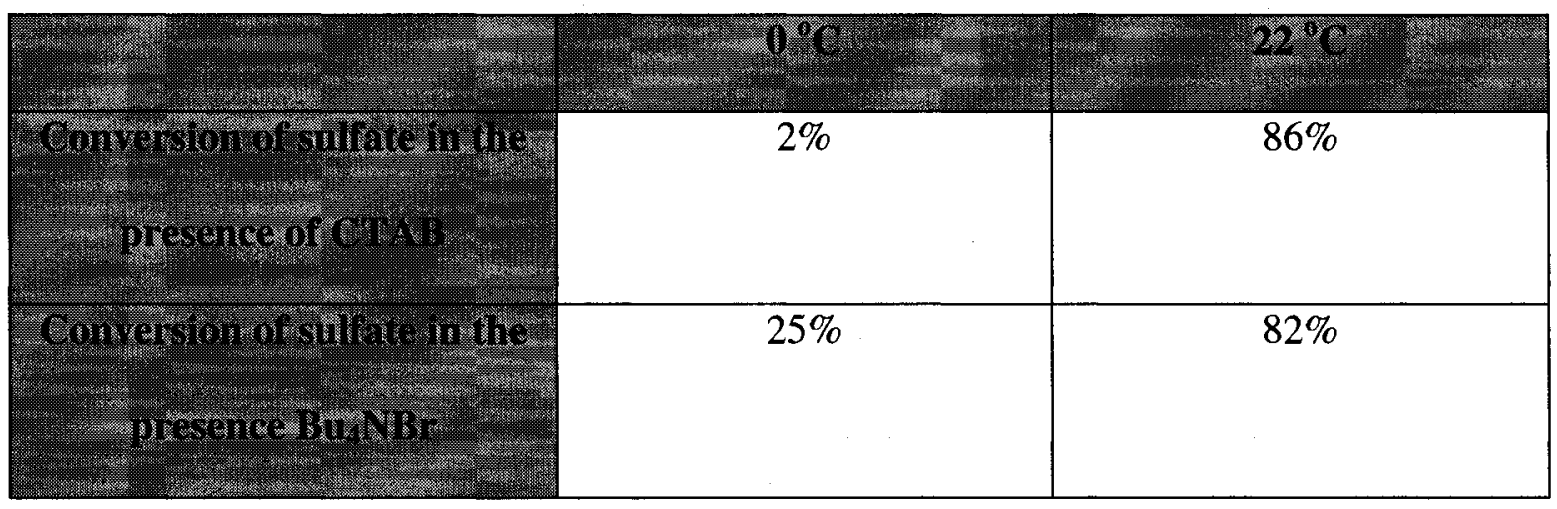




\subsection{SOOT Experiment Evaluated in the Presence of DTAB}

SOOT experiment was performed for a set of test solutions to determine the minimum concentration of DTAB required to successfully encapsulate the photosensitizer. Table 9 summarizes the results obtained after irradiating the solutions containing the photosensitizer for 8 hours in a $\mathrm{pH} 11$ medium with different concentrations of DTAB.

Table 9: Illustration of the Percentage Conversion of Thiosulfate to Sulfate in the SOOT Experiment Carried Out in the Presence of Different Concentrations of DTAB.

\begin{tabular}{|c|c|c|}
\hline [DTAB] in mM & Weight of $\mathrm{BaSO}_{4}[\mathrm{~g}]$. & \% thiosulfate conversion at \\
& & $22^{\circ} \mathrm{C}$ \\
\hline 0 & 0.0010 & 0.18 \\
\hline 4 & 0.0030 & 0.53 \\
\hline 8 & 0.0080 & 1.42 \\
\hline 12 & 0.2180 & 38.8 \\
\hline 14 & 0.5100 & 90.8 \\
\hline 16 & 0.5540 & 98.7 \\
\hline 20 & 0.5580 & 99.4 \\
\hline
\end{tabular}

As the concentration of DTAB increases in solution, the rate of photobleaching of the photosensitizer decreases, this in turn causes the generation of more singlet oxygen leading to more conversion of thiosalts to sulfate. The conversion reaches a plateau when the concentration hits the critical micelle concentration of $16 \mathrm{mM}$. Therefore, a 
concentration of $16 \mathrm{mM}$ was used in the subsequent SOOT experiments with DTAB at 0 ${ }^{\circ} \mathrm{C}$ and $22^{\circ} \mathrm{C}$ (Figure 30 ).

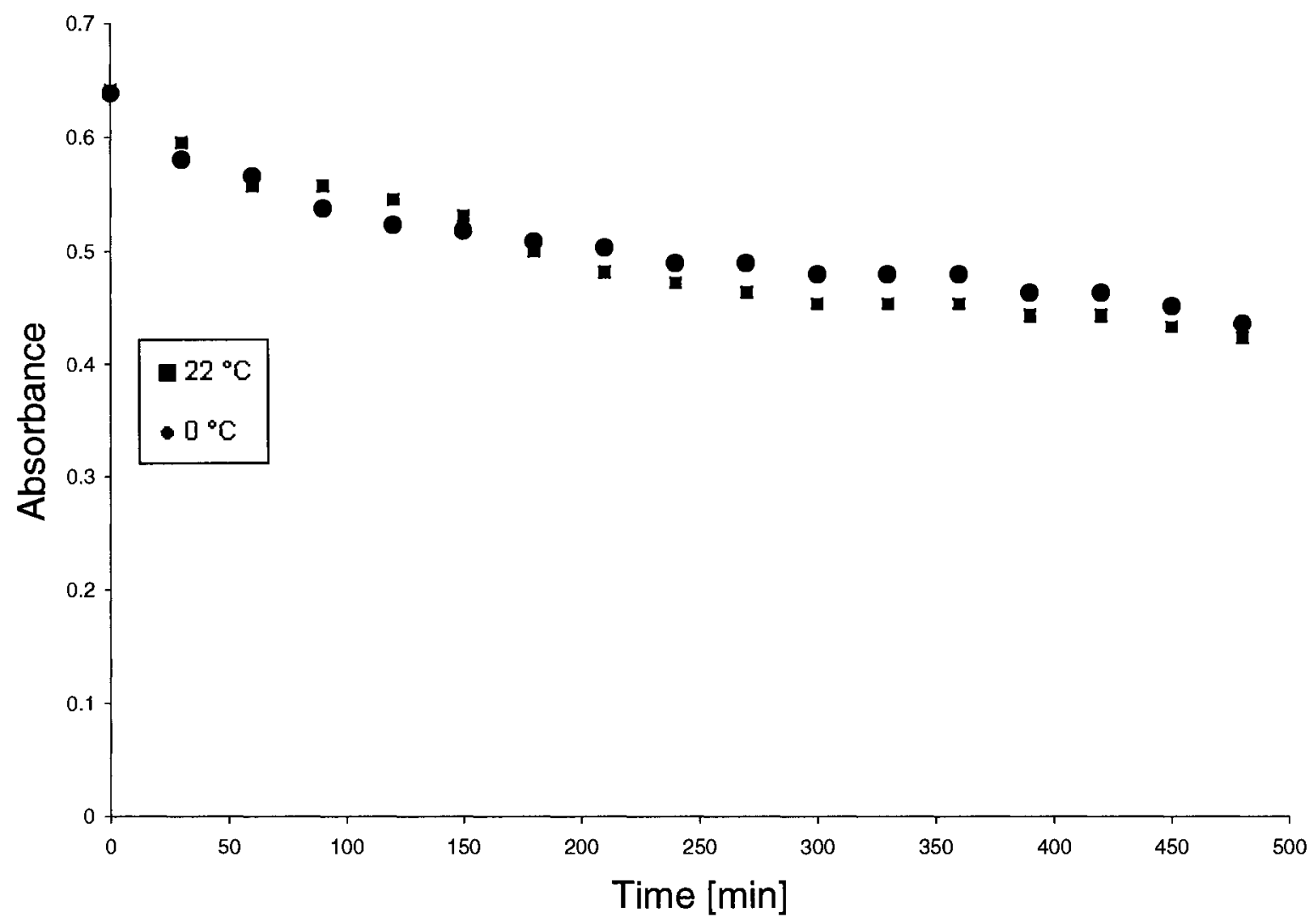

Figure 30: Bleaching of the photosensitizer (Q-band $\lambda=696 \mathrm{~nm}$ ) during the SOOT experiment with irradiation time in an oxygen saturated DTAB $(16 \mathrm{mM}) \mathrm{pH} 11$ wateralkaline solution. Conditions: $5.7 \mu \mathrm{M}$ photosensitizer; $1000 \mathrm{ppm} \mathrm{S}_{2} \mathrm{O}_{3}{ }^{2-}$; irradiation intensity 166 klux.

From Figure 30, it is evident that DTAB is efficient, even after 8 hours, in protecting the photosensitizer from photobleaching at $0{ }^{\circ} \mathrm{C}$ and $22{ }^{\circ} \mathrm{C}$, that results in a $67 \%$ and $93 \%$ conversion of thiosulfate to sulfate respectively, as compared to the minimal $\%$ conversion achieved using $\mathrm{CTAB}$ (i.e., $2 \%$ at $0{ }^{\circ} \mathrm{C}$, see Table 8 ). 


\subsection{Comparison of the Photosensitizer to the Tetracarboxylate $\mathrm{ZnPc}$ in the}

\section{presence of DTAB}

Experiments were carried out to compare the photoactivity of Dr. MacLean's $\mathrm{ZnPc}(\mathrm{COONa})_{4}$ photosensitizer $(5.7 \mu \mathrm{M})$ with the photosensitizer $(5.7 \mu \mathrm{M})$ in the presence of DTAB (16 mM). The SOOT conditions (see Chapter 2) other than the photosensitizer were equivalent in both cases. After irradiating the reaction solutions containing $\mathrm{ZnPc}(\mathrm{COONa})_{4}$ for 8 hours in the presence of DTAB, gravimetric determination of barium sulfate was performed. The percentage conversion of thiosulfate to sulfate at $0{ }^{\circ} \mathrm{C}$ with $\mathrm{ZnPc}(\mathrm{COONa})_{4}$ was determined to be $33 \%$ (compared to the photosensitizer conversion of $67 \%$ ). Therefore, it is evident that the photosensitizer converts a higher amount of thiosulfate to sulfate in oxygen saturated $\mathrm{pH} 11$ medium with minimum photodegradation observed after 8 hours when compared to $\mathrm{ZnPc}(\mathrm{COONa})_{4}$. The reason for this difference may lie with magnitude of $Q_{s}$ but it also possible that the photosensitizer is better protected by a $\mathrm{DTA}^{+}$micelle owing to its greater negative charge.

\subsection{SOOT Experiment Evaluated in the Presence of DTAC}

It might be possible that the bromide anions from the surfactant (DTAB) could participate in the SOOT processes, perhaps by being oxidized by singlet oxygen or peroxide. Replacing the bromide anions with chloride anions should have a significant effect on the SOOT process if bromide anions do participate because of the difference in their oxidation couples as shown below: 


$$
\begin{array}{ll}
\mathrm{Cl}_{2}(\mathrm{~g})+2 e^{-} \rightleftharpoons 2 \mathrm{Cl} & +1.36 \mathrm{~V}[59,60,61,67] \\
\mathrm{Br}_{2}(l)+2 e^{-} \rightleftharpoons 2 \mathrm{Br}^{-} & +1.09 \mathrm{~V}[61,62,63,67] \\
\mathrm{HO}_{2}^{-}+\mathrm{H}_{2} \mathrm{O}+2 e^{-} \rightleftharpoons 3 \mathrm{OH} & +0.88 \mathrm{~V}[66] \\
\mathrm{O}_{2}+e^{-} \rightleftharpoons \mathrm{O}_{2}^{-} & -0.137 \mathrm{~V}[57] \\
{ }^{\prime} \mathrm{O}_{2}+e^{-} \rightleftharpoons \mathrm{O}_{2}^{-} & +0.84 \mathrm{~V} \text { (see detailed calculation in Chapter 1) }
\end{array}
$$

Looking at the reduction potentials of the halides and those of the oxidants peroxide and singlet oxygen, it seems unlikely that oxidation of the halides would occur. However peroxide's reduction couple is $\mathrm{pH}$ dependent and increases to $+1.76 \mathrm{~V}$ vs NHE under acidic conditions $[58,64]$. To remove the possibility of halide oxidation, it was decided to perform the SOOT experiment at $22{ }^{\circ} \mathrm{C}$ with the chloride and bromide salts of $\mathrm{DTA}^{+}$(see Figure 31). 


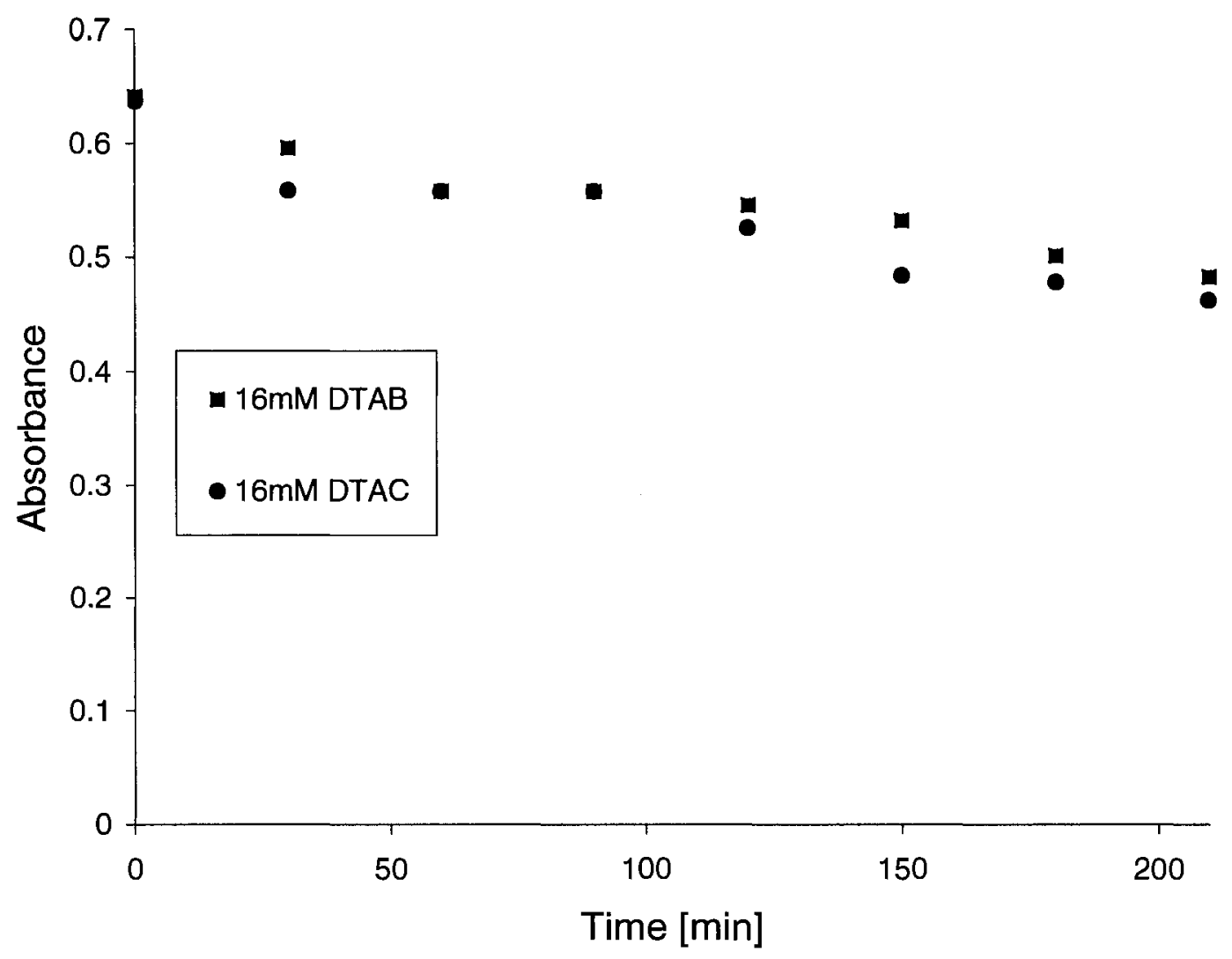

Figure 31: Bleaching of the photosensitizer (Q-band $\lambda=696 \mathrm{~nm}$ ) during the SOOT experiment at $22^{\circ} \mathrm{C}$ with irradiation time in an oxygen saturated DTAB $(16 \mathrm{mM})$ and DTAC (16 mM) pH 11 water-alkaline solution. Conditions: $5.7 \mu \mathrm{M}$ the photosensitizer; $1000 \mathrm{ppm} \mathrm{S}_{2} \mathrm{O}_{3}{ }^{2-}$ irradiation intensity $166 \mathrm{klux}$.

There was no dramatic change in the production of sulfate measured at the end of 5 hours between the two different counterions $(91 \%$ and $92 \%$ for DTAC and DTAB respectively). From this it was concluded that the oxidation of bromide anions or chloride anions, if any, is negligible. 


\section{CHAPTER 5}

\section{CONCLUSION AND FUTURE STUDIES}

\subsection{Conclusion}

In this research project, important insights were gained towards the synthetic route and characterization of the photosensitizer, which had superior qualities than the previously studied $\mathrm{ZnPc}(\mathrm{COONa})_{4}$. Research carried out by Brian MacLean showed dimerization of $\mathrm{ZnPc}(\mathrm{COONa})_{4}$ (Figure 4) in aqueous solution that is undesirable as the photophysical properties of excited dimers are not appropriate for photosensitization of singlet oxygen. Thus, the $\mathrm{ZnPc}(\mathrm{COONa})_{4}$ was modified to the photosensitizer used in this research project and as shown, this modification increased the overall negative charge on the photosensitizer, which increased the repulsion between complexes and reduced the tendency towards dimerization in aqueous solution.

The effect of irradiation on the photosensitizer was studied during the SOOT experiments using an optimum $\mathrm{pH}(\mathrm{pH} 11)$ where the complex was mostly in its monomer form and which would mimic environmental conditions of holding ponds. Within the first 90 minutes the complex was completely photobleached. Therefore, in order to protect the photosensitizer from photodegradation, the feasibility of using surfactants was explored. A much lower concentration of cationic surfactants such as CTAB $(1 \mathrm{mM})$ and DTAB $(16 \mathrm{mM})$ was required as compared to $\mathrm{Bu}_{4} \mathrm{NBr}(0.12 \mathrm{M})$ to protect the photosensitizer from peroxide. The SOOT experiment was carried out under 
different temperature conditions $\left(0\right.$ and $\left.22^{\circ} \mathrm{C}\right)$ in the presence of $\mathrm{CTAB}, \mathrm{TBAB}$ and DTAB using the photosensitizer and the percentage conversion at $0{ }^{\circ} \mathrm{C}$ of thiosulfate to sulfate (by gravimetric analysis of barium sulfate) for solutions containing $\mathrm{CTAB}, \mathrm{TBAB}$ and DTAB was calculated to be $2 \%, 25 \%$ and $67 \%$ respectively; thus making DTAB a more practical alternative than the previously used $\mathrm{Bu}_{4} \mathrm{NBr}$.

Experiments were carried out to compare the photoactivity of the $\mathrm{ZnPc}(\mathrm{COONa})_{4}$ with the photosensitizer in the presence of DTAB $(16 \mathrm{mM})$. The percentage conversion of thiosulfate to sulfate at $0{ }^{\circ} \mathrm{C}$ with $\mathrm{ZnPc}(\mathrm{COONa})_{4}$ was determined to be $33 \%$ (compared to the photosensitizer conversion of $67 \%$ ). Therefore, it is evident that the photosensitizer is more efficient in the SOOT process (higher conversion of thiosulfate to sulfate).

The singlet oxygen production levels remained approximately the same in the presence and absence of DTAB $([\mathrm{DTAB}]=16 \mathrm{mM})$ with $\mathrm{Q}_{\mathrm{s}}=0.47$ and 0.50 , respectively; thus suggesting that the primary function of the surfactant in the SOOT process was to protect the photosensitizer from photobleaching.

Therefore, we have shown a stable surfactant-photosensitizer system that is successful in converting thiosalts to sulfates, where the surfactant protects the photosensitizer from photobleaching by preventing permeation of the peroxide through the micelles while allowing molecular oxygen to permeate through the micelles. Nevertheless, there exist many challenges that need to be dealt with in order to create an application based system that can be used in the holding ponds. Working with numerous surfactants it was observed that as the number of carbons in the organic tail increased, the solubility in water at $0{ }^{\circ} \mathrm{C}$ decreased. Although the large sized surfactants have a low 
CMC (e.g. $\mathrm{CTAB}=1 \mathrm{mM})$ and are comparatively low in cost $(\mathrm{CTAB}, \$ 49$ for 100 or $\sim 179 / \mathrm{m}^{3}$ of effluent), they are not efficient in forming a micelle around the photosensitizer at $0{ }^{\circ} \mathrm{C}$ and this eventually results in photobleaching of the photosensitizer. As previously discussed, DTAB is a small surfactant having 15 carbons in its tail and is more soluble in water at $0{ }^{\circ} \mathrm{C}$. Unfortunately, it is expensive to use in the SOOT process ( $\$ 100$ for $20 \mathrm{~g}$ or $\sim \$ 2400 / \mathrm{m}^{3}$ of effluent) because of its high CMC (16 $\mathrm{mM}$ ). As mentioned in the introduction, the goal is to obtain a method of treating mining effluent at a cost of only $0.30 / \mathrm{m}^{3}$ of effluent. Using surfactants in the SOOT process is economically impractical and alternative methods are the subject of future studies.

\subsection{Future Studies}

The chemistry of singlet oxygen is rich and its potential uses have recently been realized. Much needs to be done to modify and improve existing photosensitizers to better suit their properties and desired applications. This of course requires better understanding of the mechanism of the photosensitizer quenching and photobleaching.

Future studies may involve a dendrimer wrapping around the photosensitizer via covalent bonding with the carboxylates, where the dendrimer would protect the photosensitizer from photobleaching and would remove the need for surfactants [23]. The dendrimer may wrap more than one photosensitizer molecule depending on its chain length thus reducing cost further. Also the dendrimer-photosensitizer being large (typically $>40 \mathrm{~nm}$ ) may be easily filtered out prior to release of the effluent into the rivers. Along with industrial advantages, dendrimers offer Environmental Health and Safety (EHS) benefits where surfactants are highly toxic to aquatic life while dendrimers 
being large typically do not elicit toxic affects. However, during the SOOT experiment the mechanism of diffusion of oxygen and peroxide in and out of the dendrimer would require detail understanding of the polymer and further studies would need to be implemented with respect to photobleaching of the dendrimer-photosensitizer system.

Also, the photosensitizer may be absorbed onto the surface of particles (such as quantum dots) that would mediate reactions on the nanoparticle surface (where the photosensitizer is rendered active by coupling between the nanoparticles and photosensitizer) [24] and mitigate the release of the photosensitizer into waterways (i.e., by recovering or destroying the particles and constituents sorbed onto its surface). Of course, a detailed understanding of the coupling between nanoparticles and photosensitizers, such as possibly energy quenching, will need to be thoroughly investigated. Substances such as cadmium-selenide quantum dots are currently prime candidates in EHS research due to their ease of detection [24]. 


\section{APPENDIX 1}

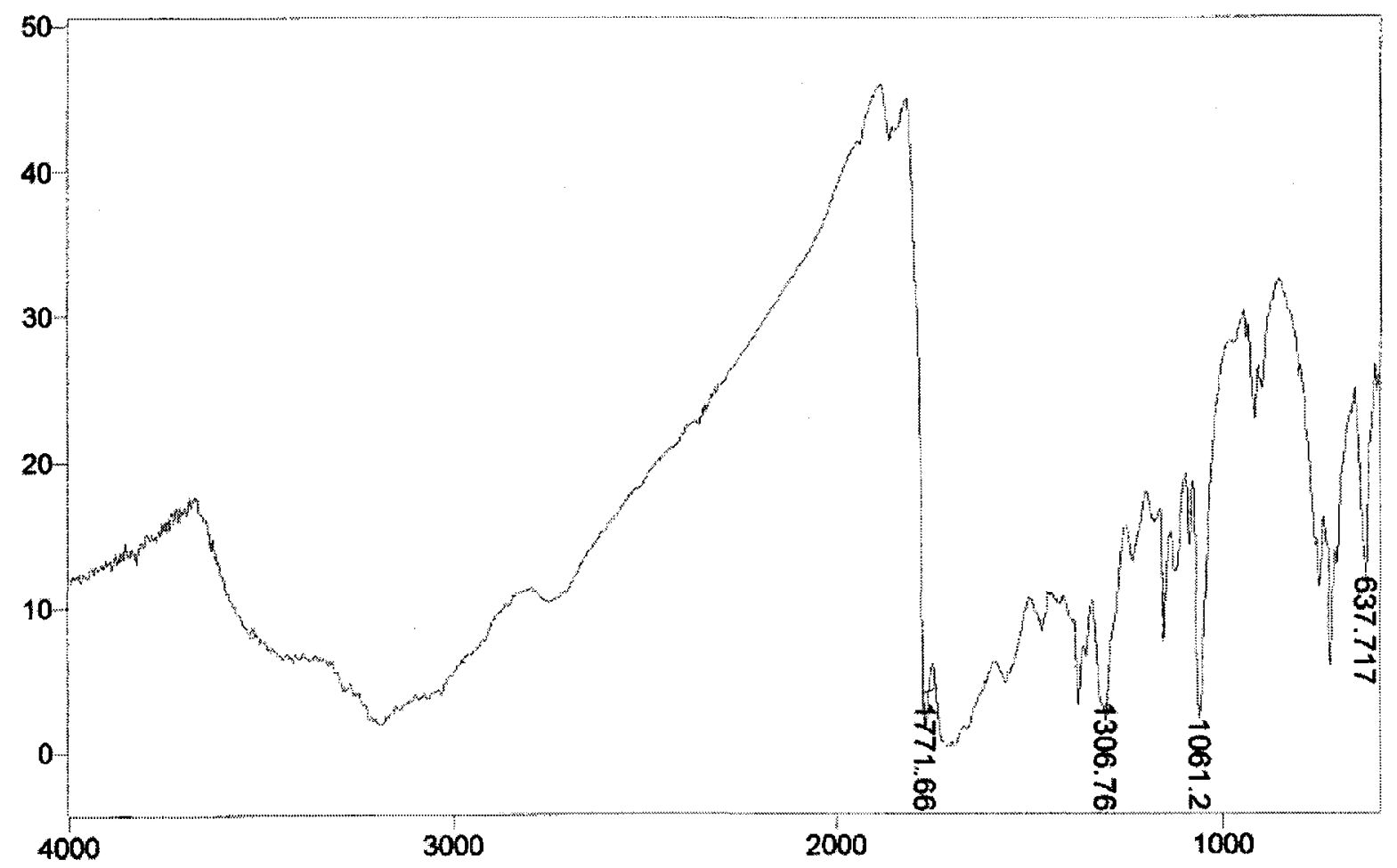

Transmittance / Wavenumber (cm-1)

Figure A: IR spectrum of the impure Zinc tetraimide 


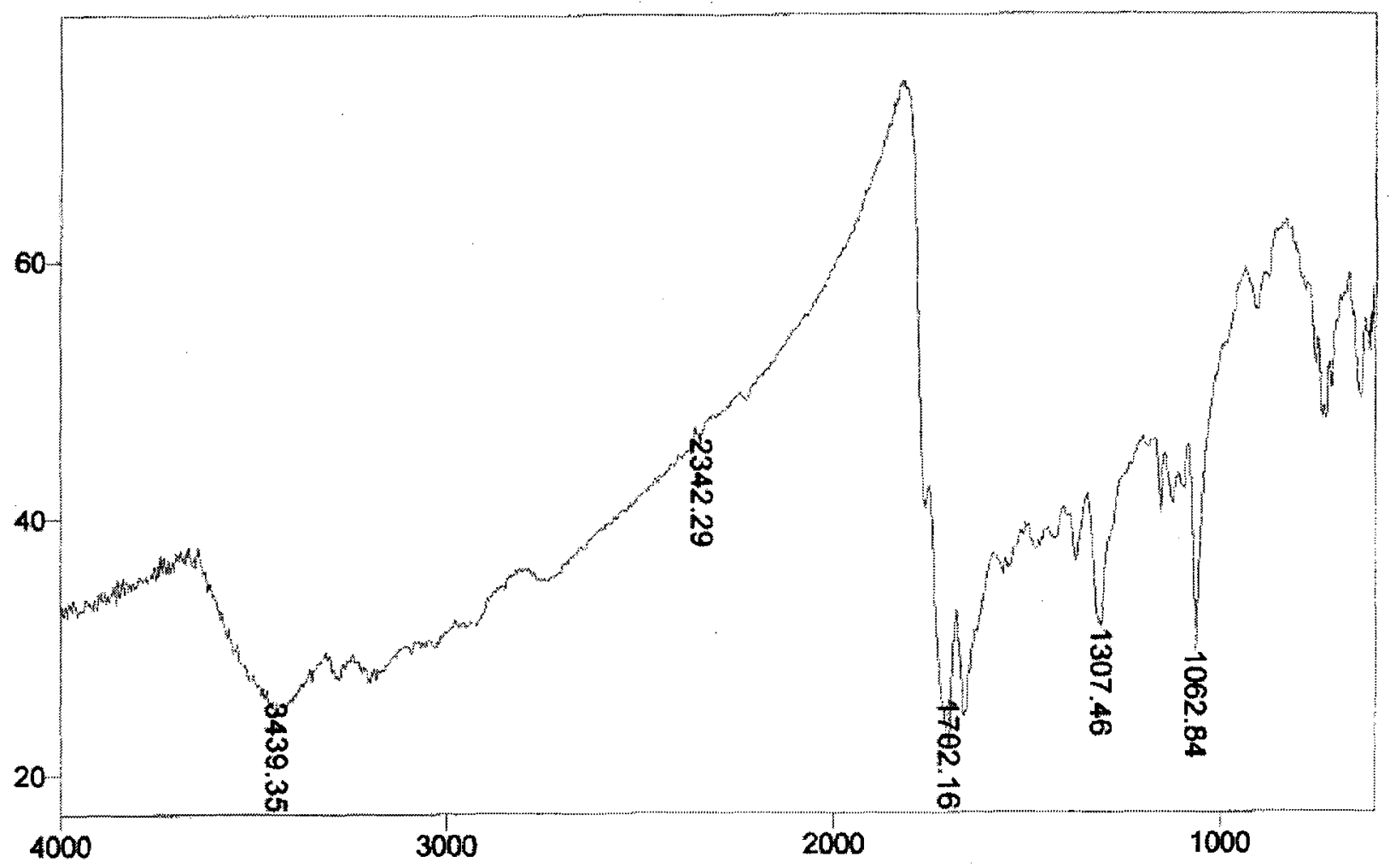

Transmittance / Wavenumber $(\mathrm{cm}-1)$

Figure B: IR spectrum of the tetraimide complex after acid/base extraction 


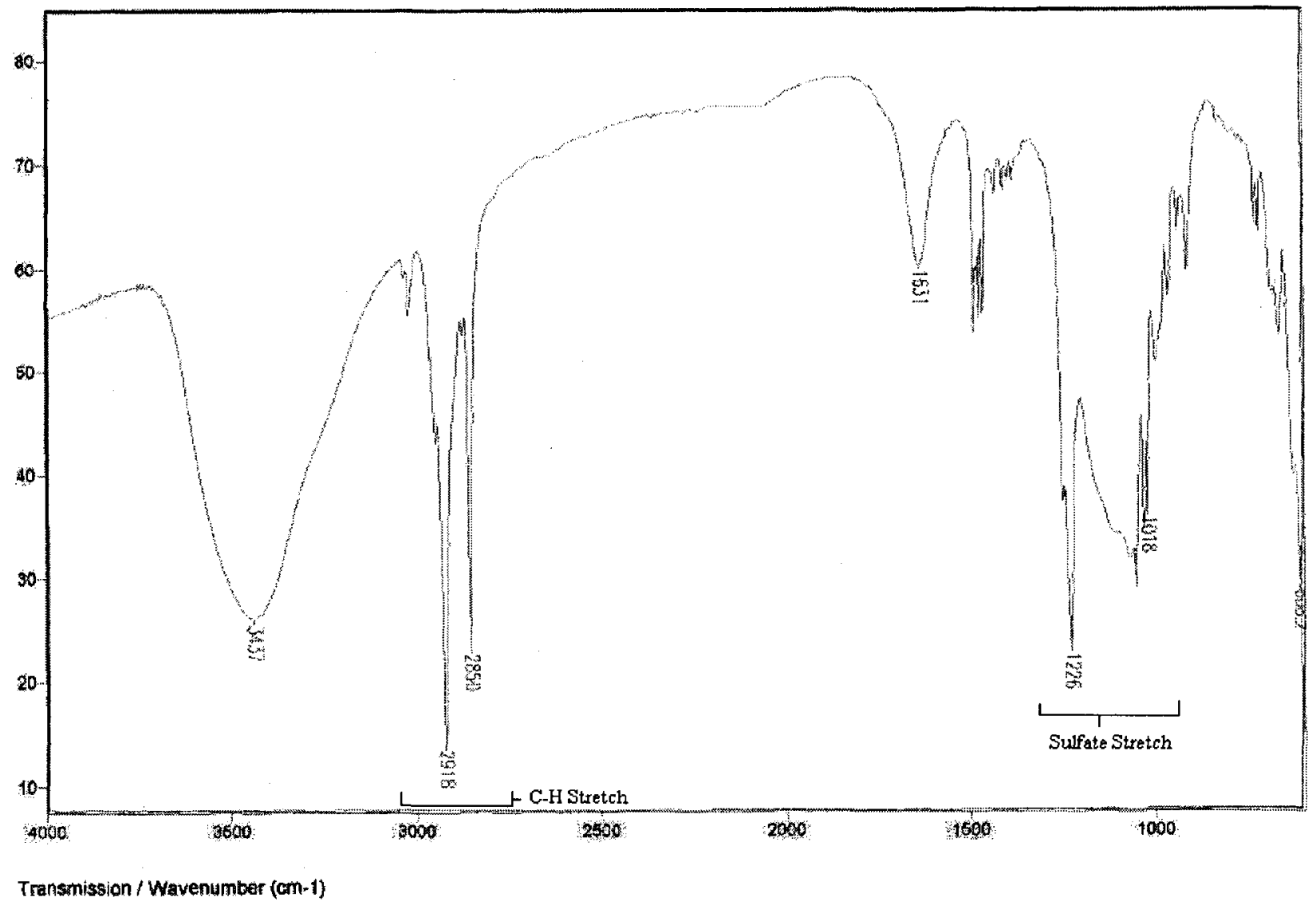

Figure $\mathrm{C}$ : Infrared spectrum in $\mathrm{KBr}$ of $[\mathrm{CTA}]_{2} \mathrm{SO}_{4}$ 


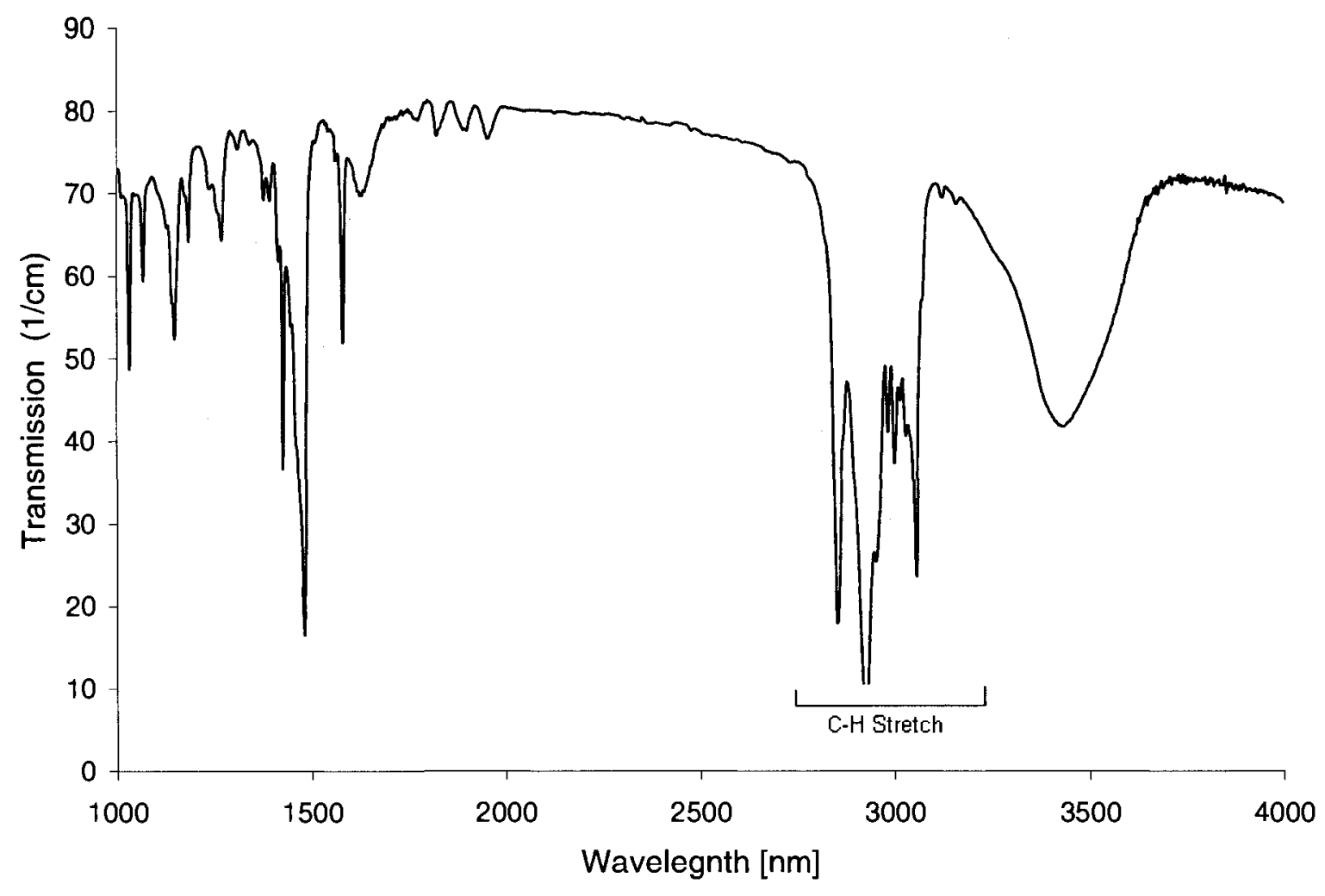

Figure D: IR spectrum in $\mathrm{KBr}$ of [DTA][BPh4]. 


\section{REFERENCES}

1. Braun, A., and Tcherniac, J., Ber. Deut. Chem. Ges. 40 (1907), p. 2709

2. Byrne, G., T., Linestead, R., P., and Lowe, A., R. J. Chem. Soc. (1934), p. 1022

3. Chanda, A., O'Driscoll, K., F., and Rempel, G., L. J. Mol. Cat. A. 7 (1980), p. 389

4. Dinardo, O., CANMET, Personal communication

5. Hackett, J., and Turro, C. Inorganic Chemistry. 37 (1998), p. 2039

6. Haque, K., E., and Dinardo, O. Div. Rep. MMSL 96-039 (OP\&J), CANMET, Energy, Mines and Resources Canada (1997)

7. Iliev, V., Prahov, L., Bilyarska, L., Fischer, H., Schulz-Ekloff, G., Wohrle, D., and Petrov, L. J. Mol. Cat. A. 151 (2000), p. 161

8. Iliev, V., and Ileva, A. J. Mol. Cat. A 103 (1995), p. 147

9. Lebedeva, N., S., Pavlycheba, N., A., Petrova, O., V., Vyugin, A., I., Kinchin, A., N., Parfenyuk, E., V., Mayzhlish, V., E., and Shaposhnikov, G., P. Mendeleev Communications. 13 (2003), p. 237

10. Leznoff, C., C., Lever, A., B., P. Phthalocyanine: Properties and Applications, $2^{\text {nd }}$ edition. Wiley-VCH, 1993

11. Lissi, E., A., Encinas, M., V., Lemp, E., and Rubio, M., A. Chem. Rev. 93 (1993), p. 699

12. Mckeown, N. Phthalocyanine Materials. Cambridge University Press (Jul 13 1998)

13. Robertson, J., M. J. Chem. Soc. (1935), p. 615 
14. Rolia, E. Div. Rep. MRP/MSL 84-144 (TR). CANMET, Energy Mines and Resources Canada (1984)

15. Rosen, Milton J. Surfactants and Interfacial Phenomena. John Wiley \& Sons. 1-7 (1978), p. 234

16. Silver, M. Appl. Environ. Microbio. 50 (1985), p. 663

17. Spiller, W., Wohrle, D., Schulz, G., Ford, W., and Stark, J. Journal of photochemistry and photobiology A. (1996), p. 161

18. Wasserlauf, M., and Ditrizac, J., E. Canadian Metallurg. Quart. 23 (1984), p. 259

19. Wong, W., S. Division Report MRP/MSL 81-112 (TR), CANMET, Energy, Mines and Resources Canada (1981)

20. http://sales.hamamatsu.com

21. Iliev, V., and Mihaylova, A. Journal of Photochemistry and Photobiology A: Chemistry. (2002). Vol 149, Issues 1-3, p. 23

22. Drinkard, W., C., and Bailer, J., C. J. Amer. Chem. Soc. 81 (1959), p. 475

23. Zhang, Guo-Dong, Harada, A., Nishiyama, N., Jiang, Dong-Lin., Koyama, H., Aida, T., and Kataoka, K. Jour. Cont. Rel. 93 (2003) 2, p. 141

24. Hodon, M., Horvath, E., Haspel, H., Kukovecz, A., Konya, Z., and Kiricsi, I. Chem. Phys. Lett. (2004) 4-6, p. 512

25. Black, Shaun, D. Properties of Detergents (Ampiphiles). University of Texas Health Centre at Tyler

26. Huang, X., Yang, J., Zhang, W., Zhang, Z., and Zesheng, M. Journal of Chemical Education. 76 (1999), No.1, p. 93

27. Moser, F.H., Thomas, A.L. The Phthalocyanines. CRC press (1968) 
28. West, W., and Pearce. S. Journal of Physical Chemistry. 69 (1894), p. 16

29. Schwartz, Melissa, L., Vigneault, B., and McGeer, J. (2006). Report CANMETMMSL 06-053(CR)

30. Metal Mining Effluent Regulations. Canada Gazette Part II. SOR/2002 202 to 206 and SI/2002-90 to96. (2002), p.1246

31. Thomas, J., L., and Allen, N., S. Dyes and Pigments. 53 (2002) p. 195

32. Helman, W., P., and Ross, A., B. J. Phys. Chem. Ref. Data. 24(1995), p. 663

33. DeRosa, M., and Crutchley, R., J. Coordination Chemistry Reviews. 233-234 (2002), p. 351

34. Torinuki, W., and Miura, T. The Tohoku Journal of Experimental Medicine. 140 (1983), p. 297

35. Schweitzer, C., and Schmidt, R. Chem. Rev., 103 (2003), p.1685

36. Kuznetsova, N., A., Gretsova, N., S., Derkachena, V., M., Mikhalenko, S., A., Solov'eva, L., I., Yuzhakova, O., A., Kaliya O., L., and Luk'yanets E., A. Russian Journal of General Chemistry. 172 (2002), p. 300

37. Ozoemena, Kenneth, I., and Nyokong, T. 6 (2003), p.1192

38. Boston, D. R., and Bailer, J., C. Inorganic Chemistry. 11 (1972), Issue 7, p. 1578

39. Sakamoto, K., and Ohno, E. Progress in Organic Coatings. 31 (1997), p.139

40. Mathai, S., Smith, T., A., and Ghiggino, K., P. Photochem. Photobiol. Sci. 6(2007), p. 995

41. Faure, S., Stern, C., Guilard, R., and Harvey, P., J. Am. Chem. Soc., 126 (2004), p. 1253 
42. Anderson, S., E., and Nyberg, G., L. Applications of Surface Science. 22-23 (1985), p. 325

43. Lebedeva, N., Sh., Petrova, O., V., V'yugin, A., I., Maizlish, V., E., and Shaposhnikov, G., P. Optics and Spectroscopy. 94(2003), p. 924

44. Jeffery, W., B., Micheal, F., Reynolds, J., R., and Kim, S. Langmuir-American Chemical Society. 15 (1999), p. 6460

45. Finlayson, Chris, E., Ginger, D., S., and Greenham, N., C. Chemical Physics Letters. 338 (2001), p. 83

46. Hong, Suc-Kyoung. Physica E. 28 (2005), p.66

47. Ozoemena, K., Kuznetsova, N., and Nyokong, T. Journal of Photochemistry and Photobiology A: Chemistry 139 (2001), p. 217

48. Maclean, B., and Crutchley, R., J. Chemistry Department of Carleton University. CAMNET-NRCan. October 31, 2002. http://www.nrcan.gc.ca/ms/canmet$\mathrm{mtb} / \mathrm{mmsl}-\mathrm{lmsm} /$ enviro/effluents/effthiosalts-e.htm

49. Yates, Stephen, Good, Mary, L., Gaita, Romulus. World Intellectual Property Organization (WO 1990007144). June 28, 1990

50. Malinauskas, A. Journal of Applied Polymer Science. 73 (1999), p. 287

51. Mata, J., Varada, D., Ghosh, G., and Bahadur, P. Colloids and Surfaces A: Physiochemical and Engineering Aspects. 245 (2004), p. 69

52. Baudin, H., B. Comprehensive Summary of Uppsala Dissertations from the Faculty of Science and Technology. Acta University Upsaliensis Uppsala (2001)

53. Neta, P., Alberta, B., R., and Huie, R. J. Phys. Chem. 17 (1988), p. 1027 
54. Saito, I., T., Matsuura, and Inoue, K. Journal of the American Chemical Society. 105 (1983), p. 3200

55. Afanas'ev, Igor, B. Superoxide Ion: Chemistry and Biological Implications Volume I. CRC Press, 1991

56. Eriksen, J., Foote, C., S., Parker, T., L. Journal of the American Chemical Society 99 (1977), Issue 19, p. 6455

57. Petlicki, J., and Van de Ven, Theo, G., M. Chem. Soc., Faraday Trans. 94 (1998), p. 2763

58. Doyle, F., M., and Wang, L. University of California. Proceedings VMIC 2003 (12 $2^{\text {th }}$ Int. VLSI Multilevel Interconnection Conference). (2003), p. 267

59. Snyder, Milton, K. Chemistry; Structure and Reactions. Holt, Rinehart and Winston, 1966

60. Kirk, Raymond, Eller, and Othmer, Donald, Frederick. Encyclopaedia of Chemical Technology. Published 1947

61. Barrett, Jack. Inorganic Chemistry in Aqueous Solution. RSC Publishing, 2003

62. Kerner, Nancy, Konigsberg, and Konigsberg, Nancy. Chemical Investigations. Benjamin/Cummings Pub. Co ., 1985

63. Brady, George, S., Clausar, Henry, R., and Vaccari, John, A. Materials Handbook. McGraw-Hill Professional, 2002

64. Bockris, John, O’M., Conway, Brian, E., and Yeager, Ernest, B. Comprehensive Treatise of Electrochemistry. Springer, 1985

65. Pouchert, Charles, J. The Aldrich Library of Infrared Spectra - 3rd edition. Aldrich Chemical (1997) ISBN: 978-0-941633-39-0 
66. Douglas, B., McDaniel, D., H., and Alexander, J., J. Concepts and Models of Inorganic Chemistry, $2^{\text {nd }}$ ed. Wiley, 1983

67. Atkins, Peter. Physical Chemistry, 6th ed. W.H. Freeman and Company, 1997

68. Borgmann, U., Couillard, Y., Doyle, P., and Dixon, G. Environmental Toxicology and Chemistry. 124 (2005), p. 641 